\title{
Electropolishing as a \\ Decontamination Process: Progress and Applications
}

\section{April 1978}
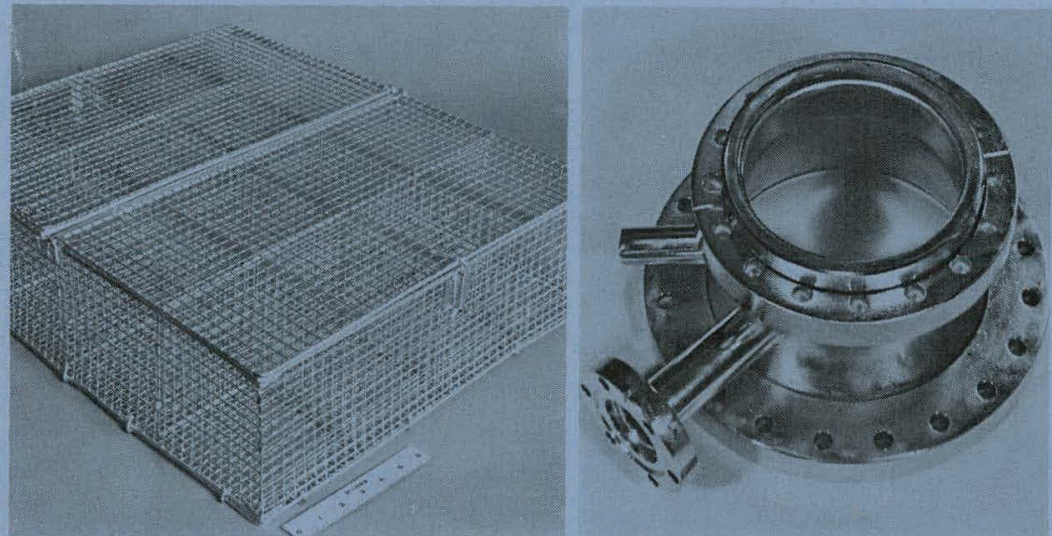

Typical objects decontaminated by Electropolishing
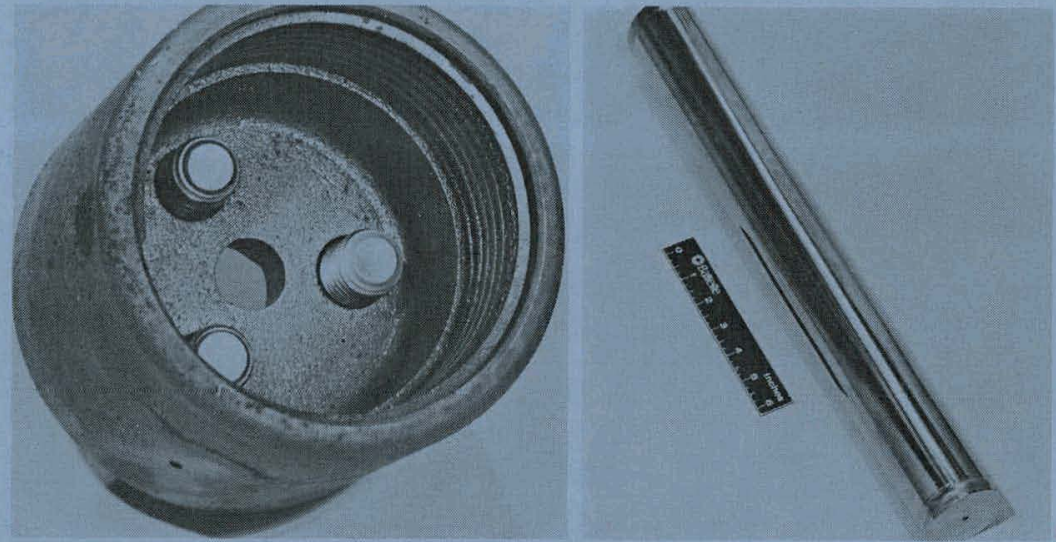

by

R. P. Allen

H. W. Arrowsmith

L. A. Charlot

J. L. Hooper

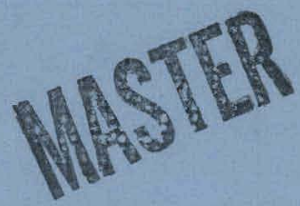




\section{DISCLAIMER}

This report was prepared as an account of work sponsored by an agency of the United States Government. Neither the United States Government nor any agency Thereof, nor any of their employees, makes any warranty, express or implied, or assumes any legal liability or responsibility for the accuracy, completeness, or usefulness of any information, apparatus, product, or process disclosed, or represents that its use would not infringe privately owned rights. Reference herein to any specific commercial product, process, or service by trade name, trademark, manufacturer, or otherwise does not necessarily constitute or imply its endorsement, recommendation, or favoring by the United States Government or any agency thereof. The views and opinions of authors expressed herein do not necessarily state or reflect those of the United States Government or any agency thereof. 


\section{DISCLAIMER}

Portions of this document may be illegible in electronic image products. Images are produced from the best available original document. 


\title{
NOTICE
}

This report was prepared as an account of work sponsored by the United States Covernment. Neither the United States nor the Department of Energy, nor any of their employees, nor any of their contractors, subcontractors, or their employees, makes any warranty, express or implied, or assumes any legal liability or responsibility for the accuracy, completeness or usefulness of any information, apparatus, product or process disclosed, or represents that its use would not infringe privately owned rights.

The views, opinions and conclusions contained in this report are those of the contractor and do not necessarily represent those of the United States Government or the United States Department of Energy.

\author{
PACIFIC NORTHWEST LABORATORY \\ operated by \\ BATTELLE \\ for the \\ LNITED STATES DEP,ARTMENT OF ENERCY \\ Under Contract EY-76-C-06-1830
}


ELECTROPOLISHING AS A DECONTAMINATION TECHNIQUE--PROGRESS AND APPLICATIONS

Prepared for the U.S. Department of Energy under Contract EY-76-C-06-1830

by

R.P. Allen

H.W. Arrowsmith

L.A. Charlot

J.L. Hooper

Apri1 1978

BATTELLE

Pactflc Nurlliwest Laboratories

Richland, Washington 99352 


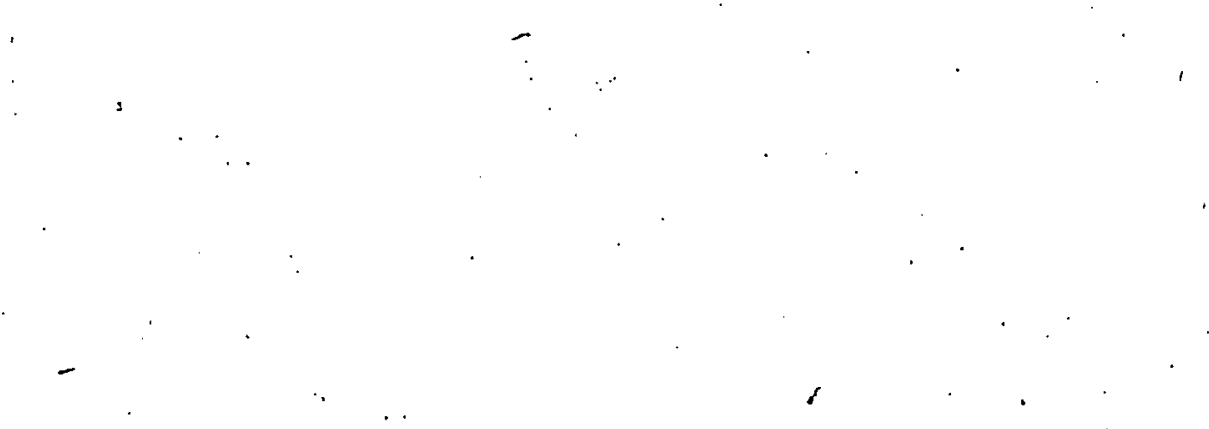

\section{THIS PAGE}

WAS INTENTIONALLY

LEFT BLANK 
1. SUMMARY

2. INTRODUCTION

3. ElECTROPOLISHING PROCESS.$\quad$.

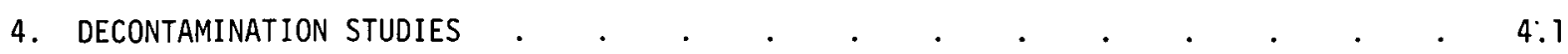

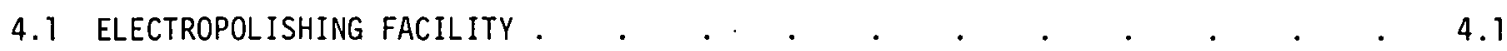

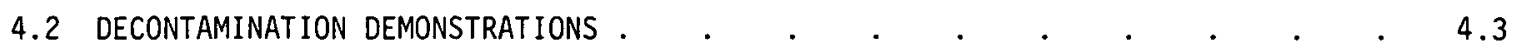

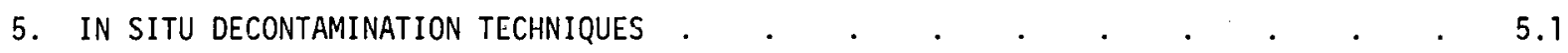

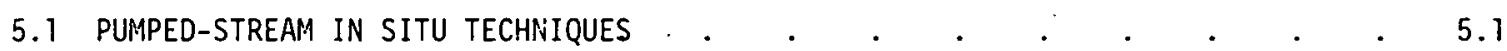

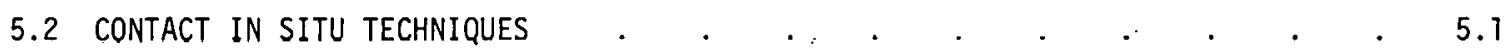

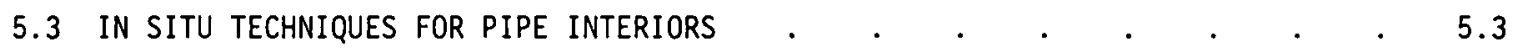

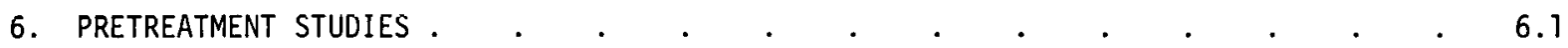

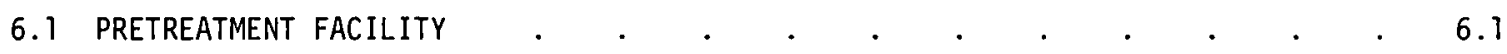

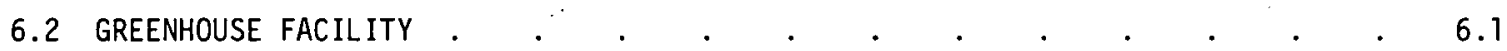

6.3 MECHANICAL SECTIONING TECHNIQUES . . . . . . . . . . . . . . . 6.2

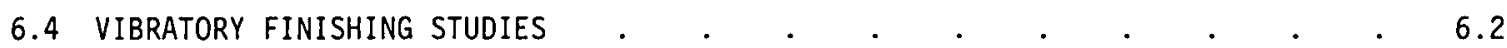

7. SOLUTION TREATMENT

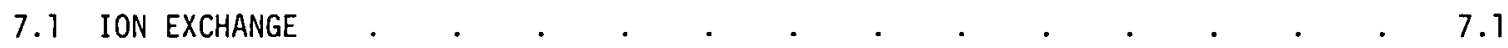

7.2 SOLVENT EXTRACTION

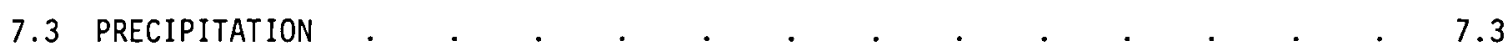

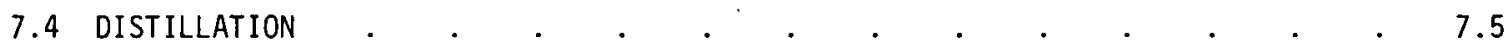

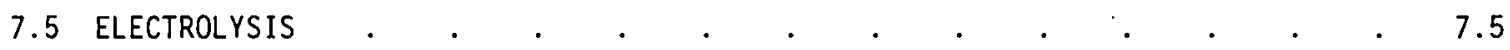

7.6 MEMBRANE SEPARATION .

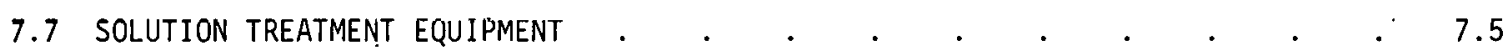

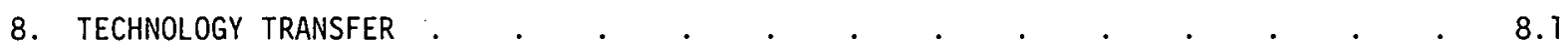

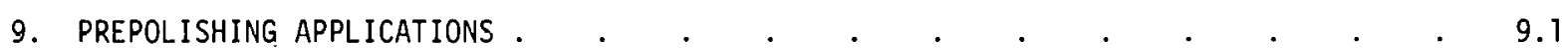

10. RACKING TECHNOLOGY . . . . . . . . . . . . . . . . . . . . 10.1

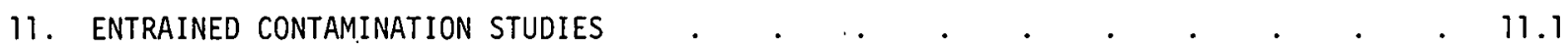

11.1 RECAST LAYER STUDIES . . . . . . . . . . . . . . . . . . . . . . . . . . 11.1

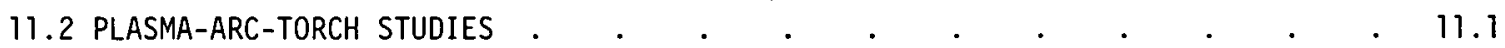

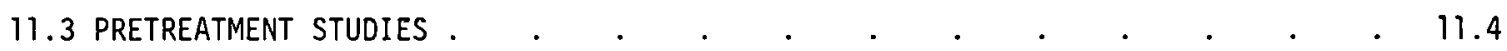

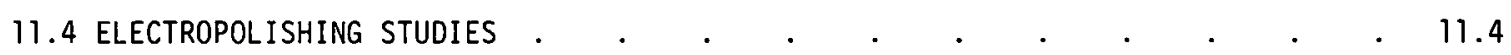

12. BASIC STUDIES AND PROCESS OPTIMIZATION

12.1 THROWING POWER STUDIES . . . . . . . . . . . . . . . . . . . . . 12.1

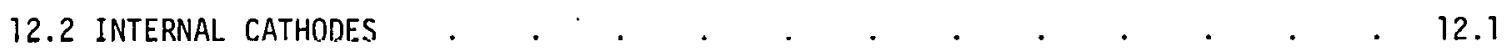

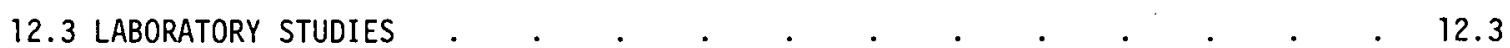

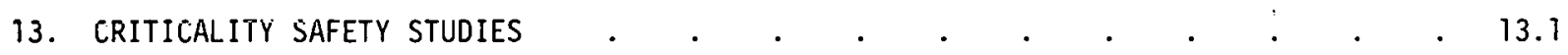

14. CONTAMINATION MEASUREMENT STUDIES . . . . . . . . . . . . . . . . . . 14.1

15. POTENTIAL APPLICATIONS

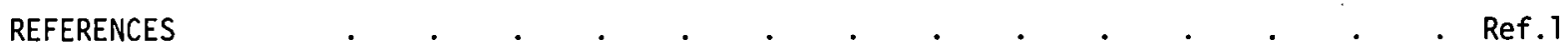

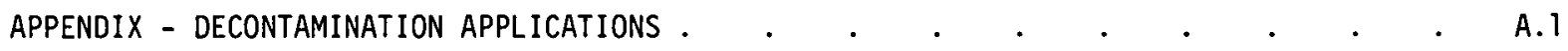




\section{$\underline{\text { LIST OF FIGURES }}$}

1 Schematic Drawing of the Type of Electropolishing Cell Used to Decontaminate Metal Surfaces

2 Relationship of Current Density and Cell Voltage for [1ectropolishing Showing Optimum Operating Region for Electrochemical Decontamination

3 Arrangement of the Demonstration Decontamination Facility in the Hanford 231-Z Building

4 View of the 400-Gal Electropolishing Facility

5 Sections from a Stainless Steel Duct, Representing a Total Surface Area of $20 \mathrm{ft}^{2}$, Decontaminated by Electropolishing in Less than 5 min . . $\quad 4.4$

6 Stainless Steel Animal Cage Decontaminated by Electropolishing Within 20 min

7 Mild Steel Valve (A) Heavily Corroded and Contaminated Before Electropolishing, and (B) Completely Decontaminated After Electropolishing . . $\quad .4 .5$

8 Glove Box Tools Decontaminated from $1 \mathrm{million}$ dis $/ \mathrm{min} \cdot 100 \mathrm{~cm}^{2}$ to Background in Less than 5 min

9 Traveling Wire Flux Monitor Decontaminated Using Electropolishing Without Affecting Critical Tolerances . . . . . . . . . . . . . 4.6

10 Demonstration of the Ability to Electropolish at a Distance Using a Pumped Stream of Electrolyte

11 Pumped Stream In Situ Device

12 Contact In Situ Device

13. Schematic of the $\mathrm{N}$-Reactor Corrosion Test Loop with Electropolishing Equipment Installed

14 Front View of Walk-In Hood Showing Master-Slave Manipulators Used for Remote Disassembly, Sectioning, and Pretreatment Operations

15 Stainless Steel Ducting From Downdraft Facility (24-in.-diameter, 22-Gauge Stainless Steel) That was Sectioned into the Pieces Shown in Figure 5 Using a Mcchanical Nibler

16 Abrasive Media Used for Pretreatment Studies in the Vibratory Finisher: Triangular Ceramic Media (above) and Conical Plastic Media (below) Vibratory Finisher with 4-ft $\mathrm{f}^{3}$ Tub Capacity Used in Pretreatment Studies

18 Mild Steel Pipe Clamps (A) as Received and (B) After Removal of Rust and Gross Contamination by 4-hr of Vibratory Finishing. Spent Electrolyte Purification by Reciprocating Acid Adsorption Spent Electrolyte Purification by Solvent Extraction Industrial Electropolishing of Large Stainless Steel Sheets. Electropolishing the Interior of Long Pipes (Three at a Time) Without Racking

'27 Titanium Rack Used in the Decontamination' of Fission Product 
29 Optical Micrograph Showing the Recast Layer at the Center of 0.24-in.-thick Stainless Steel Plate Cut Using a Plasma Arc Torch.$\quad$. . . . . $\quad 11.2$

30 Optical Micrographs Illustrating the Type of Surface Produced by Explosive Cutting: A) 0.3-in.-thick Stainless Steel Pipe Cut from the Inside and

31 Scanning Electron Micrographs Illustrating the Surface Cracking and Copper Distribution for Explosively Cut Mild Steel Pipe: A) Back-Scattered Electron Image and B) Copper X-Ray Map of the Same Region . . . . . . 11.3

32 Plasma-Arc Torches to be Used to Develop Effective Sectioning Techniques for Contaminated Metal While Minimizing the Thickness of the Recast Layer: 100-A, Dry Torch (Left) and 400-A, Water-Injected Torch (Right) . .

33 Use of Vibratory Finishing to Remove the Recast Layer Produced by Plasma Arc Torch Cutting: As Sectioned Using a 100-A, Dry Plasma Arc Torch (Left) and

34 Test Fixture and Specimen Used to Investigate the Throwing Power of Electropolishing Solutions

35 Stainless Steel Elbows (8-in. Diameter by 35-in. Long) Decontaminated Without an Internal Cathode

36 Internal Cathode (Bottom) Used to Electropolish the Inside of $0.25-i n$.Diameter by 36-in.-Long Fuel Cladding (Top)

A-l Mild Steel Core Drill Bit Used to Sample Salt Cake in the Waste Tanks at Hanford

A-2 Product Receiving Canister Used to Transport Plutonium Nitrate Solution . . A.2

A-3 Uranium-Contaminated Aluminum Compressor Blade Decontaminated by . . . . . . A.2

A-4 Stainless Steel Diffusion Pump Adaptor from a Vacuum System Used on a Plutonium Glove Box

A-5 Manipulator Tong Assembly Used in a Fission-Product Hot Cell . . . . . A.4

A-6 Hastelloy. C Fission Product Storage Capsule . . . . . . . . . . . A.5

A-7 Mild Steel Pneumatic Cylinder and Piston Assembly from Hanford N-Reactor Decontaminated by Electropolishing

A-8 Cross Section of 0xidized Inconel 601 Canister Material, Comparing the Original 0xidized Surface and the Descaled Surface Produced by Electropolishing . 


\section{ACKNOWLEDGMENTS}

The work summarized in this report is an outgrowth of earlier studies sponsored by the Division of Basic Energy Sciences, U.S. Department of Energy. The first application of this decontamination technique at Hanford was suggested by D. W. Jeppson of the Rockwell Hanford Operations Company. Appreciation is expressed to Dr. R. E. Felt of the Rockwell Hanford Operations Company and T. M. Hall of United Nuclear Industries, Inc., for their encouragement and support of these earlier application studies. The present process development studies are sponsored by the Division of Waste Management, U.S. Department of Energy, with the Division of Nuclear Power Development sponsoring the solution processing, technology transfer, and entrained contamination studies.

Appreciation is extended to Dr. R. D. Nelson and Dr. N. J. Olson of the Metallurgy Research Section of Pacific Northwest Laboratory for their guidance and encouragement in this work, and to the members of the decontamination project team for their dedication and assistance in developing this new decontamination technology. The technical information and assistance provided by L. S. Winter and other staff members of the Hydrite Chemical Company have contributed immeasurably to the success of this work and their help is gratefully acknowledged. 


\section{ELECTROPOLISHING AS A DECONTAMINATION TECHNIQUE - PROGRESS AND APPLICATIONS}

\section{SUMMARY}

Research conducted at the Pacific Northwest Laboratory, operated by Battelle Memorial Institute for the Department of Energy, has shown that electropolishing is a rapid and effective technique for removing plutonium and other radionuclide contamination from a variety of metal surfaces. The major objective of this continuing research is to develop electropolishing into a large-scale decontamination technique that can completely and economically remove transuranic and other surface contamination from large volumes of metallic waste. The successful development and widespread application of this decontamination technique would permit a substantial reduction in the volume of metallic waste requiring expensive perpetual care or geologic disposal. Other benefits include minimization of personnel exposure, reduced risk of environmental contamination and the preservation of large quantities of irreplaceable metals and alloying elements for possible future use.

Electropolishing is an electrochemical process used in both laboratory and industrial applications to produce a smooth, polished surface on a variety of metals and alloys. The object to be decontaminated serves as the anode in an electrolytic cell. The passage of electric current results in the anodic dissolution of the surface material and, for proper operating conditions, a progressive smoothing of the surface. Any radioactive contamination on the surface or entrapped within surface imperfections is removed and released into the electrolyte by this surface dissolution process. The production of a polished surface also facilitates the removal of residual electrolyte by rinsing to leave a contamination-free surface.
These research studies have demonstrated the ability of electropolishing to reduce the radiation levels of steel tools and stainless steel vacuum system components, which were heavily contaminated with plutonium oxide, from 1 million dis/min. $100 \mathrm{~cm}^{2}$ to background in less than $10 \mathrm{~min}$. Other examples of objects that have been decontaminated within minutes using electropolishing include hot cell manipulator assemblies, analytical instrument components, laboratory transfer containers, offsite shipping containers, fission product storage capsules, laboratory animal cages, and nuclear reactor process tube components.

One of the major activities of this research has been the establishment and intensive operation of a $400-\mathrm{gal}$ immersion electropolishing system designed specifically to develop and demonstrate decontamination techniques for representative plutonium- and beta/gamma-contaminated components. Items that have been successfully decontaminated in this electropolishing facility include:

- large, plutonium-contaminated components with more than $15 \mathrm{ft}^{2}$ of surface area

- many smaller components, such as 60 radiumcontaminated animal cages

- the inside of 3-ft-long, plutoniumcontaminated ventilation ducts

- sectioned ducting, processed $20 \mathrm{ft}^{2}$ at a time

- threaded and precision-machined parts that were decontaminated while maintaining critical tolerances to permit their reuse. 
Substantial progress has also been made in developing in situ electropolishing techniques that can be used to decontaminate metallic surfaces that cannot readily be transported to or immersed in a conventional electropolishing tank. This capability will be valuable in onsite decontamination and decommissioning operations for tanks, equipment, pipe interjors, and other large or immobile metal surfaces prior to dismantling.

Before an object is suitable for decontamination by electropolishing, it must be relatively clean and in a geometry and size that can be accommodated in the electropolishing facility. Sectioning/pretreatment studies are underway to develop and demonstrate optimum disassembly, sectioning, surface preparation, and gross contamination removal procedures. The various methods of cutting or sectioning contaminated objects often lead to entrained contamination in the cut surfaces. Consequently, arc saw, plasma arc torch, and explosive cutting techniques are being evaluated in terms of the thickness and characteristics of the disturbed metal layer. Some of the pretreatment methods under consideration for removal of paint, grease, corrosion layers, and gross contamination include vibratory finishing, ultrasonics, dry and liquid abrasive blasting, and high-pressure spray systems.

Other supporting studies are also in progress to provide a sound technical basis for scale-up and widespread application of this new decontamination process. These include:
- laboratory-scale studies to understand decontamination mechanisms and optimize the decontamination process through control of electrolyte composition, current density and other electropolishing variables

- establishment of criticality safety limits and operating procedures for work with plutonium and other fissile contaminants and development of contamination measurement systems needed for criticality safety and process control

- development of solution treatment procedures to extend electrolyte life and minimize secondary waste through removal of dissolved metal and contamination from the electrolyte and rinse solutions.

Electropolishing has great potential for exposure reduction applications because of its ability to rapidly remove beta and gamma surface contamination. Exposure reduction projects include the development of electropolishing techniques to facilitate contact maintenance on failed equipment, and the development of an electropolishing system for the Hanford N-Reactor to decontaminate valves, fuel spacers, process tube fittings, and other components for repair and reuse. In addition, experience has shown that the smooth surfaces produced by electropolishing are much easier to clean using standard decontamination téchñiqués thân métal surtaces with a normal as-received finish. Significant interest is developing in using electropolishing to prepolish stainless steel laboratony ware, shipping and transfer cont.ainers, and nther items that require rnutine dernntamination. 


\section{INTRODUCTION}

The operation and eventual retirement of nuclear industry facilities will generate large quantities of surface-contaminated metallic waste. This metallic waste, and particularly that contaminated with transuranic elements, will require expensive handling, storage, and ultimate geologic disposal. The ability to remove this surface contamination would eliminate both the expense of radioactive storage and disposal and any associated risk of environmental contamination. It also would contribute to conservation efforts by permitting the rccovery and reuse of irreplaceable alloying elements such as chromium and nickel that would otherwise be lost by burial.

Electrolytic decontamination methods have been used on a limited basis in the past, primarily as an adjunct to other decontamination procedures. I Although effective, electropolishing techniques never were widely adopted for decontamination appiications because of the additional expense and complexity associated with specialized equipment, chemicals, and operating procedures. Now, however, these economic and convenience considerations, which probably never were valid for large-scale decontamination applications, are inconsequential compared with the need for effective surface decontamination techniques to minimize the amount of metallic waste requiring geologic disposal.

Laboratory-scale studies by Pacific Northwest Laboratory (PNL), in cooperation with Rockwell Hanford Operations Company and United Nuclear Industries, Inc., have shown that electropolishing is a rapid and effective technique for removing plutonium and other radionuclide contamination from a variety of metal surfaces. For example, the radiation levels of steel tools and stainless steel vacuum system components heavily contaminated with plutonium oxide have been reduced from more than $1 \mathrm{million}$ dis/min. $100 \mathrm{~cm}^{2}$ to backyruund in less than $10 \mathrm{~min}$. Other objects that have been decontaminated within minutes using electropolishing include large components with more than $15 \mathrm{ft}^{2}$ of surface area, ducting, threaded and precision-machined parts having critical tolerances, and small conponents such as animal cages.

As part of the nuclear waste management program activities sponsored by the Department of Energy, PNL is developing electropolishing into a large-scale decontamination technique capable of processing large volumes of surface-contaminated metallic waste.
These studies also include developing the support technology needed for process scale-up and maintenance of the safety and effectiveness of the technique; adapting electropolishing for specific decontamination and exposure reduction applications at Hanford and other DOE sites; and coordinating the transfer of this decontamination technology to other DOE sites and for general use by the nuclear industry. Specific activities as they are described in this report include:

- establishment and operation of a demonstration decontamination system

- development of in situ electropolishing techniques for the decontamination of surfaces that cannot be transported to or immersed in an electropolishing cell

- installation and operation of a pretreatment facility; development and selection of optimum preparation, sectioning, and gross contamination removal procedures to prepare metal surfaces for final decontamination by electropolishing

- development of solution treatment procedures to extend electrolyte life and minimize secondary waste through removal of dissolved metal and contamination from the electrolyte and rinse solutions

- racking studies, including the evaluation of titanium and tantalum as low erosionrate rack, basket and barrel materials

- transfer of compatible technology from the commercial electropolishing industry

- development of enhanced removal techniques for contamination incorporated in cut surfaces by the disassembly, sectioning, or shredding procedures used to prepare metal waste for subsequent decontamination operations

- laboratory-scale studies to understand decontamination mechanisms and optimize the decontamination process through control of electrolyte composition, current density, and other electropolishing variables

- establishment of criticality safety limits and operating procedures for work with fissile contaminants

- development of contamination measurement systems needed for criticality safety and process control 
- study of the advantages and applications of prepolishing techniques

- investigation of the use of electropolishing to remove oxide layers on various components

- development of electropolishing techniques to facilitate contact maintenance on failed equipment
- development of an electropolishing system for the Hanford $\mathrm{N}$-Reactor to decontaminate valves, fuel spacers, process tube fittings, and other components for repair and reuse

- identification of future applications.

The technical details of specific objects decontaminated by electropolishing are included in the Appendix. 


\section{ELECTROPOLISHING PROCESS}

Electropolishing is an electrochemical process used in both laboratory and industrial applications to produce a smooth, polished surface on a variety of metals and alloys. Our studies have shown that electropolishing is a versatile, rapid, and effective decontamination technique for radioactive metallic surfaces. Its versatility has been illustrated by its ability to decontaminate compositions ranging from mild steel, copper, and aluminum to stainless steel and highly alloyed, corrosion- and heat-resistant materials. Electropolishing can also be used to decontaminate, without prior disassembly, relatively complex components and shapes, including assemblies with moving parts, the interior of tubing, and threaded sections. Special electrodes can be used as required for the in situ electropolishing of objects that cannot be accommodated in an electrolytic cell. Moreover, electropolishing is effective for a variety of radionuclides including plutonium, uranium, radium, cobalt, strontium, cesium, and americium and for contamination that is baked-on, ground-in, or otherwise difficult to remove using conventional decontamination procedures.

Only a few minutes of electropolishing are required to completely remove most types of surface contamination. Consequently, use of electropolishing could reduce man-hours and personnel exposure for applications that normally require decontamination by scrubbing or other labor-intensive procedures.

Electropolishing is an effective decontamination technique. The ability to rapidly clean even highly contaminated surfaces to background radiation levels is important both from an environmental and an economic standpoint. Complete decontamination permits the repair and return to service of critical components with a minimum of time and personnel exposure. Decontaminated items can be reused in nonradioactive applications and metals and alloys can be recycled rather than buried.

Electropolishing is an intrinsically simple process with no moving parts except as required for circulation or agitation of the electrolyte. Thus, it is amenable to remote operation and mechanization to further minimize personnel exposure. Experience also has shown that the smooth surfaces produced by electropolishing are much easier to clean using standard decontamination techniques than metal surfaces with a normal as-received finish. Significant interest is developing in using electropolishing to prepolish stainless steel laboratory ware, shipping and transfer containers, and other items that require routine decontamination.

The use of electropolishing to decontaminate surfaces is illustrated in Figure 1. The object to be electropolished serves as the anode in an electrolytic cell. The passage of electric current results in the anodic dissolution of the surface material and, under proper operating conditions, a progressive smoothing of the surface. Any radioactive contamination on the surface or entrapped within surface imperfections is removed and released into the electrolyte by the surface dissolution process. The amount of metal removed from the component surface to effect decontamination is usually less than 0.002 in. and is removed uniformly with no preferential attack of grain boundaries or other microstructural features. In fact, the surface produced by electropolishing usually has better corrosion resistance and other properties than did the original surface. ${ }^{2}$

Phosphoric acid was used as the reference electrolyte in these decontamination studies because of its stability, safety, and applicability to a number of alloy systems. In addition, the hygroscopic nature of phosphoric acid helps minimize airborne contamination and the good complexing characteristics of phosphoric acid for metal ions may be a significant factor in minimizing recontamination from the electrolyte. ${ }^{3}$ other acids and chemicals can be added to the phosphoric acid as required to enhance surface passivity, increase brightness, or promote sludging.

Representative operating conditions for decontamination using phosphoric acid electrolytes are solution temperatures of $40^{\circ}$ to $80^{\circ} \mathrm{C}$, phosphoric acid concentrations of 40 to $80 \%$, electrode potentials of 8 to $12 \mathrm{~V}(\mathrm{dc})$, and current densities of 50 to $250 \mathrm{~A} / \mathrm{ft}^{2}$.

Figure 2 illustrates the complex currentvoltage relationship observed for many of the decontamination studies. At low voltages and current derisities the metal removal is nonuniform, resulting in etching rather than polishing. Conversely, at high voltages the dissolution process is accompanied by excessive oxygen evolution resulting in severe pitting of the surface. 


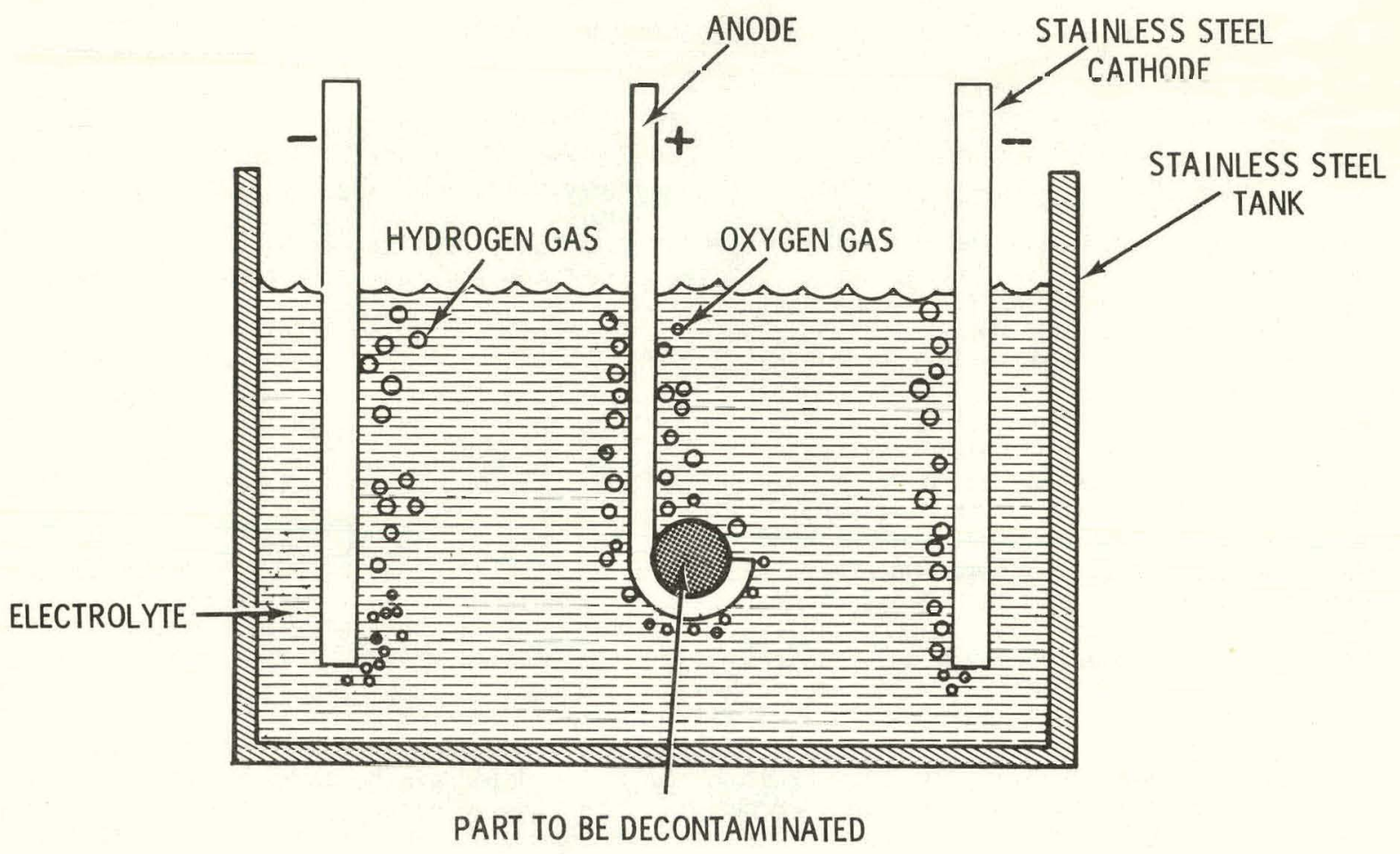

FIGURE 1. Schematic Drawing of the Type of Electropolishing Ce11 Used to Decontaminate Metal Surfaces

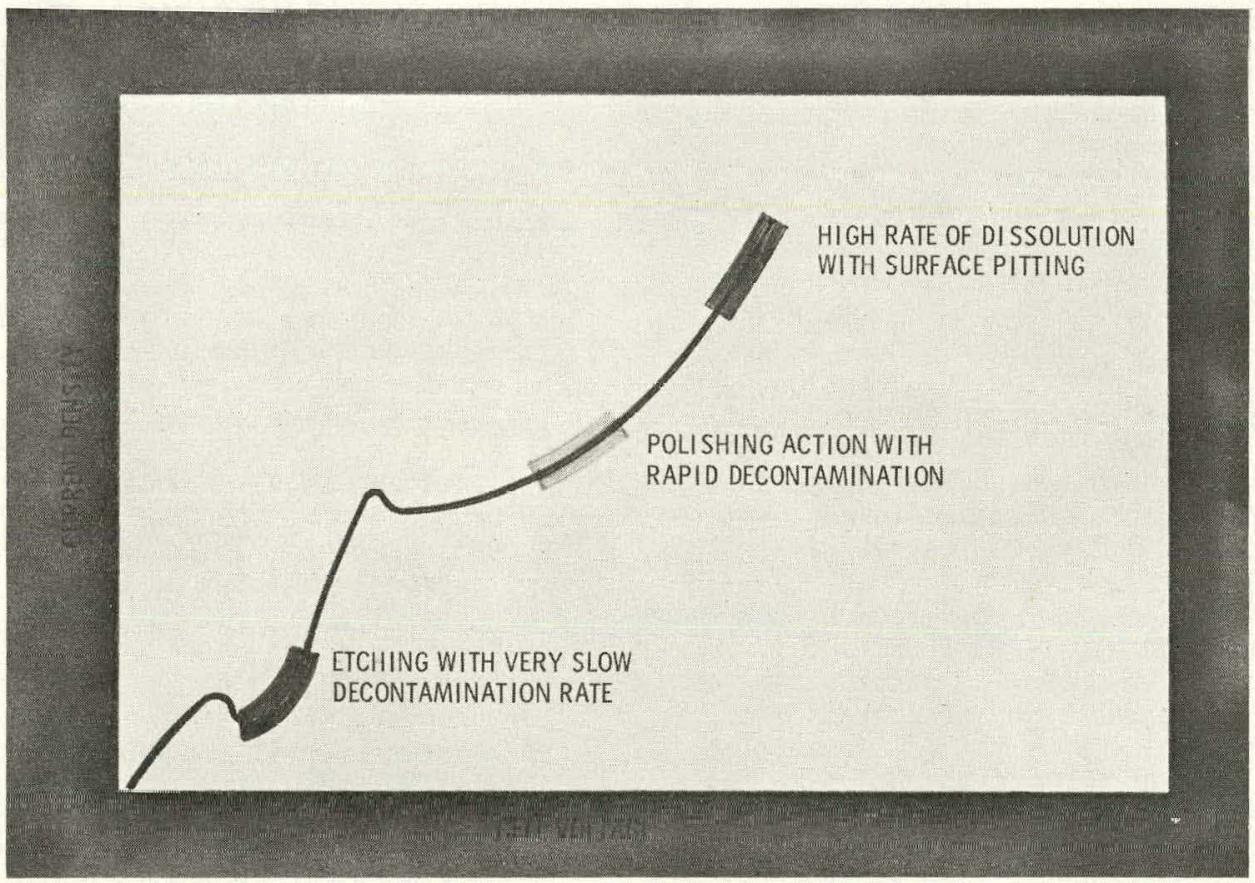

FIGURE 2. Relationship of Current Density and Cell Voltage for Electropolishing Showing Optimum Operating Region for Electrochemical Decontamination 
Typical decontamination times range from 5 to $30 \mathrm{~min}$, corresponding to the removal of 0.3 to 2 mils of surface material at a current density of $150 \mathrm{~A} / \mathrm{ft}^{2}$. It usually is necessary to move the anode contacts once during the electropolishing cycle to ensure decontamination of the area under the contacts.

Stainless steel electropolishing tanks are preferred for decontamination applications because the electropolishing system itself can be decontaminated whenever required by making the tank walls anodic. Also, the metallic tank walls can serve as the cathode for waste processing applications where maintenance of tolerances on the decontaminated component is not important. Otherwise, separate cathodes are used that are shaped and positioned either to ensure uniform polishing of the entire component or to minimize metal removal on threaded sections or other critical component areas.

Other components of an electropolishing decontamination system are a dc power supply, one or more rinse tanks, a ventilation system, and provision for heating and agitating the electrolyte and rinse solutions. 


\section{DECONTAMINATION STUDIES}

A 400-gal manual electropolishing facility to develop and demonstrate electropolishing as an effective large-scale decontamination technique has been established. This facility will be used to decontaminate increasingly larger components and quantities of metallic wastes and to provide experience in working with large volumes of contaminated electrolyte and rinse solutions. Operating conditions will be varied to determine optimum decontamination procedures, and materials representing a variety of alloys, types of contamination, and component geometries will be processed to help define and demonstrate process effectiveness and versatility.

\subsection{ELECTROPOLISHING FACILITY}

The arrangement of the demonstration decontamination facility in the Hanford $231-Z$ Building is illustrated in Figure 3 and a view of the electropolishing facility is shown in Figure 4. The electropolishing system consists of an open-face hood for unpacking the material to be decontaminated, a 400-gal electropolishing tank, two 400-gal rinse tanks, a $5600 \mathrm{~A}(\mathrm{dc})$ power supply (located in a noncontaminated zone above the decontamination facility), and an overhead hoist system for handling the contaminated material. Other equipment and features include a ventilation system for control of contamination and process gases; heating, agitation and filtration systems for the electrolyte and rinse solutions; safety systems to monitor for leaks, airborne contamination and other out-of-bounds conditions; and a remote control system for the power supply.

The entire electropolishing facility is designed to facilitate self-cleaning and the maintenance of a very low background contamination level. The tanks are stainless steel and, as noted previously, can be decontaminated by making the tank walls the anode. The sides of the electropolishing and rinse tanks and the adjacent room walls are 1 ined with polished stainless steel sheet for added containment of the electrolyte and rinse solutions. The floor also is stainless steel with removable panels that can be decontaminated by electropolishing. The part of the room containing the electropolishing system is isolated by a floor dam so that the room itself serves as secondary containment for the electrolyte and rinse solutions in the event of tank failure.

The power supply is located in a noncontaminated zone above the decontamination facility. The power leads run to a distribution box just above the electropolishing

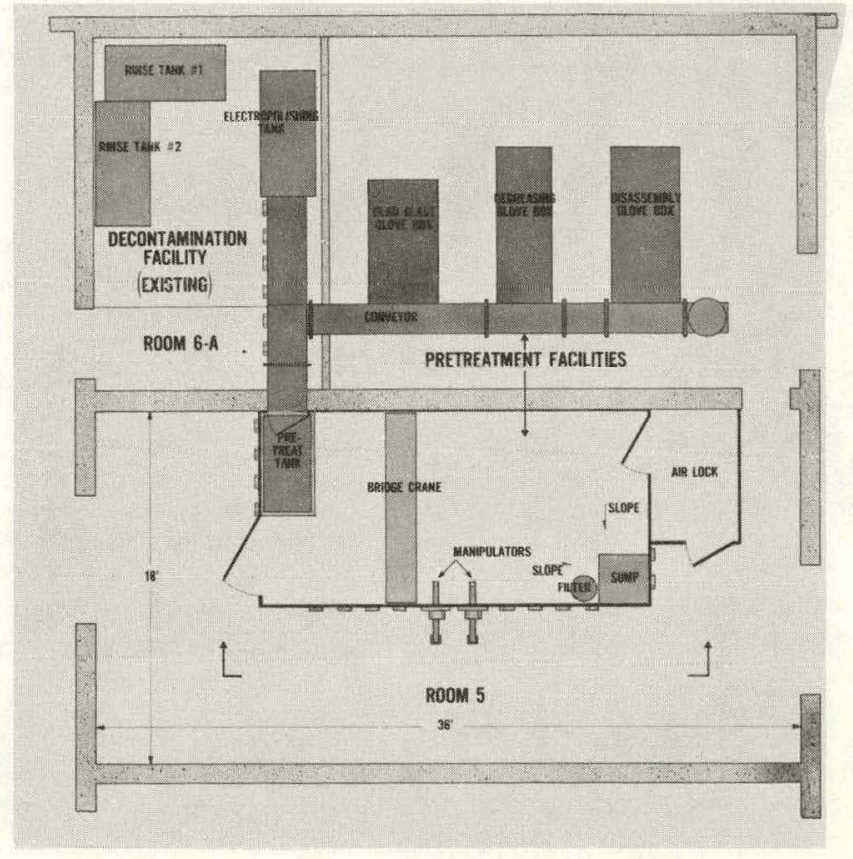

FIGURE 3. Arrangement of the Uemonstration Decontamindiun Facility in the Hanford 231-Z Building 


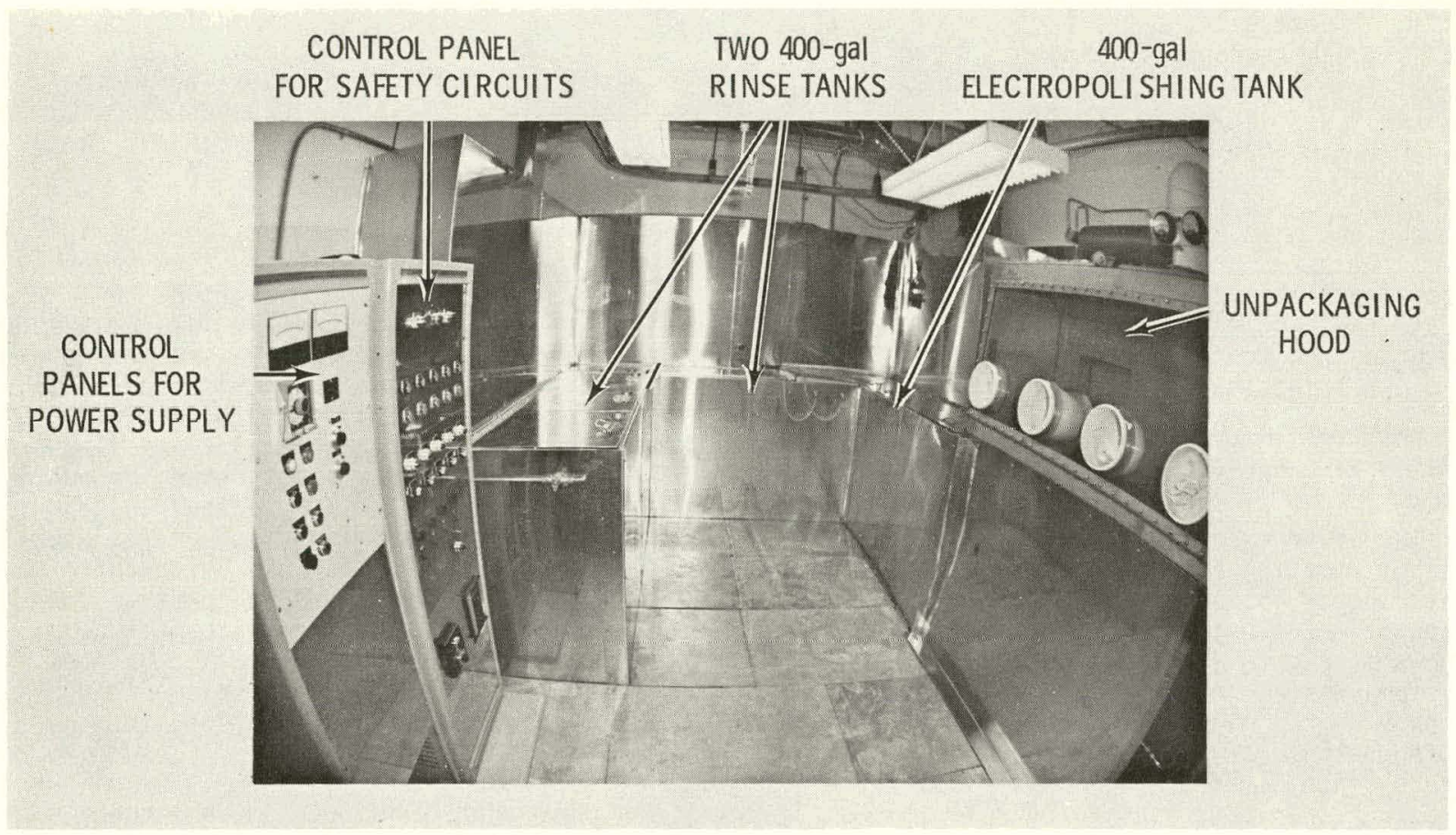

FIGURE 4. View of the 400-Gal Electropolishinq Facility

tank. Up to eight anode leads can be used to provide the necessary current capability and current distribution characteristics for large components. The power distribution system also permits use of the tank walls as the cathode and up to eight separate leads for auxiliary and internal cathodes. The power supply is run remotely from the decontamination facility using the control unit.

Safety features of the power supply include current and voltage 1imiting capability and the ability to shutdown within half a cycle in the event of a short circuit. The control system also incorporates a programmer for automatic operation of the power supply including specification of any desired current-time profile.

The unpacking hood is used to unwrap the items to be decontaminated and for any necessary precleaning such as the removal of paint, grease, or other nonconductive coatings or material. The metal surfaces are thoroughly wiped in accordance with criticality safety requirements to remove any gross contamination and are sprayed with phosphoric acid to tie down any loose contamination before transport to the electropolishing tank. The end of the unpacking hood next to the electropolishing tank opens to permit entry and removal of the test pieces. The top of the hood is slotted so that the hoist can be used inside the hood.

The pumps and filters for the electrolyte and rinse solutions are located under the unpacking hood. This permits removal and replacement of the contaminated filter elements through the floor of the hood. The use of a pumped stream to agitate the electrolyte has a number of advantages over the simpler and more commonly used air and mechanical agitation methods. Ejecting the high-pressure stream at the bottom of the electropolishing tank produces a rollingtype of agitation that minimizes splashing and misting and also preverils the builduip of sludge on the tank bottom. The circulating electrolyte can be filtered to remove the sludge and any contamination or corrosion products that are not in solution. Also, electrolyte is available under pressure for use in internal cathodes and for in situ decontamination applications using pumped stream and brush techniques.

These advantages of pumped-stream agitation also apply to the rinse system. Filtered water from the first rinse tank can be used 
to spray rinse the decontaminated parts over the electropolishing tank. This serves as an additional rinsing step and, more importantly, helps minimize the buildup of contamination in the rinse tanks by returning the contaminated dragout to the electropolishing tank.

Process control and safety systems include an on-stream density cell for continuous measurement of the specific gravity of the electrolyte, several circuits to detect leaks or out-of-bounds solution level changes for the electropolishing and rinse tanks, continuous radiation monitors for airborne contamination, and a monitoring system to ensure adequate ventilation of the electropolishing and rinse tanks. The safety systems automatically turn off the power supply, pumps and water supply to the decontamination system as well as sound an alarm in the event of leakage or other abnormal operation conditions.

Al1 components of the electropolishing facility have operated satisfactorily with the exception of the $50 \mathrm{gal} / \mathrm{min}$ pump used to circulate the electrolyte. Although designed for acid service, the pump experienced successive seal failures resulting in minor leakage of electrolyte into a containment tank positioned under the pumps and filtration system. This pump was replaced with a zeroleakage, magnetically coupled acid pump which failed after $100 \mathrm{hr}$ of service with the phosphoric acid electrolyte. Pump evaluation tests were continued with another type of zero-leakage pump with special acid-resistant alloy seals. This pump worked successfully.

\subsection{DECONTAMINATION DEMONSTRATIONS}

The 400-gal electropolishing system will accommodate planar components $4 \mathrm{ft}$ long by $2 \mathrm{ft}$ high and cylindrical components $4 \mathrm{ft}$ long by $1.25 \mathrm{ft}$ diameter. Anything larger than this must be disassembled or sectioned before processing in the electropolishing tank. The largest item decontaminated during initial operation of the electropolishing system is a stainless steel container (16 in. diameter by 22 in. high) that had been used as the electropolishing tank for earlier plutonium decontamination studies. The initial contamination level inside the container was 20,000 dis $/ \mathrm{min} \cdot 100 \mathrm{~cm}^{2}$ fixed and 2,000 dis/min. $100 \mathrm{~cm}^{2}$ smearable. Electropolishing the entire container in the 400-gal system using the tank walls as the cathode reduced the contamination level to nonsmearable with less than 2,500 dis/min. $100 \mathrm{~cm}^{2}$ of fixed contamination. The ability to partially decontaminate the inside of the container without using an auxiliary cathode illustrates the good throwing power of the electropolishing process. The remaining contamination was readily removed by electropolishing the interior of the tank for an additional 14 min using an internal cathode.

Examples of other items decontaminated using the 400-gal system include:

- Stainless steel ducting. Eight 2.5-ft-long by $1.3-\mathrm{ft}$-wide curved sections (Figure 5 ) from a 2-ft-diameter stainless steel duct were processed, three at a time, representing a total surface area of $20 \mathrm{ft}^{2}$. Electropolishing reduced the radiation level from $15,000 \mathrm{dis} / \mathrm{min} \cdot 100 \mathrm{~cm}^{2}$ to background in less than 5 min and removed less than 0.002 in. of surface materials.

- Stainless steel animal cages (Figure 6). Electropolishing for $20 \mathrm{~min}$ with the lid closed removed radium and lead-210 contamination that had resisted all previous decontamination efforts using standard techniques.

- Mild steel valve from the Hanford $\mathrm{N}$-Reactor (Figure 7). The as-received unit was heavily corroded as well as contaminated with beta/gamma fission products. Electropolishing removed the corrosion layer and reduced the contamination level from $40 \mathrm{mR} / \mathrm{hr}$ to background.

- Mild steel and stainless steel tools removed from a glove box (Figure 8 ). The radiation levels were reduced from more than 1 million dis $/ \mathrm{min} \cdot 100 \mathrm{~cm}^{2}$ to background in less than $5 \mathrm{~min}$. Even the threaded areas were completely decontaminated.

- Traveling wire flux monitor from the Hanford N-Reactor (Figure 9). This was decontaminated from $2 \mathrm{mR} / \mathrm{hr}$ to background in 15 min and illustrates the ability to remove light surface contamination without affecting critical tolerances.

A summary of items decontaminated in the electropolishing facility is shown in Table 1. More detailed technical information concerning these decontamination applications is given in the Appendix. 


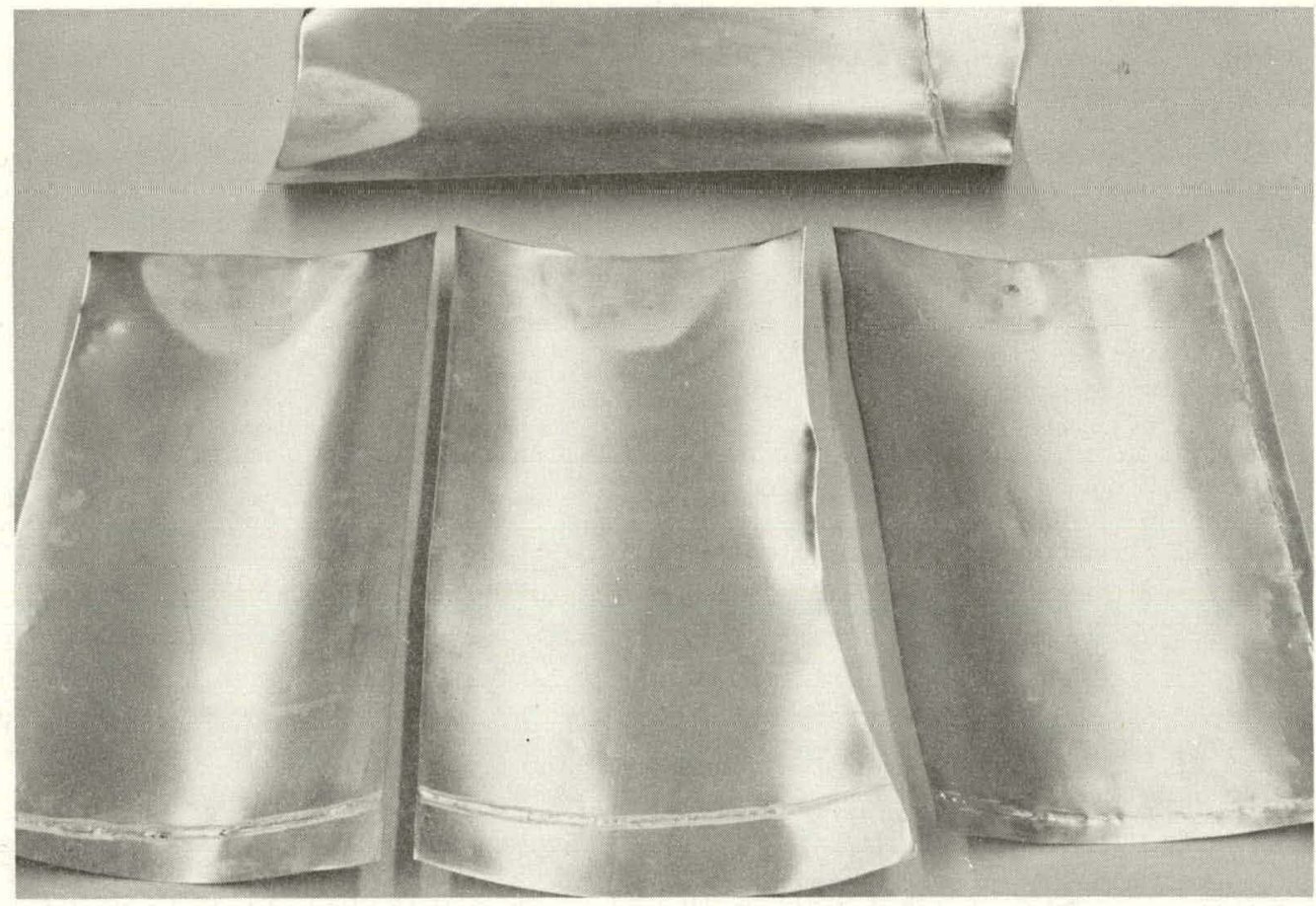

FIGURE 5. Sections from a Stainless Steel Duct, Representing a Total Surface Area of $20 \mathrm{ft}^{2}$, Decontaminated by Electropolishing in Less than 5 min

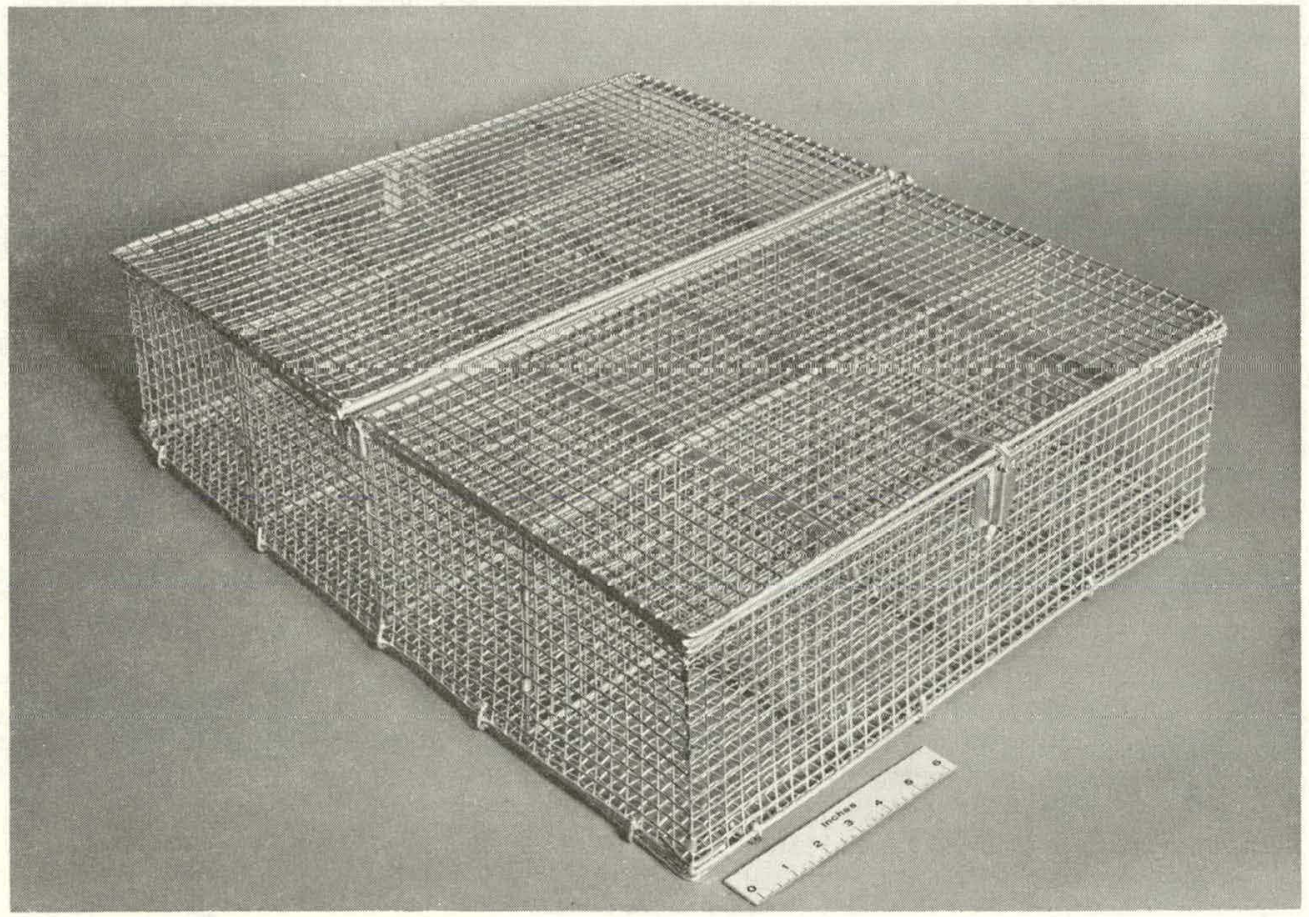

FIGURE 6. Stainless Steel Animal Cage Decontaminated by Electropolishing Within 20 min 

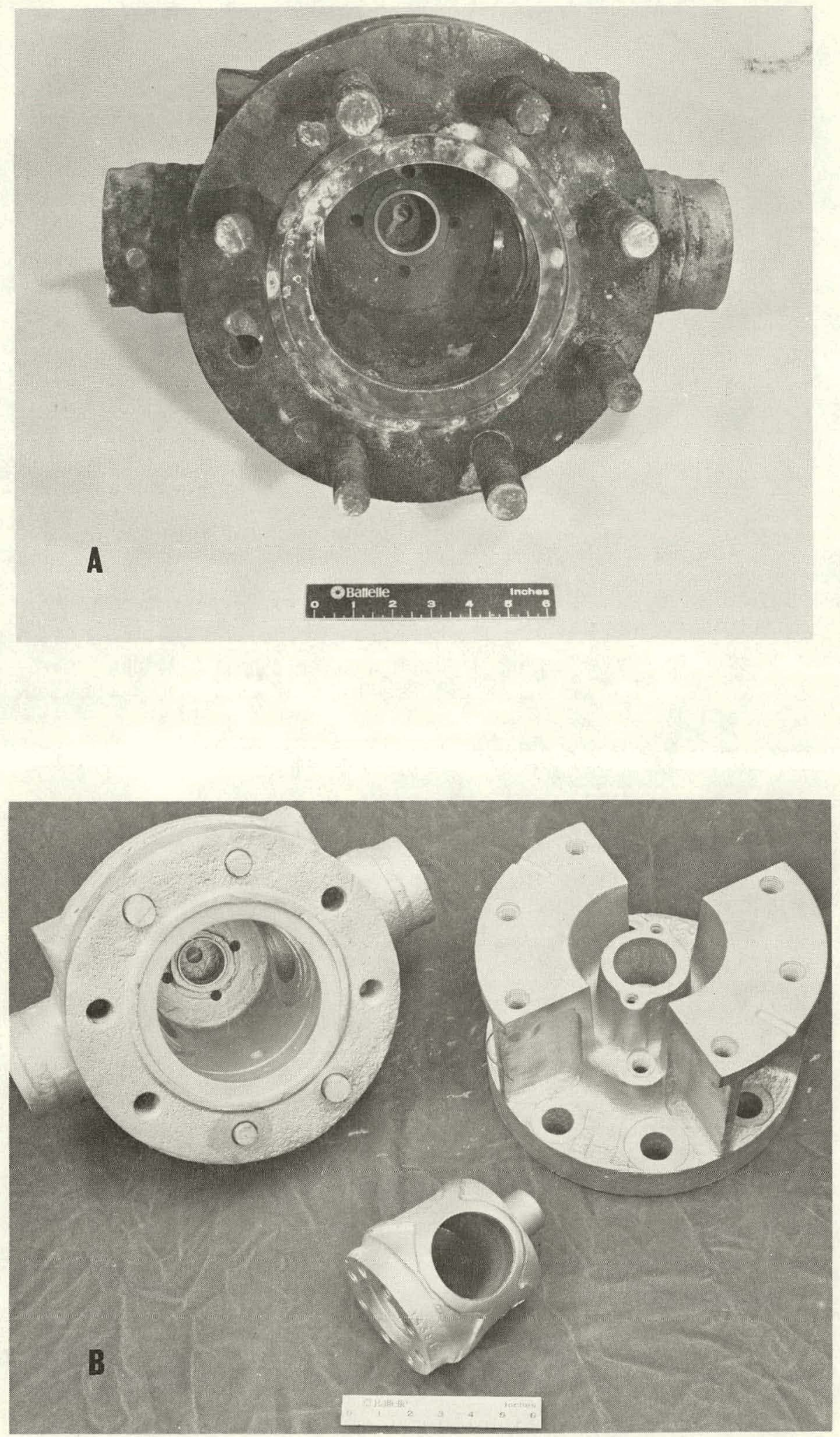

FTGIIRF 7. Mild Steel Valve (A) Heavily Corroded and Contaminated Before Electropolishing and (B) Completely Decontaminated After Electropolishing 


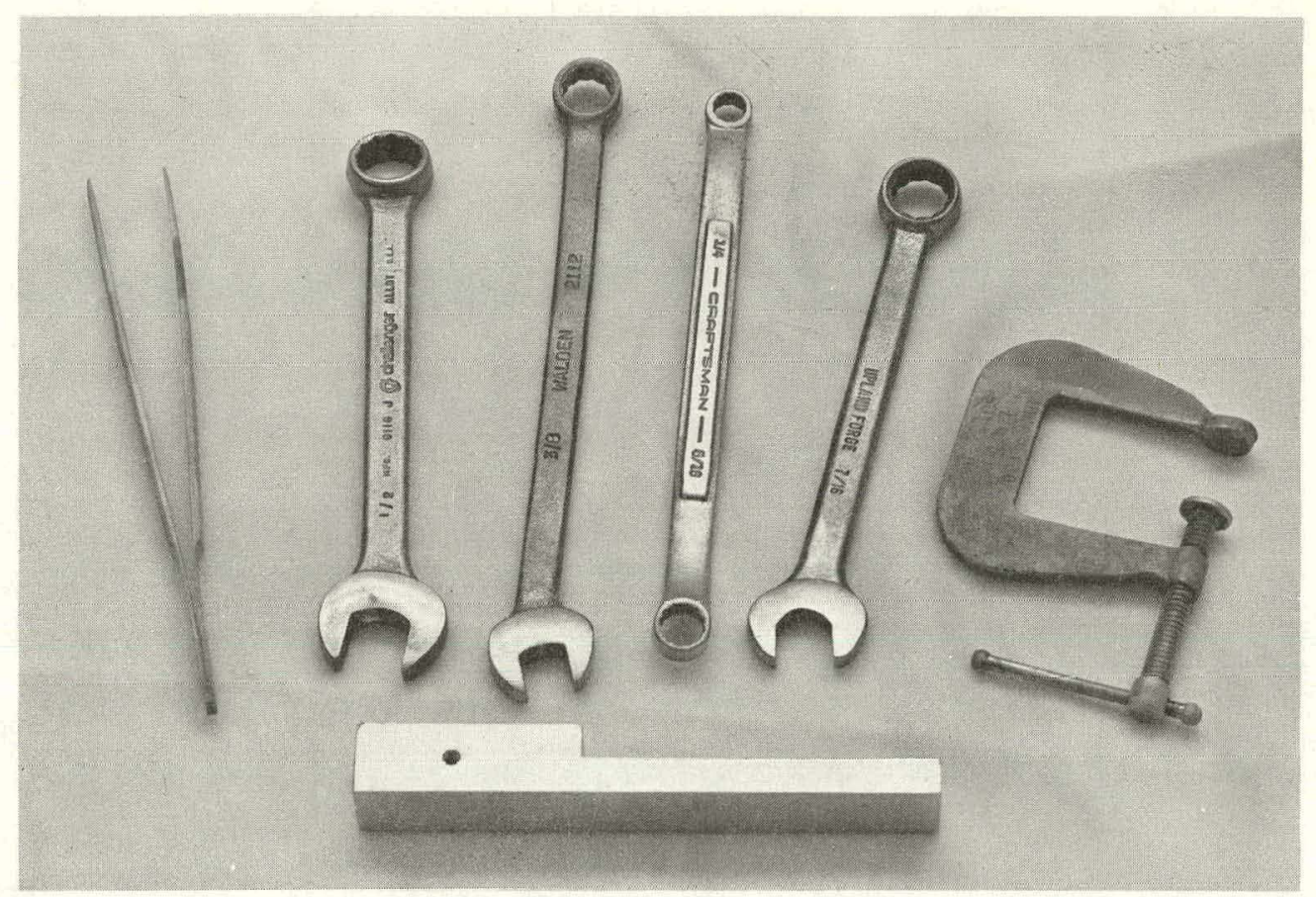

FIGURE 8. Glove Box Tools Decontaminated from 1 Million dis/min. $100 \mathrm{~cm}^{2}$ to Background in Less than 5 min

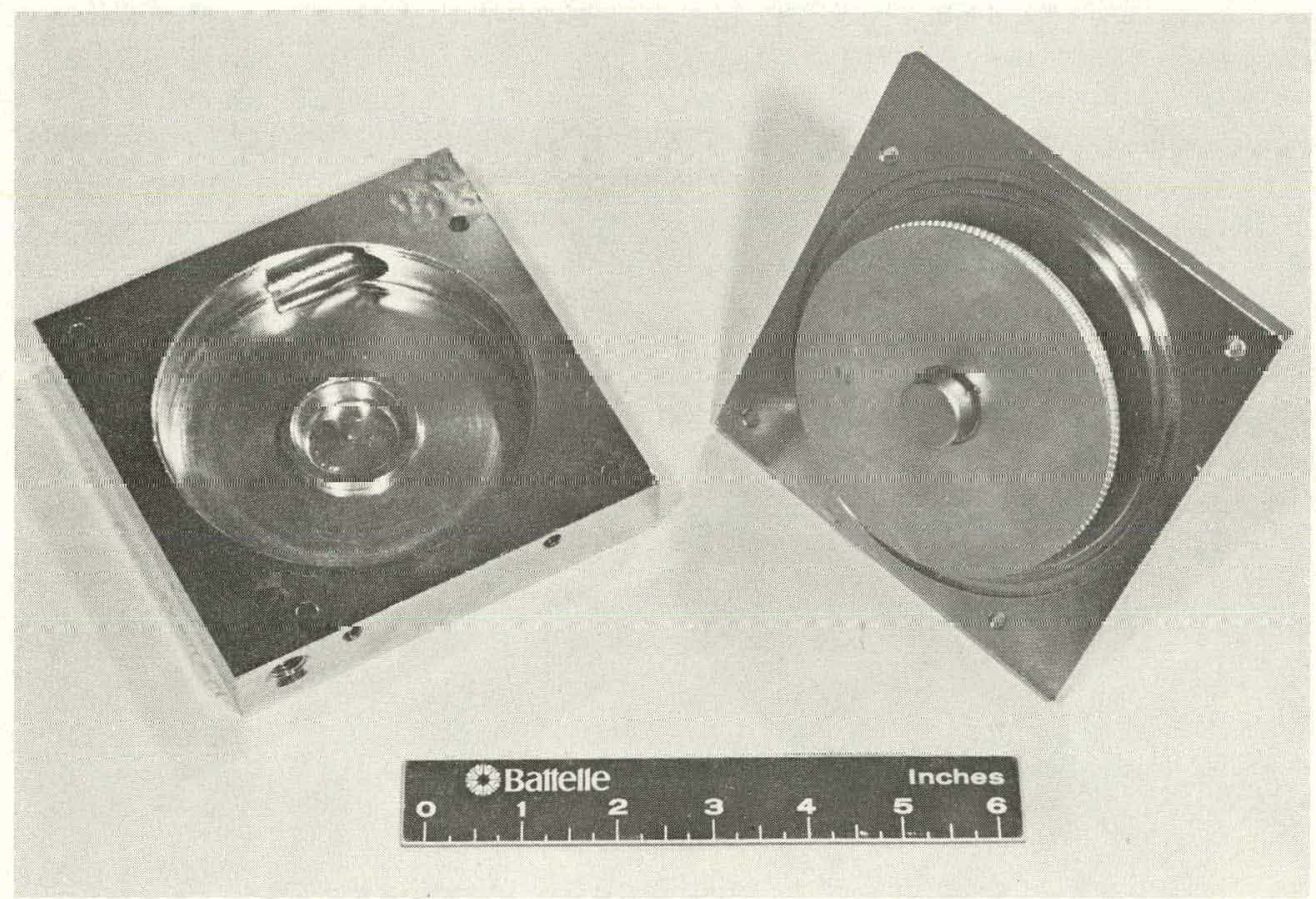

FIGURE 9. Traveling Wire Flux Monitor Decontaminated Using Electropolishing Without Affecting Critical Tolerances 
TABLE 1. Items Decontaminated by Electropolishing Techniques

\begin{tabular}{l} 
Item \\
\hline Core drill bit \\
Animal cages and trays \\
Product receiving canister \\
Standards capsules \\
Traveling wire flux monitor \\
Waste sampling tubes \\
Large reactor valves \\
Electropolishing tank \\
Compressor blades \\
Ducting \\
Pipe \\
Glove box waste \\
Vacuum system parts \\
Manipulator tong assemblies \\
Analytical instrument compo- \\
nents \\
Laboratory ware \\
Storage capsules \\
Pneumatic cylinder \\
Demister \\
Connector rings \\
Pipe clamps \\
Mass spectrometer components \\
Chemical vessel \\
End caps and inserts
\end{tabular}

\begin{tabular}{l}
\multicolumn{1}{c}{ Material } \\
\hline Mild steel \\
Stainless steel \\
Stainless steel \\
Stainless steel \\
Stainless steel \\
Mild steel \\
Mild steel \\
Stainless steel \\
Aluminum \\
Stainless steel \\
Mild steel \\
Stainless and mild steel \\
Stainless steel \\
Stainless and mild steel \\
and aluminum \\
Stainless steel \\
Stainless steel \\
Hastelloy C \\
Stainless steel \\
Mild steel \\
Stainless steel \\
Mild steel \\
Mild steel \\
Stainless steel \\
Mild steel \\
Mild steel
\end{tabular}

\begin{tabular}{l}
\multicolumn{1}{c}{ Contamination } \\
\hline Beta/gamma \\
Radium; lead-210 \\
Plutonium \\
Plutonium \\
Beta/gamma \\
Alpha/beta/gamma \\
Beta/gamma \\
Plutonium \\
Uranium; beta/gamma \\
Plutonium \\
Plutonium \\
Plutonium \\
Plutonium \\
Beta/gamma \\
Alpha/beta/gamma \\
Beta/gamma \\
Strontium fluoride \\
Cesium chloride \\
Beta/gamma \\
Plutonium \\
Beta \\
Beta/gamma \\
Alpha/beta/gamma \\
Plutonium \\
Beta/gamma
\end{tabular}




\section{IN SITU DECONTAMINATION TECHNIQUES}

In situ electropolishing techniques are under development for use in decontaminating large tanks, the interior of long pipes, pool walls, and other contaminated surfaces that either cannot be transported to or immersed in a conventional electropolishing cell. This in situ capability should be particularly valuable for decommissioning operations at retired facilities to decontaminate tanks, equipment, pipe interiors, and other large or immobile metal surfaces prior to dismantiling. In situ techniques should also have many applications in decontaminating valves, pumps, piping, pool walls, and other components of power reactors and other operating nuclear industry facilities to reduce radiation exposure and facilitate maintenance and inspection operations.

This section discusses the development and application of different types of in situ electropolishing techniques and illustrates the use of in situ techniques to decontaminate the interior of a $20-\mathrm{ft}-\mathrm{long}$ pipe at the Hanford N-Reactor.

\subsection{PUMPED-STREAM IN SITU TECHNIQUES}

The test facility shown in Figure 10 has been used to develop and demonstrate the ability to electropolish at a distance using a pumped stream of electrolyte. For example, a 0.31 in. ${ }^{2}$ area of stainless steel surface can be electropolished in less than 2 min by a 0.75 -in.-long stream of electrolyte from a

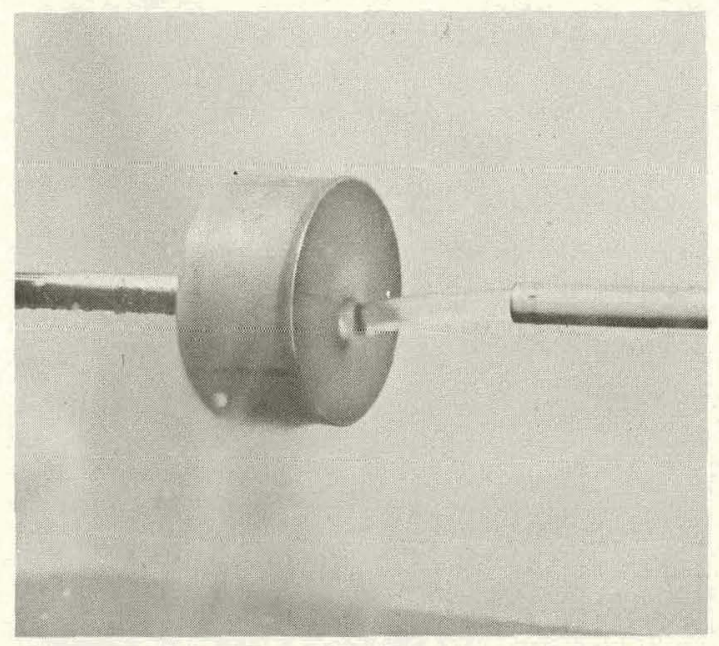

FIGURE 10. Demonstration of the Ability to Electropolish at a Distance Using a Pumped Stream of Electrolyte stainless steel pipe that also served as the cathode. The current densities are about the same as in-tank electropolishing (280 A/ft ${ }^{2}$ ), but the voltages are significantly higher, i.e., 24 versus $12 \mathrm{~V}(\mathrm{dc})$. Also, phosphoricsulfuric electrolytes are used for increased electrical conductivity.

Based on this work, a pumped-stream in situ electropolishing device has been developed and used as illustrated in Figure 11 to remove adherent contaminated oxide from difficult-to-clean component areas. A 0.5-in.diameter stream of phosphoric acid electrolyte conducting a current of $2 \mathrm{~A}$ reduced the radiation level of plutonium-contaminated areas on a carbon steel component from 15,000 dis-min $-1 / 100 \mathrm{~cm}^{2}$ to background in less than 2 min.

\subsection{CONTACT IN SITU TECHNIQUES}

A second type of in situ electropolishing device was developed that can rapidly electropolish defined surface areas using high current densities but normal electropolishing voltages. This contact-type device is illustrated in Figure 12 and consists of an insulated fixture that holds the cathode (the perforated stainless steel disc inside the cylinder) at a fixed distance from the anode surface. Electrolyte is pumped through the unit while maintaining a slight negative pressure to contain the electrolyte. Testing of the unit shown in Figure 12 demonstrated its ability to electropolish the $3-i n .^{2}$ area on the stainless steel surface in 5 min using phosphoric-sulfuric electrolyte, a current density of $550 \mathrm{~A} / \mathrm{ft}^{2}$, and an electrode potential of less than $12 \mathrm{~V}(\mathrm{dc})$. The capability of this device to in situ electropolish at high current densities and low voltages is important because it minimizes electropolishing time while retaining the safety of tank-type operations. Heat input to the electrolyte is also minimized at the lower electropolishing potentials.

Work is in progress to develop this contact-type in situ device into a large system with flexible seals that could decontaminate several square feet of surface area at a time while providing complete containment of the electrolyte. Possible applications would be storage tank walls, fuel pool walls, hot cell surfaces, and any other large, near-planar contaminated surface.

The ability to electropolish surfaces using a brush or swab technique also has been demonstrated and studies are in progress to evaluate 


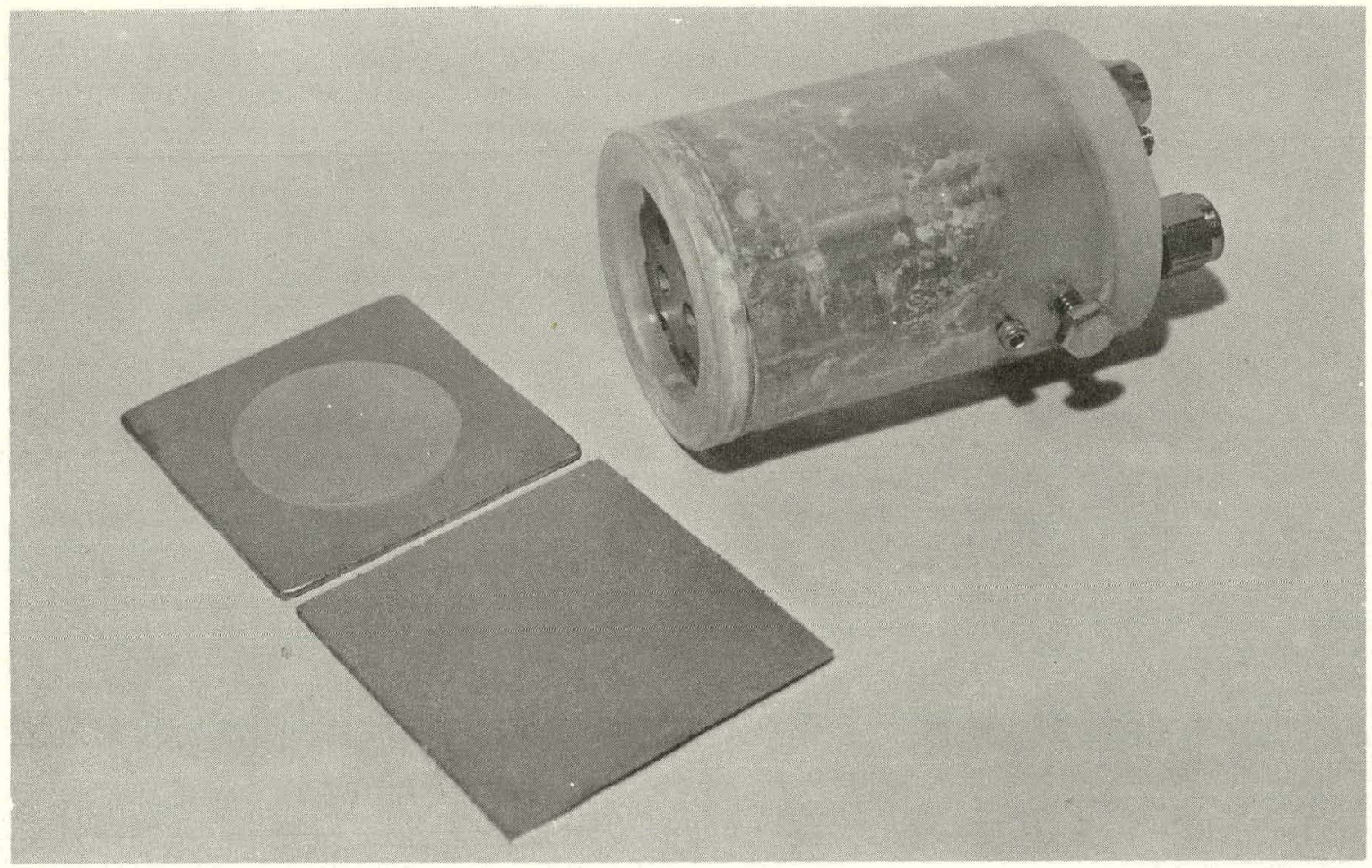

FIGURE 11. Pumped Stream In Situ Device

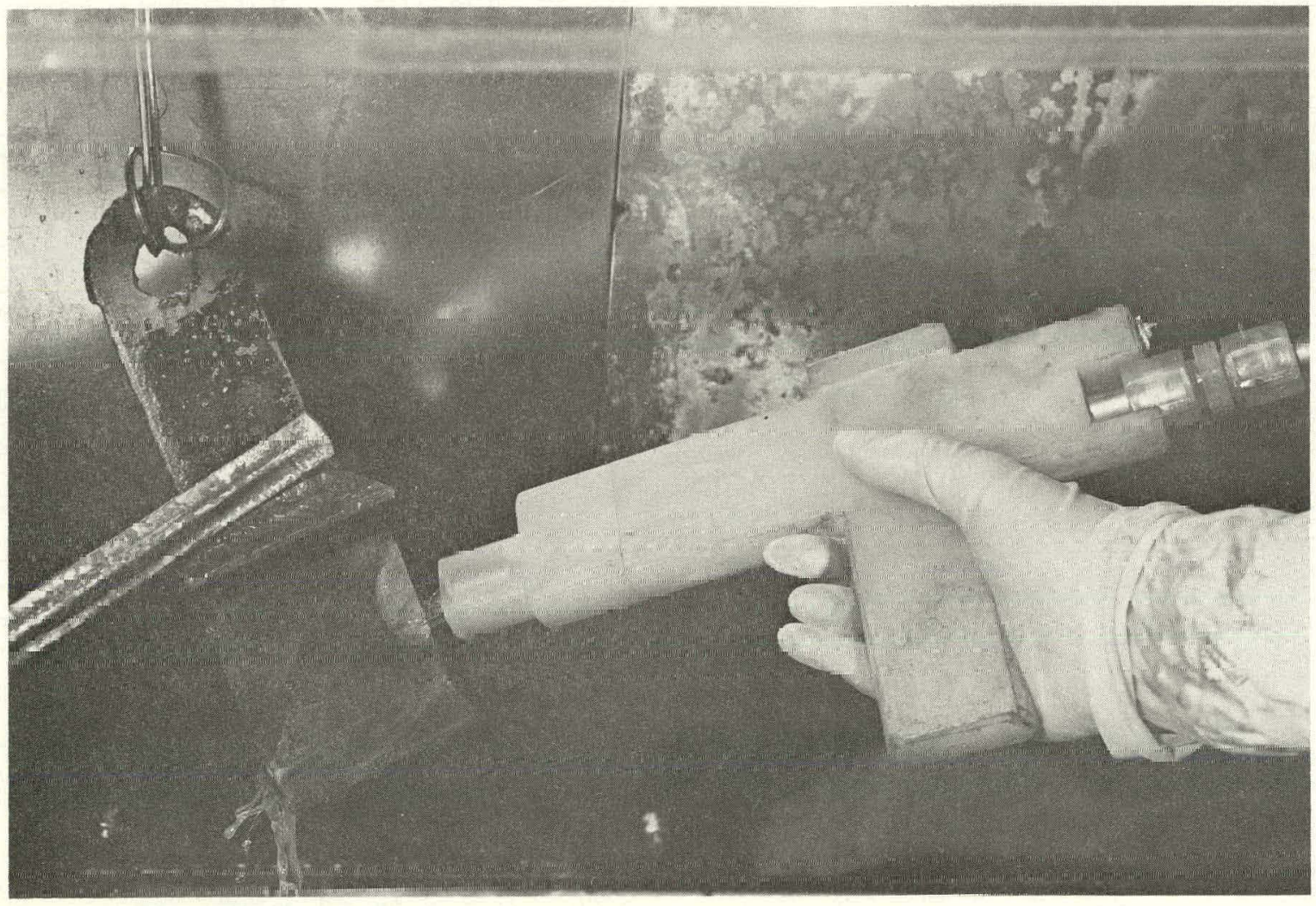

FIGURE 12. Contact in Situ Device 
this approach for spot decontamination applications and as a precleaning technique for gross contamination removal.

\subsection{IN SITU TECHNIQUES FOR PIPE INTERIORS}

Special eletropolishing techniques have been developed for the in situ decontamination of the inside of long pipes. This important application of in situ electropolishing techniques was demonstrated on the corrosion test loop at the Hanford $\mathrm{N}$-Reactor in a test sponsored by United Nuclear Industries, Inc.

The corrosion test loop, which had been in contact with the primary coolant for approximately $15 \mathrm{yr}$, is a $20-\mathrm{ft}$-long section of 2.7-in.-I.D. steel pipe. The inside of this pipe was electropolished $2 \mathrm{ft}$ at a time using a movable cathode (Figure 13) that consisted of a 2-ft-long, 1-7/8-in.-0.D., stainless steel pipe with nylon insulators at each end. The electrolyte was pumped through the cathode into the pipe, which was isolated from the primary coolant system by valves, and returned to the external electrolyte reservoir through a drain line at each end of the loop. The electrolyte was supplied to the cathode through a $20-\mathrm{ft}-1$ ong PVC pipe that also served to move the cathode and, in addition, contained the electrical cable to the cathode. A standard reactor process tube end cap was modified to allow free passage of the plastic pipe while ensuring containment of the electrolyte.

Each 2-ft section of pipe was electropolished for 20 min at a current of approximately $100 \mathrm{~A} / \mathrm{ft}^{2}$. The hydrogen generated by the electropolishing process was flushed out of the pipe by the circulating ( $4 \mathrm{gal} / \mathrm{min}$ ) electrolyte and was vented from the external electrolyte reservoir. The measured hydrogen level in the working area was always well below a hazardous concentration. At the conclusion of the electropolishing runs, the electrolyte was removed and the pipe rinsed by pumping water through it. The limited test time did not permit a more adequate internal spray rinse.

The radiation levels inside the pipe before and after electropolishing were measured at 1-ft-intervals using a GeigerMueller tube. The electropolishing treatment reduced the average radiation levels in the less contaminated portion of the pipe by about $4 \mathrm{R} / \mathrm{hr}$. The readings near pipe fittings, where pockets of contamination had collected, were reduced by more than $40 \mathrm{R} / \mathrm{hr}$. Electrolyte containing corrosion inhibitors was used to minimize corrosion of the pipe by the phosphoric acid. U1trasonic wall thickness measurements and pressure tests at the conclusion of the decontamination study verified the integrity of the pipe and permitted its return to service.

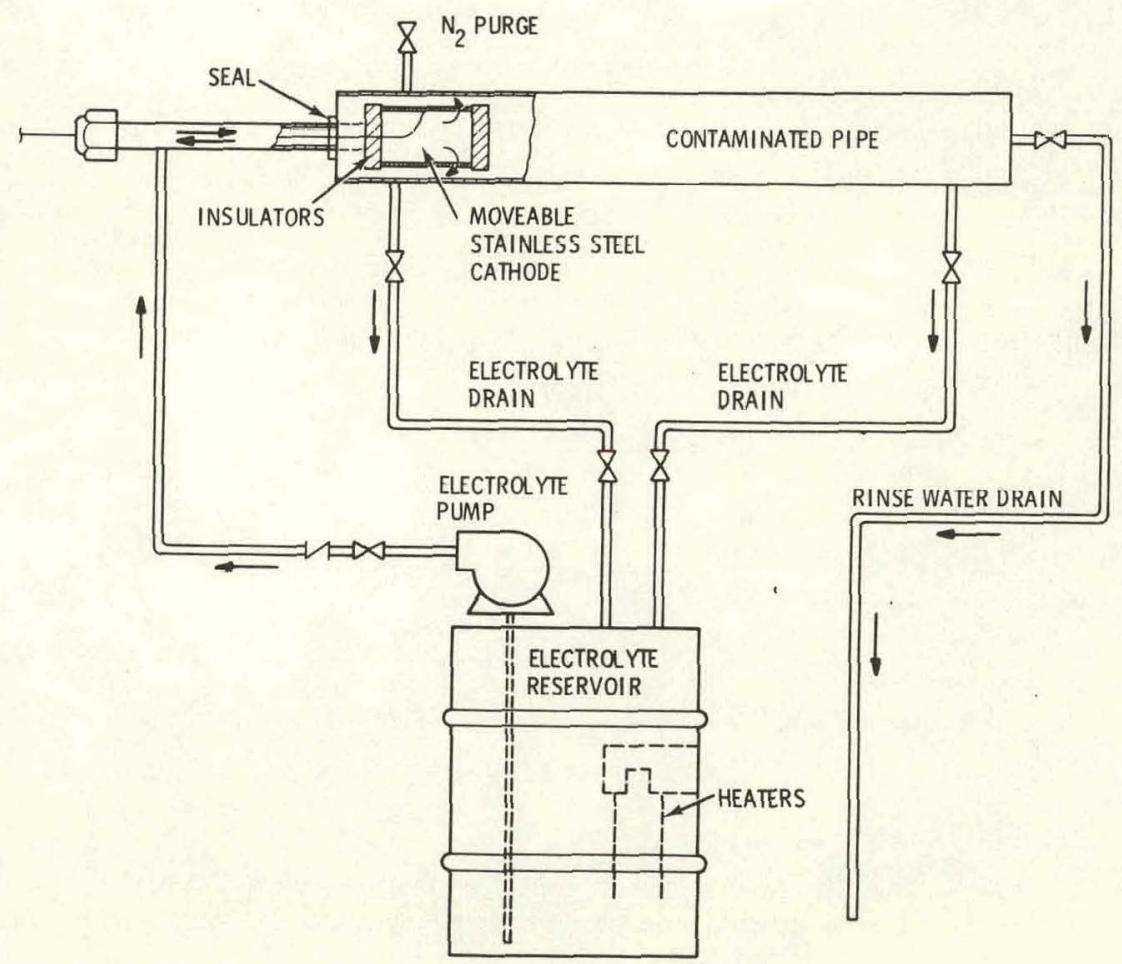

FIGURE 13. Schematic of the N-Reactor Corrosion Test Loop with Electropolishing Equipment Installed 


\section{PRETREATMENT STUDIES}

Before an object is suitable for decontamination by electropolishing, it must be relatively clean and in a geometry and size that can be accommodated in the electropolishing facility. The electropolishing decontamination studies described in Chapter 4 and detailed in the Appendix have demonstrated the importance of removing paint, grease, corrosion layers and other surface materials that reduce the effectiveness of electrolytic decontamination. It also is desirable to remove as much of the contamination as possible before electropolishing to reduce the rate of contamination buildup in the electrolyte.

A pretreatment facility has been established and studies are in progress to develop and demonstrate optimum disassembly, precleaning, sectioning, and surface preparation techniques to prepare metal components for final decontamination by electropolishing. The pretreatment facility also will provide the test material for the 400-gal electropolishing facility as part of the pretreatment studies.

\section{1 PRETREATMENT FACILITY}

The arrangement and location of the pretreatment facility with respect to the 400gal electropolishing facility is shown in Figure 3. Components of the pretreatment facility include a glove-box line, a conveyor system, and a stainless steel walk-in hood, which contains a bridge crane, a precleaning tank, a pair of master-slave manipulators, high-pressure water/solvent spray systems, a vibratory finisher, and plasma arc torch cutting equipment.

The glove-box line consists of three boxes for disassembly, abrasive blasting, and ultrasonic cleaning and vapor degreasing. These glove boxes are interconnected by a conveyor system, which also leads to the pretreatment area and the electropolishing facility (Figure 3 ).

A stainless steel walk-in hood will be used for most of the disassembly, precleaning, sectioning, and pretreatment studies. Al1 interior surfaces of this 10 by 20 by $10 \mathrm{ft}$ room are polished stainless steel to help maintain a low background contamination level. The floor is slightly sloping to facilitate drainage and collection of the cleaning solution. An overhead bridge crane will be used to position heavier objects within the facility and to move the plasma arc torch for the sectioning studies.

Several different pieces of equipment will be used in the pretreatment tacility to test various methods of precleaning or pretreatment. A precleaning tank will be used to study the effectiveness of electropolishing using dilute electrolyte to remove the gross contamination. Water/solvent spray systems capable of delivering a 3.2 gal/min stream through an adjustable nozzle at a pressure of 500 psi will also be used in precleaning studies. A vibratory finisher with a $4 \mathrm{ft}^{3}$ tub capacity will be used in the pretreatment facility to optimize removal procedures for paint, grease, corrosion layers, and gross contamination from components before electropolishing.

A pair of master-slave manipulators (Figure 14) will be used to minimize personnel exposure during the disassembly, sectioning, and pretreatment operations. These units are capable of lifting $100 \mathrm{1b}$ each and have a special hooking device (load hook) to facilitate hoisting operations.

\subsection{GREENHOUSE FACILITY}

Pending completion of the walk-in hood, a temporary plastic greenhouse (12 ft square by $8 \mathrm{ft}$ high) was constructed adjacent to the electropolishing facility to permit initiation of mechanical sectioning studies and to provide test material for the initial decontamination studies. The greenhouse was constructed of $2-i n$. by $2-i n$. aluminum angle with 15-mil plastic stretched over the outside of the aluminum frame. Major features included a change room for personnel to enter and exit and a port for introducing large pipes for sectioning into approximately $3-\mathrm{ft}$ lengths. The greenhouse was ventilated by approximately $500 \mathrm{ft}^{3}$ of air/min flowing

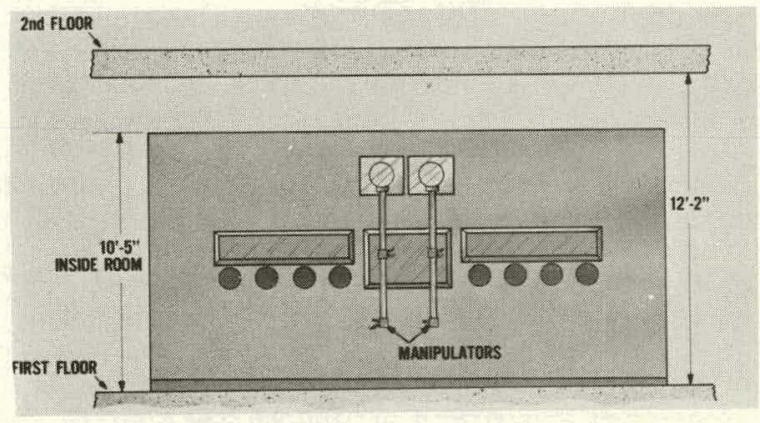

FIGURE 14. Front View of Walk-In Hood Showing Master-Slave Manipulators Used for Remote Disassembly, Sectioning, and Pretreatment Operations 
through a double layer of fiberglass filters, through the downdraft sectioning facility, and into the contaminated exhaust of the building.

Typical items processed through the sectioning facility were 4-in.-0.D. mild steel pipes. The inside of the pipes was heavily corroded and highly contaminated to over $1 \mathrm{million}$ dis/min. $100 \mathrm{~cm}^{2}$. Other sectioned material included an 8-in.-diameter Schedule 10 stainless steel pipe used primarily for glove box exhausts. The contamination in the glove box exhaust pipes ranged from a few hundred to over 1 million dis/min. $100 \mathrm{~cm}^{2}$. Altogether more than $500 \mathrm{ft}^{2}$ of $3.5-\mathrm{in}$. to 2-ft diameter mild steel and stainless steel pipe and ducting was mechanically sectioned into sizes suitable for processing in the 400-gal electropolishing facility.

\subsection{MECHANICAL SECTIONING TECHNIQUES}

Mechanical cutting techniques for sectioning contaminated components were investigated using the temporary greenhouse facility. The first method used a tubing cutter to section 3 -ft lengths of 4-in.-0.D. mild steel pipe. The tubing cutter was placed on the pipe and gradually tightened and revolved about the pipe until the pipe was sectioned. Neither the tubing cutter nor the surrounding area became contaminated. However, this sectioning technique is only useful for smaller diameter pipe and requires complete accessibility to all sides of lhe pipe.

The second cutting method used a heavyduty reciprocating saw with 12- to 24-in. blades to section 4-in.-diameter mild steel pipe and, also, 8-in.-diameter stainless steel pipe. lhis saw was equipped with a pivot bracket that used the weight of the saw to provide the necessary cutting force. A typical cutting time for an 8-in.-diameter stainless steel Schedule 10 pipe was approximately 5 minutes. Cutting oil was used to help cool the reciprocating saw blade and to contain the contamination inside the pipe. Approximately 100 linear ft of 8-in.-diameter pipe was sectioned using this technique.

The third cutting method used a hand-held reciprocating saw with short (approximately 3 in.) blades. This tool was also able to cut the pipe, but blade life was shorter and the work was much harder for the operators.

The fourth type of cutting used a nibbler device with a scissor action to section $15 \mathrm{ft}$ of 2-ft-diameter, 22-gauge, highly contaminated stainless steel ducting (Figure 15) from a downdraft facility into 1.5 - by $2.5-\mathrm{ft}$ sections (Figure 5 ).
The results of these studies show that mechanical cutting techniques can be used to safely and effectively section pipe, ducting, and other contaminated components into sizes and geometries suitable for processing in an electropolishing decontamination facility. Typical sectioning times were 10 min or less and all contamination was restricted to the saw blades and the immediate cutting area. No airborne contamination was ever detected by the constant air monitor in the sectioning facility. The greenhouse itself was uncontaminated and was reassembled in a different location and used for preliminary pretreatment and sccondary waste disposal studies.

\subsection{VIBRATORY FINISHING STUDIES}

Several different pretreatment techniques, including high-pressure sprays, ultrasonic cleaning, vapor degreasing, wet and dry abrasive blasting and vihratory finishing, will be evaluated as a means of removing paint, grease, corrosion layers and gross contamination from sectioned components before final decontamination by electropolishing.

Vibratory finishing is one of the most promising of these pretreatment techniques because it has the potential for accomplishing all of these objectives in a single step with a minimum of operator attention and at a high production rate. A plastic or ceramic media containing abrasive particles (Figure 16) is vibrated at a high frequency in the presence of a cleaning solution. The abrasive scours the surface of the metal components in contact with the media and the cleaning solution flushes away the spent abrasive and the material removed from the surface. The compusition of the solution can be varied as required to promote removal of grease and paint.

A vibratory finisher with a $4 \mathrm{ft}^{3}$ tub capacity (Figure 17) has been obtained for these pretreatment studies. Even this sma11 unit is capable of processing more than $300 \mathrm{lb}$ of metal at a time and equipment with $>50 \mathrm{ft}^{3}$ capacity is readily available.

A variety of noncontaminated metal specimens were tested in the vibratory finisher using the conical-type plastic media shown in Figure 16. The vibratory finisher successfully removed rust and even epoxy-type paint from irregularly shaped objects (pipe support bracket, 2-in.-0.D. pipe, 1-in. hexagonal nut) in less than $10 \mathrm{hr}$ processing time. Tests with rectangular stainless steel samples of varying length-to-width ratios showed that although the sharp corners and edges are rounded by the abrasion process, the actual amount of metal removed is very small (less than $0.5 \mathrm{wt} \%$ for $31 \mathrm{hr}$ of processing). 


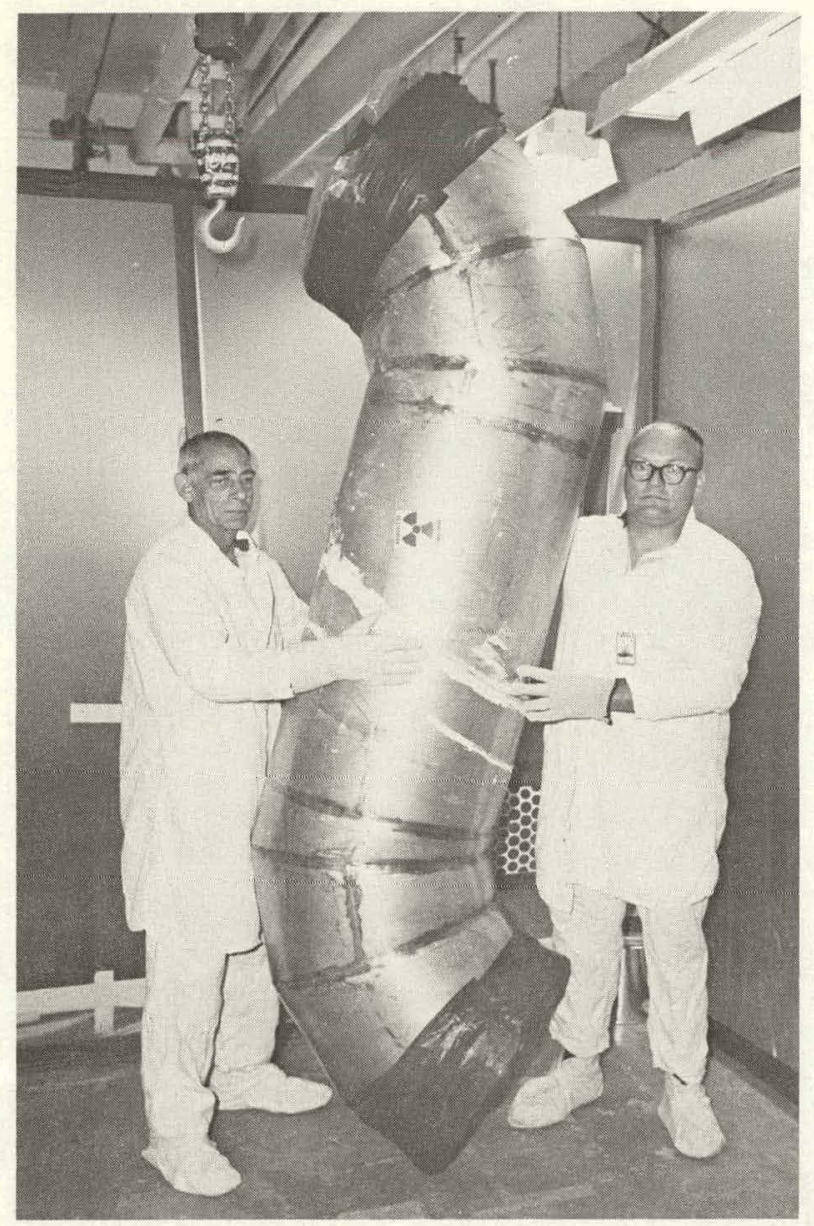

FIGURE 15. Stainless Steel Ducting From Downdraft Facility (24-in.-diameter, 22Gauge Stainless Steel) That was Sectioned into the Pieces Shown in Figure 5 Using a Mechanical Nibler. The temporary greenhouse used for these mecanical sectioning studies is shown in the background.

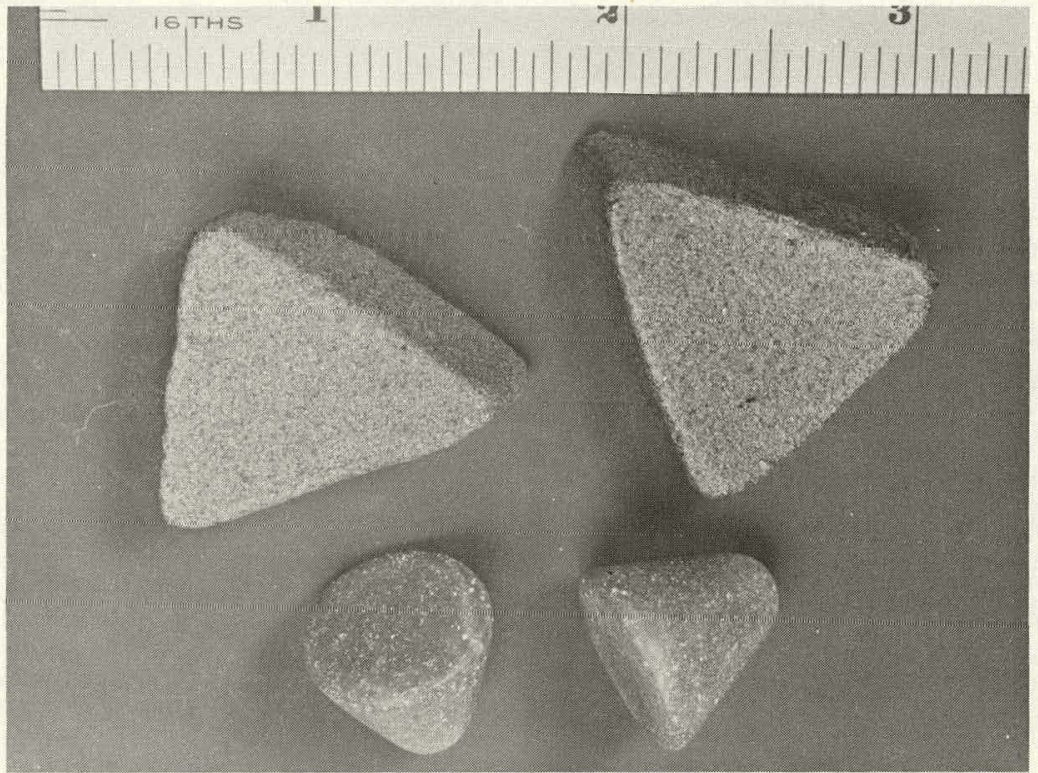

FIGURE 16. Abrasive Media Ilsed for Pretreatment Studies in the Vibratory Finisher: Triangular Ceramic Media (above) and Conical Plastic Media (below) 


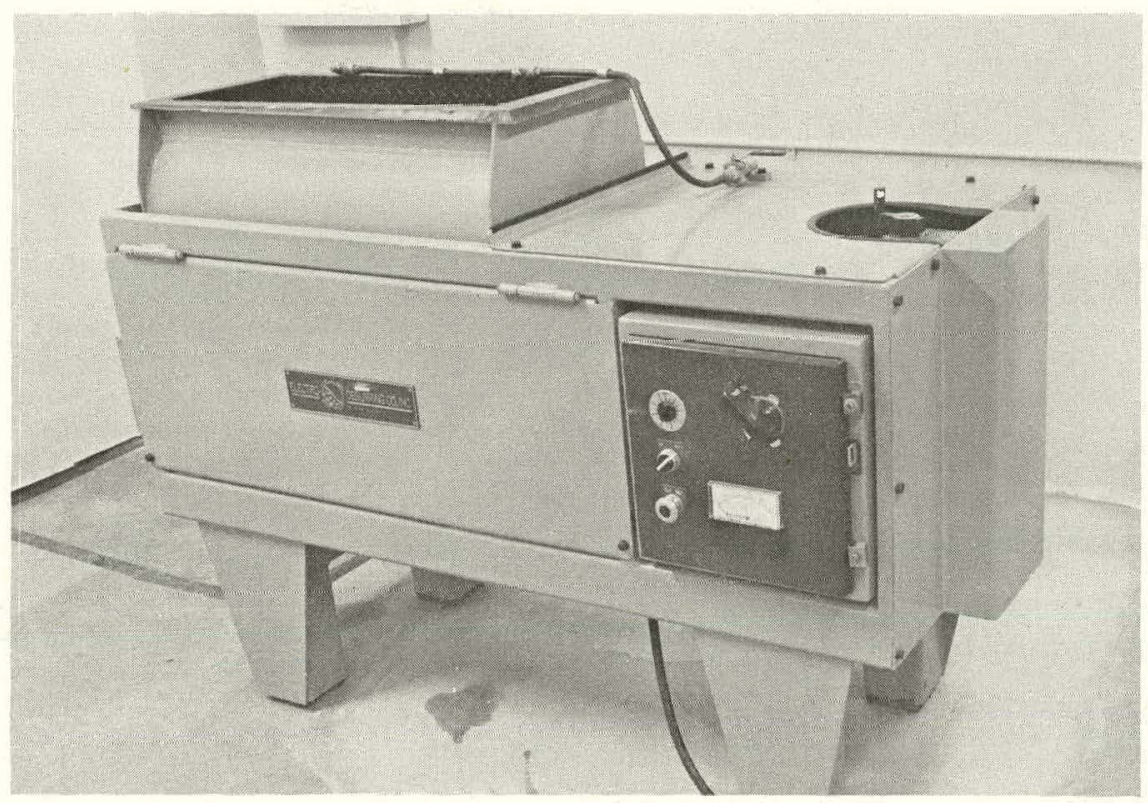

FIGURE 17. Vibratory Finisher with $4-\mathrm{ft}^{3}$ Tub Capacity Used in Pretreatment Studies

Similar encouraging results were obtained using different types of ceramic media and different cleaning solutions, including dilute phosphoric acid and dilute sodium hydroxide. The caustic solution was particularly effective in rapidly removing grease as well as latex and enamel paints. Epoxy paints require substantially longer processing times, but preliminary studies using special caustic additives and higher operating temperatures indicate that just a few hours of vibratory finishing under these conditions may be adequate even for these paints.

An initial series of pretreatment studies on contaminated material was conducted using the vibratory finisher in the temporary plastic greenhouse described earlier. Beta/gammacontaminated mild steel clamps and connector rings from the Hanford $\mathrm{N}$-Reactor were processed using the medium cutting rate, triangular ceramic media shown in Figure 16. The vibratory tub containing the media and contaminated metal parts was continuously flushed with $4 \mathrm{gal} / \mathrm{hr}$ of filtered, recirculated water containing a rust inhibitor.

The first test load consisted of 16 contaminated, rusted pipe clamps with a total we ighl of $621 \mathrm{~b}$. I hese clamps were processed in the vibratory finisher with $2 \mathrm{ft}^{3}$ of the ceramic media. The initial radiation level of the clamps averaged about $100 \mathrm{mR} / \mathrm{hr}$, with most of the contamination associated with the heavy rust layer. Four hours of vibratory finishing were sufficient to remove this corrosion layer and leave a clean, bright surface ready for electropolishing as illustrated by the before and after picture in Figure 18. In addition, this pretreatment reduced the average radiation level to about $1 \mathrm{mR} / \mathrm{hr}$, with higher readings in a few small areas that werc inaccessable lo this size media.

The second test consisted of 150 contaminated carbon steel rings, 3-in.-0.D. by 2-in.-I.D. by 0.4-in.-thick, processed in the same $2 \mathrm{ft}^{3}$ of ceramic media used for the pipe clamps. The rings weighed a total of $66 \mathrm{lb}$ and had an initial radiation reading of 3 to $6 \mathrm{mR} / \mathrm{hr}$. This was reduced to less than 0.5 $\mathrm{mR} / \mathrm{hr}$ by $4 \mathrm{hr}$ of processing. As before, most of the remaining contamination was in small inaccessable grooves. This is not a problem, however, as media can be obtained in a variety of sizes and configurations.

These tests show that vibratory finishing can successfully remove gross beta/gamma contamination as well as rust and other surface material to produce surfaces that are clean and ready for final decontamination by elertrnpolishing. Furthcrmore, evell dfler processing more than $0.5 \mathrm{ft}^{3}$ of contaminated, rusted metal parts in only $2 \mathrm{ft}^{3}$ of media, the media and tub walls were found to be essentially uncontaminated. The same abrasive action that removes the contamination 


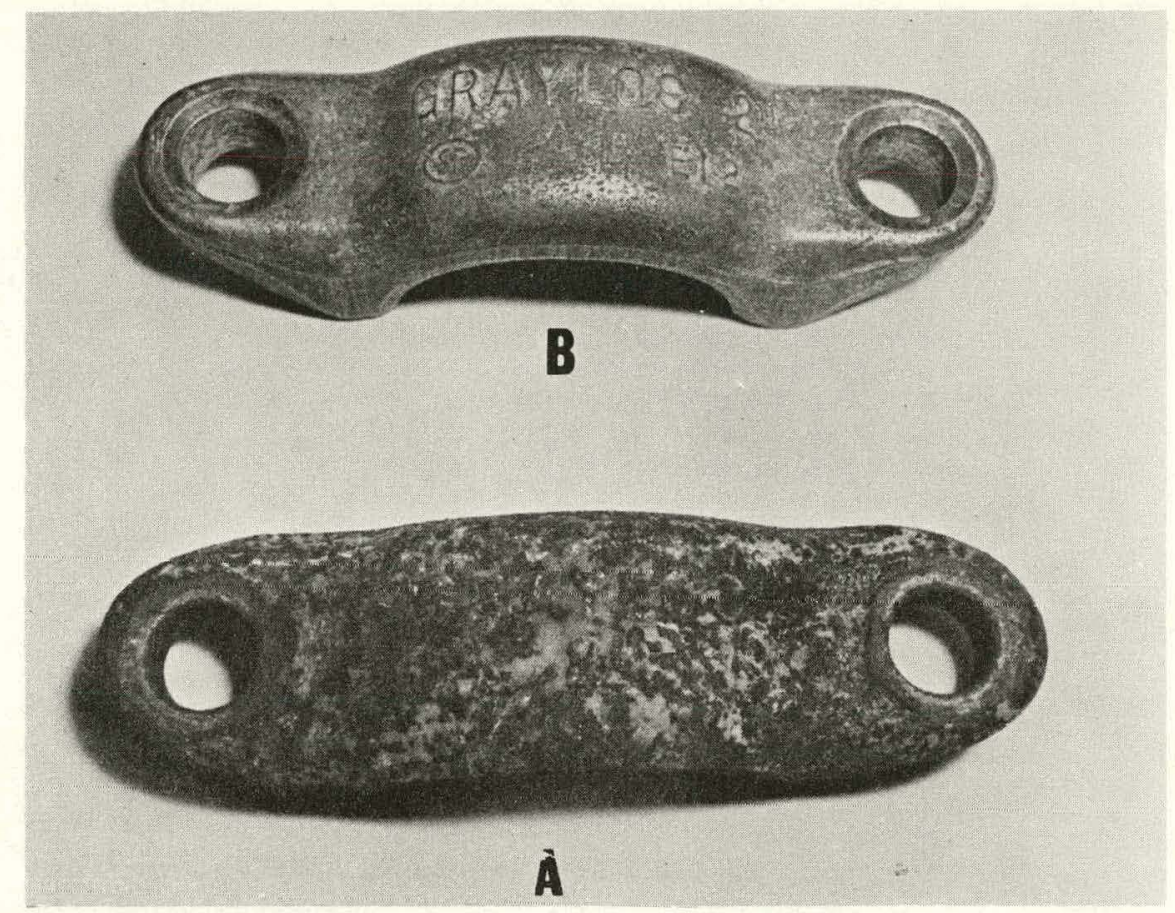

FIGURE 18. Mild Steel Pipe Clamps A) As Received and B) After Removal of Rust and Gross Contamination by $4-h r$ of Vibratory Finishing

also keeps these surfaces clean. The contamination, rust, paint, spent abrasive, etc., are continuously washed out of the vibratory finisher into a waste container where they can be collected and concentrated for disposal. Thus, in addition to preparing surfaces for final decontamination by electropolishing, the use of vibratory finishing as a pretreatment technique can help extend solution life by minimizing contamination and other surface residue introduced into the electropolishing bath. Moreover, for exposure reduction applications where complete decontamination is not required, vibratory finishing alone may be an adequate decontamination treatment.

In discussions with manufacturers of vibratory finishing equipment, another possible decontamination application of vibratory finishing has been identified. Some industries routinely use vibratory finishing to remove flashings from die-molded plastic and rubber parts. Softer parts are processed at subzero temperatures. This would suggest that vibratory finishing techniques potentially could be used to decontaminate selected nonmetallic components such as Plexiglas ${ }^{\circledR}$ panels from glove boxes. 


\section{SOLUTION TREATMENT}

Solution treatment studies are in progress to extend electrolyte life and minimize secondary waste volume by developing techniques for removing dissolved metal and contamination from the electrolyte and rinse solutions. This work includes an evaluation of both energy separation (distillation, electrolysis) and mass separation (solvent extraction, precipitation, ion exchange) methods. The solution treatment approaches that have been investigated for purification of the phosphoric acid electrolyte are listed in Table 2 .

\section{TABLE 2. Electrolyte Purification Methods}

Ion Exchange

Solvent Extraction

Precipitation

Alcohol Precipitation

Neutralization

Dilution

Sulfide Precipitation

Potassium or Barium Salt Precipitation

Distillation

Electrolysis

Membrane Separation

\subsection{ION EXCHANGE}

Although removal of cationic impurities from concentrated phosphoric acid by conventional ion exchange techniques is generally not considered practical as a large-scale separation method, there are examples of strong acid cation exchangers being used in the purification of wet-process phosphoric acid, as well as phosphoric acid purification by adsorption of the acid on ion exchange resins.4-7 This latter acid adsorption approach has been identified as the most promising electrolyte purification method for the electropolishing decontamination work.

The acid absorption purification process is illustrated in Figure 19. The spent electrolyte is forced through a column containing a suitable ion exchange resin. The phosphoric acid is preferentially adsorbed (retarded), allowing the dissolved impurities to pass through the column. ${ }^{8}$ The purified acid is then recovered by using water as the elutant.

Tests of the effectiveness of this solution processing approach have been conducted by the manufacturer of a commercial acid purification system using a synthetic spent 75 wt\% phosphoric acid electrolyte containing $3 \mathrm{wt} \%$ stainless steel impurities. The results indicated that the full strength spent acid could be purified at a scaled flow rate of about $40 \mathrm{gal} / \mathrm{hr}$ with about a $40 \%$ decrease in impurity content. Additional tests have

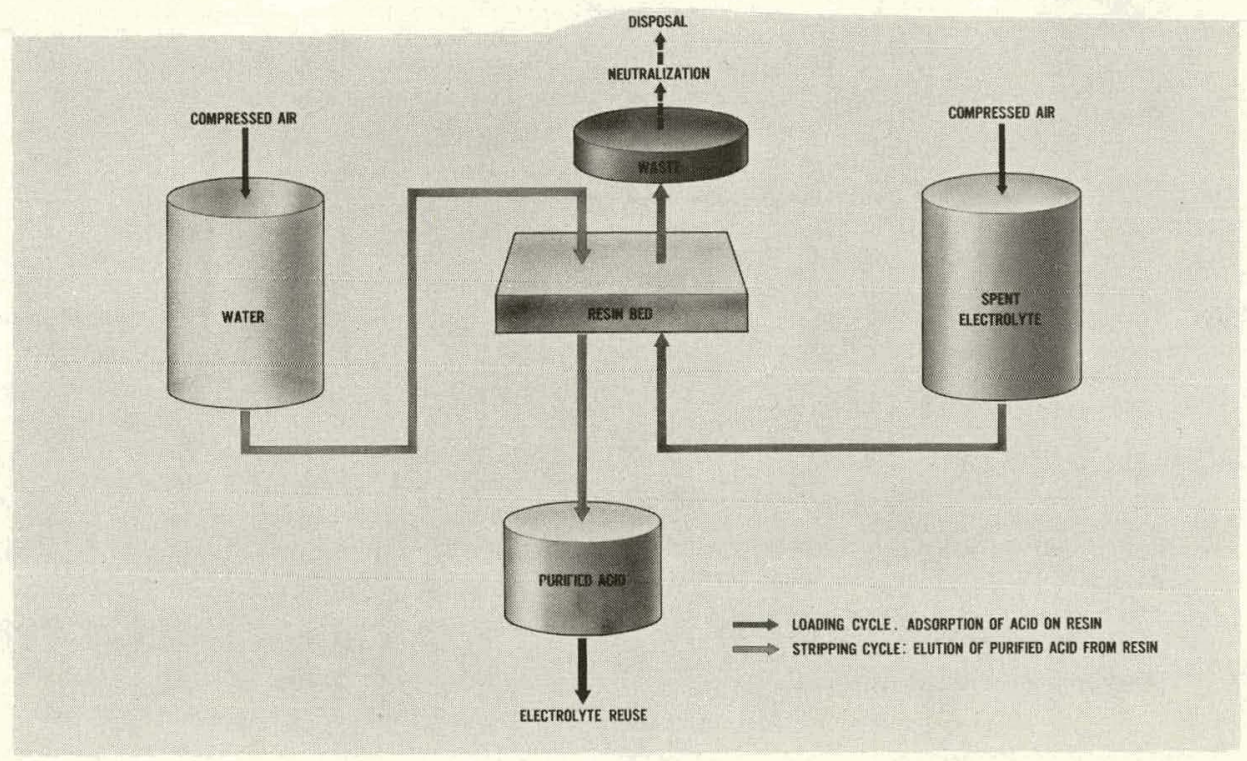

FIGURE 19. Spent Electrolyte Purification by Reciprocatiny Acid Adsorption 
shown that phosphoric-sulfuric electropolishing solutions also can be purified using this technique, although dilution and heating of the solution is required to reduce its high viscosity.

The advantages of acid adsorption over solvent extraction, which has been selected as the back-up technique for electrolyte purification, include:

- availability of an inexpensive commercial system

- simplicity and flexibility of operation to emphasize either acid recovery or acid purity

- ability to achieve adequate separations without the addition of expensive or potentially hazardous processing chemicals.

A commercial acid purification system has been acquired and will be used for a comprehensive evaluation of acid adsorption as an electrolyte purification technique, including its ability to remove the radioactive contamination as well as the dissolved metals and its capability for recycle of the waste stream to maximize acid recovery.

\subsection{SOLVENT EXTRACTION}

The separation of impurities from phosphoric acid by solvent (1iquid-1iquid) extraction (Figure 20) generally takes advantage of the solubility of the acid in a water-immiscible organic solvent. For purification of a phosphoric acid electrolyte, the objective is to extract a major fraction of relatively pure phosphoric acid into an organic phase, leaving most of the impurities in an aqueous phase. Few solvents are completely selective for only one solute, so the extracted fraction of the product also contains part of the impurity load. Following separation of the extract (generally the organic phase) from the raffinate (the aqueous waste), the product can be further purified by scrubbing the extract with a stream of previously purified product. Recovery of the product occurs in a slripping stage where, in the case of phosphoric acid recovery, water is generally used to reclaim the product. Most liquid-liquid extraction methods recycle extractant, scrub, and strip solutions. The only major loss is waste raffinate.

Several solvent extraction tests using methyl isobutyl ketone as the extractant

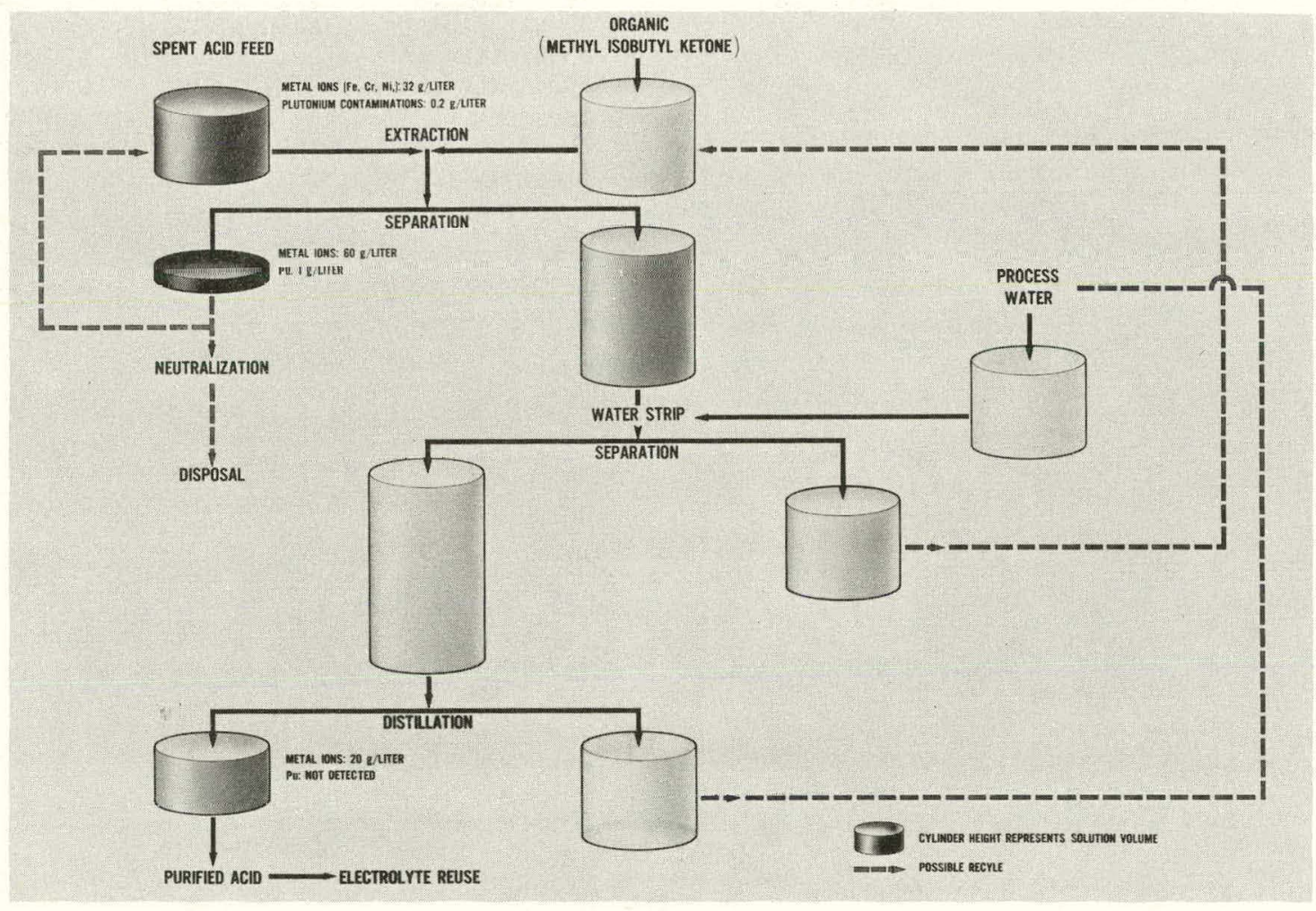

FIGURE 20. Spent Electrolyte Purification by Solvent Extraction 
were conducted on synthetic spent phosphoric acid solutions containing from 2 to 5 wt\% metal ions (iron, chromium, nickel) and 0 to $1 \mathrm{~g} / \mathrm{l}$ plutonium. The plutonium impurity was introduced as an oxide and/or as metallic ion electrolytically dissolved in 75 wt\% phosphoric acid. The iron, chromium, and nickel impurities were introduced into the acid by electrolytic dissolution of 304 stainless steel.

The results of these extractions are summarized in Table 3 . In Test 2, solvent extraction decreased the impurity level of the phosphoric acid electrolyte by a factor of almost 10. For this particular test, the estimated recovery of acid from the feed was $60 \%$. In Tests 3 to 6 , part of the decrease in iron, chromium, and nickel resulted from dilution (makeup) with $75 \%$ phosphoric acid to the original feed volume. Acid recoveries in these tests varied from 54 to $70 \%$.

The most important result of these studies is that essentially all of the plutonium was removed from the electrolyte and rejected to the raffinate. This means that solvent extraction can be used to extend electrolyte life through removal of fissile contaminants as well as the dissolved metal impurities. The major disadvantage of solvent extraction as an electrolyte purification technique is its relative complexity and possible safety considerations related to the use of organic extractants.

\subsection{PRECIPITATION}

The removal of impurities from solution by precipitation is a time-related process depending on such factors as impurity concentration, temperature, hydrogen ion activity, nature of the solvent or mixed solvents and other ions in solution. Several different precipitation methods were evaluated as a possible means of purifying the phosphoric acid electrolyte: alcohol precipitation, dilution, neutralization, sulfide precipitation, and barium or potassium salt precipitation.

Alcohol precipitation combines the action of a completely miscible solvent in an acid feed with the addition of alkali metals or ammonia.9-11 Laboratory-scale alcohol precipitation studies were conducted using a $75 \%$ phosphoric acid containing 2 wt\% dissolved metal (iron, chromium, and nickel electrolytically dissolved from 304 stainless steel). The spent electrolyte was first ammoniated, then either methanol or isopropanol was added to precipitate complex ammoniumimpurity phosphates. Table 4 summarizes the purified acid recoveries and the impurity concentration from these precipitation tests.

The results of these alcohol precipitation tests show that a substantial decrease in the impurity content of the spent electrolyte can be obtained with reasonably high recovery of the phosphoric acid. The disadvantage of the

TABLE 3. Summary of Phosphoric Acid Extractions Using Methyl Isobutyl Ketone

\begin{tabular}{|c|c|c|c|c|c|c|c|c|c|c|c|c|}
\hline \multirow{2}{*}{$\begin{array}{l}\text { Test } \\
\text { Number } \\
\end{array}$} & \multicolumn{4}{|c|}{$\begin{array}{c}\text { Acid Feed Impurities } \\
(\mathrm{g} / \ell)\end{array}$} & \multicolumn{4}{|c|}{$\begin{array}{l}\text { Raffinate } \\
(\mathrm{g} / \mathrm{l})\end{array}$} & \multicolumn{4}{|c|}{$\begin{array}{c}\text { Punified Acid(a) } \\
(\mathrm{g} / \mathrm{l})\end{array}$} \\
\hline & $\mathrm{Fe}$ & $\mathrm{Cr}$ & $\mathrm{Ni}$ & $\mathrm{Pu}$ & $\mathrm{Fe}$ & $\mathrm{Cr}$ & $\mathrm{Ni}$ & Pu & $\overline{\mathrm{Fe}}$ & $c r$ & Ni & $\mathrm{Pu}$ \\
\hline 1 & 23.4 & 5.8 & 2.9 & 0 & 43.8 & 10.8 & 6.0 & 0 & 16 & 4 & 2 & 0 \\
\hline 2 & 54.0 & 13.3 & 6.7 & 0 & 74.8 & 17.9 & 8.8 & 0 & 5 & 2 & 1 & 0 \\
\hline 3 & 22.3 & 5.5 & 2.7 & $0.2^{(b)}$ & 30.6 & 6.7 & 3.3 & 0.3 & 7 & 5 & 1 & trace \\
\hline 4 & 19.0 & 4.7 & 2.3 & $0.3^{(c)}$ & 37.4 & 8.6 & 5.6 & 0.3 & 10 & 4 & 1 & $0^{(d)}$ \\
\hline 5 & 0 & 0 & 0 & $1.0^{(\mathrm{e})}$ & 0 & 0 & 0 & 1.0 & 0 & 0 & 0 & $0^{(d)}$ \\
\hline 6 & 22.3 & 5.5 & 2.7 & $0.2^{(b)}$ & 41.4 & 8.9 & 4.4 & 0.2 & 10 & 4 & 1 & $0^{(d)}$ \\
\hline
\end{tabular}

(a) These values are corrected impurity levels for the purified acid after extraction, concentration to $275 \% \mathrm{H}_{3} \mathrm{PO}_{4}$ and makeup to the original feed volume with impurity-free $75 \% \mathrm{H}_{3} \mathrm{PO}_{4}$.

(b) Plutonium impurity from electropolishad $\mathrm{Pu}$ metal.

(c) Combination of plutonium oxide and plutonium ion.

(d) X-ray fluorescence analysis for plutonium was verified by low-level radioactivity measurements.

(e) Plutonium impurity added as the oxide. 
TABLE 4. Summary of Alcohol Precipitation Tests

Using Methanol and Isopropanol

\begin{tabular}{|c|c|c|c|c|c|c|c|c|}
\hline \multicolumn{2}{|c|}{ Solution } & $\begin{array}{l}\text { Alcohol } / \mathrm{P}_{2} \mathrm{O}_{5} \\
\text { (wt) }\end{array}$ & $\begin{array}{l}\mathrm{NH}_{3} / \mathrm{P}_{2} \mathrm{O}_{5} \\
\text { (mole) }\end{array}$ & $\begin{array}{l}\text { Est. Acid } \\
\text { Recovery }(\%) \\
\end{array}$ & \multicolumn{2}{|c|}{$\begin{array}{l}\text { Feed Acid } \\
\text { Impurity } \\
(\mathrm{g} / \ell) \\
\end{array}$} & \multicolumn{2}{|c|}{$\begin{array}{l}\text { Product Acid } \\
\text { Impurjty } \\
(\mathrm{g} / \ell)(\mathrm{a})\end{array}$} \\
\hline 100 & $75 \% \mathrm{H}_{3} \mathrm{PO}_{4}$ & 0.5 & 0.13 & 78 & $\mathrm{Fe}$ & 25.3 & $\mathrm{Fe}$ & 19.7 \\
\hline 6.3 & $\mathrm{NH}_{4} \mathrm{OH}$ & & & & $\mathrm{Cr}$ & 7.2 & $\mathrm{Cr}$ & 5.6 \\
\hline 50 & isopropanol & & & & $\mathrm{Ni}$ & 3.8 & $\mathrm{Ni}$ & 3.0 \\
\hline 100 & $75 \% \mathrm{H}_{3} \mathrm{PO}_{4}$ & 3.4 & 0.38 & 90 & $\mathrm{Fe}$ & 25.3 & $\mathrm{Fe}$ & 14.5 \\
\hline 16 & $\mathrm{NH}_{4} \mathrm{OH}$ & & & & $\mathrm{Cr}$ & 7.2 & $\mathrm{Cr}$ & 4.7 \\
\hline 370 & methanol & & & & $\mathrm{Ni}$ & 3.8 & $\mathrm{Ni}$ & 3.4 \\
\hline 100 & $75 \% \mathrm{H}_{3} \mathrm{PO}_{4}$ & 1.9 & 0.40 & 79 & $\mathrm{Fe}$ & 25.3 & $\mathrm{Fe}$ & 3.1 \\
\hline 17 & $\mathrm{NH}_{4} \mathrm{OH}$ & & & & $\mathrm{Cr}$ & 7.2 & $\mathrm{Cr}$ & 0.9 \\
\hline 200 & isopropanol & & & & $\mathrm{Ni}$ & 3.8 & $\mathrm{Ni}$ & 1.7 \\
\hline 100 & $75 \% \mathrm{H}_{3} \mathrm{PO}_{4}$ & 3.0 & 0.28 & 80 & $\mathrm{Fe}$ & 25.3 & $\mathrm{Fe}$ & 15.4 \\
\hline 12 & $\mathrm{NH}_{4} \mathrm{OH}$ & & & & $\mathrm{Cr}$ & 7.2 & $\mathrm{Cr}$ & 4.7 \\
\hline 225 & methanol & & & & $\mathrm{Ni}$ & 3.8 & $\mathrm{Ni}$ & 2.8 \\
\hline
\end{tabular}

(a) The analysis of the purified phosphoric acid has been corrected to the corresponding feed acid volumes.

alcohol precipitation method is the degree of process control needed to precipitate the impurities without forming an excessive filter eake.

Dilution, partial neutralization and specific, precipitation reactions with hydrogen sulfide, barium salts, and potassium salts were evaluated as a way to remove metal impurities (iron, chromium, and nickel) from phosphoric acid for subsequent recycle of the purified acid as decontamination electrolyte. The volume of water needed fur adequate dilution of the acid to cause precipitation of a part of the impurities as hydroxides makes dilution an impractical separations method. In partial neutralization tests using sodium hydroxide, ammonium hydroxide and ammonia, the precipitates that formed in the concentrated acid/base or acid/ ammonia mixtures were difficult to separate and to characterize. The liquid separated from these mixtures generally contained too much residual impurity for partial neutralization to be an effective method for reprocessing a spent phosphoric acid electrolyte.

Studies were also conducted to evaluate sulfide precipitation using hydrogen sulfide to remove selected metal ions from spent phosphoric acid electrolyte. The $\mathrm{pH}$ of the acid was varied from 0 to 2.5 by dilution and partial neutralization to enhance the precipitation of sulfides. The test results showed only a minimal reduction in the iron cunlenl of the electrolyte and nu reduction in the ilickel cuintent. The only prccipitates that did form were principally copper sulfides. The ability to remove copper from spent. electrolyte is important, however, since the erosion of copper current contacts often introduccs this ion into the electrolyte and some wastc treatment systems rannnt. ar.e.pt liquid waste containing copper.

The removal of impurities from spent electrolyte by the addition of potassium salts with subsequent precipitation of a complex potassium-iron-phosphate was investigated. Analys is of the filtrate showed an approximate $30 \%$ decrease in the iron content, but no decrease in either chromium or nickel.

Barium carbonate and sulfuric acid were added to spent phosphoric acid electrolyte to precipitate barium sulfate to determine if coprecipitation would remove the metallic impurities. X-ray fluorescence analysis of the recovered filtrate showed only $2.7 \%$ decrease in the iron content and no change in either the nickel or chromium content. 


\subsection{DISTILLATION}

Purification and concentration of a spent phosphoric acid electrolyte using distillation techniques was investigated. Dilute phosphoric acid was readily concentrated to about $100 \mathrm{wt} \%$ acid at moderate temperatures $\left(<300^{\circ} \mathrm{C}\right)$. However, even vacuum distillation was not successful as a purification method because of the low vapor pressure of the phosphoric acid. Extreme pressure and temperature conditions would be required to effect an adequate separation.

\subsection{ELECTROLYSIS}

Metallic impurities can be removed from phosphoric acid solutions by the cathode of an electrochemical cell, provided the reduction of the metallic ion is favored over the reduction of the hydrogen ion. For example, tests using a mercury cathode with a high hydrogen overvoltage demonstrated the ability to reduce the iron content of spent phosphoric electrolyte from 14 to $0.2 \mathrm{~g} / \mathrm{l}$ and the nickel content from 2 to $<0.05 \mathrm{~g} / \mathrm{l}$. However, for a large-scale process, the high ratio of cathode surface to electrolyte volume needed for effective metal ion reduction and removal becomes a problem. Also, special procedures would be required to purify the contaminated mercury for recycle.

\subsection{MEMBRANE SEPARATION}

Another method for separation of impurities from an aqueous media takes advantage of semipermeable ion selective membranes. These separation processes depend on the permeation of the membrane by some of the chemical species in contact with it. Typical membrane processes include:

- Dialysis - both cation and anion diffuse from a colloid or waste solution to a "pure" water side of an ion permeable membrane

- Reverse osmosis - pressure-assisted diffusion of water from waste side of a membrane to the "pure" water side
- Donnan dialysis - application of a cation exchange membrane to effect separation of metal ions from a salt solution to an acid solution

- Electrodialysis - electrolytic-assisted separation of cations through a cation permeable membrane and anions through an anion permeable membrane.

An evaluation of the applicability of membrane technology for purification of spent phosphoric acid electrolyte was conducted by program consultants from the Hydrite Chemical Company. The following problems were noted: 1) The relevant processes are not developed industrially; 2) High viscosity reduces mobility, throughput rates and efficiency; and 3) The high acid concentration and complexing characteristics of the phosphate ion result in an unfavorable equilibrium situation. It is concluded that membrane technology would not be applicable without a major research effort.

\subsection{SOLUTION TREATMENT EQUIPMENT}

Other progress in solution treatment studies has included the installation of a reverse osmosis water processing unit to provide makeup water for the solution processing and demonstration decontamination systems. This purification unit removes greater than $90 \%$ of the dissolved organic and inorganic impurities in the incoming water. It can produce up to 500 gal of distilled-quality water per day.

The rinse solution and water from the pretreatment facility will be purified using a commercial, dual-effect stainless steel evaporator with $50 \mathrm{gal} / \mathrm{hr}$ capacity. This system will be capable of processing nitric acid rinse solutions as well as the rinse water, and also will be used to concentrate phosphoric acid from the acid processing unit. For research purposes, this dualeffect system can be operated in a doubledistillation mode to increase product purity or, alternatively, used to process two different solutions simultaneously. 


\section{TECHNOLOGY TRANSFER}

Because electropolishing of noncontaminated metals and alloys is a well-established industrial process, it is possible to transfer much of the needed technology either directly or with some modification to the decontamination process. To initiate technology transfer, a consulting agreement was established with Hydrite Chemical Company, Milwaukee, WI, a leader in the electropolishing field. Discussions with this consultant identified commercial electropolishing technology areas that are directly useful for decontamination applications, and background information was obtained for those technology areas that require special development. The topics considered included:

- design of electropolishing facilities and systems

- automation concepts

- equipment and suppliers

- electrolytes and operating parameters

- electrode materials and racking technology

- agitation techniques

- rinsing technology

- solution treatment procedures

- removal methods for entrained contamination

- in situ electropolishing techniques.

Visits have been made to several firms and types of electropolishing facilities representing the capability to electropolish large components, the automated, high-volume surface finishing of smaller items, and the use of in situ techniques to electropolish the interior of large tanks. One company, for example, uses electropolishing tanks as large as 4000 gal to surface finish 5 - by 12-ft stainless steel sheets (Figure 21), 10-ft-diameter tank 1ids, and the interior of up to three 24-ft long pipes at a time (Figure 22). Another firm has developed in situ techniques to electropolish the interior of pipes, tubes and chemical reaction vessels using a minimum of electrolyte. For example, the interior of a 25,000-gal tank can be electropolished in place using only 2000 gal of electrolyte.

Other industrial firms use large, automated, multitank electropolishing systems (Figure 23) to process hundreds of square feet of smaller items per shift with only one operator to rack and unload the parts. Some automated systems use barrel electropolishing systems (Figure 24) to process large quantities of small items without racking. These and many similar examples show that the use of automated electropolishing systems to permit the processing of large volumes of surfacecontaminated metallic waste while minimizing personnel exposure and processing costs is well within the range of existing automation technology and equipment.

Technology transfer activities also have included visits to various firms to discuss plasma arc torch cutting techniques; systems for the purification, storage, and disposal of spent electrolyte; and distillation techniques for purification and recycling of rinse solutions. 


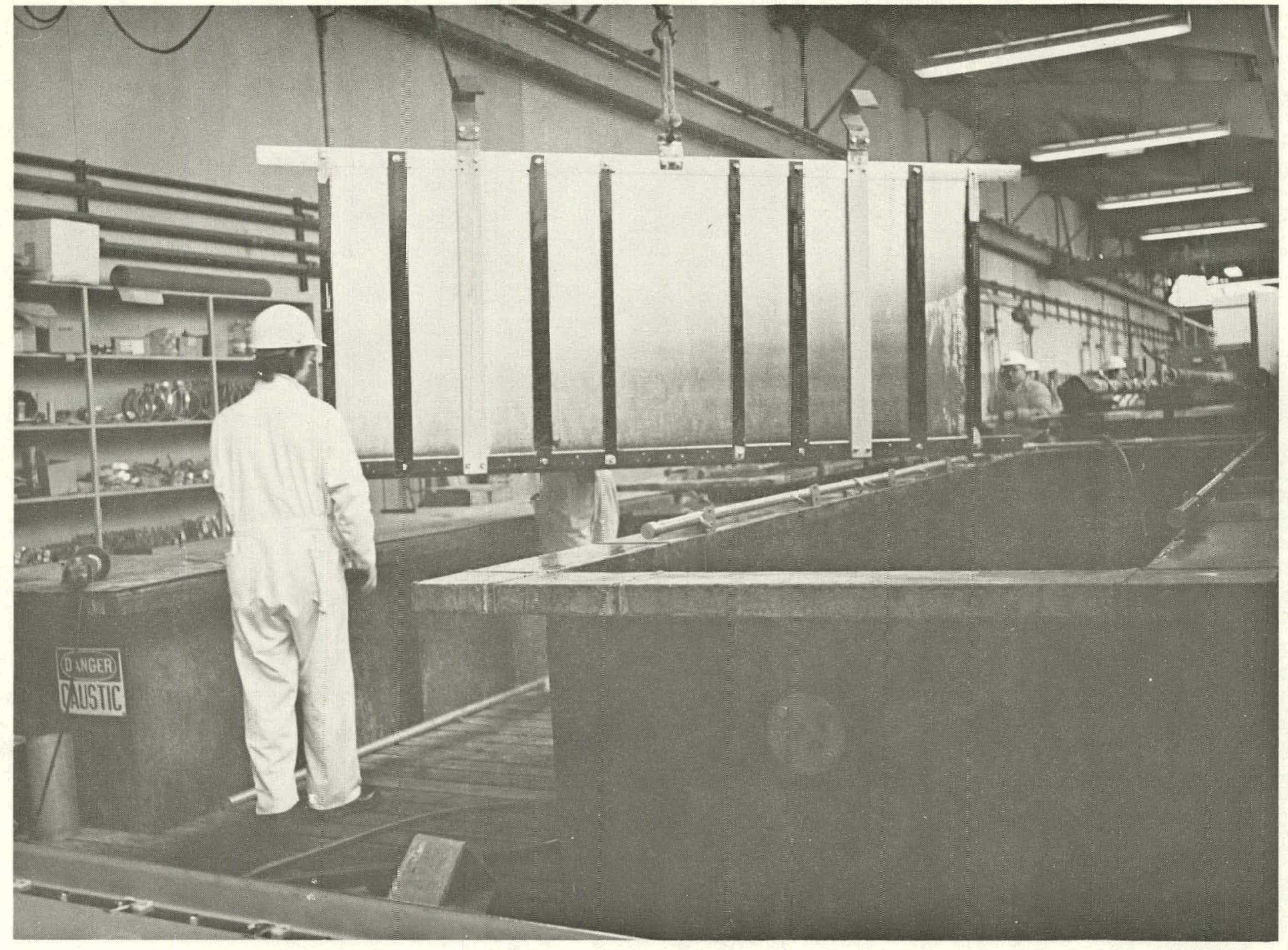

FIGURE 21. Industrial Electropolishing of Large Stainless Steel Sheets 


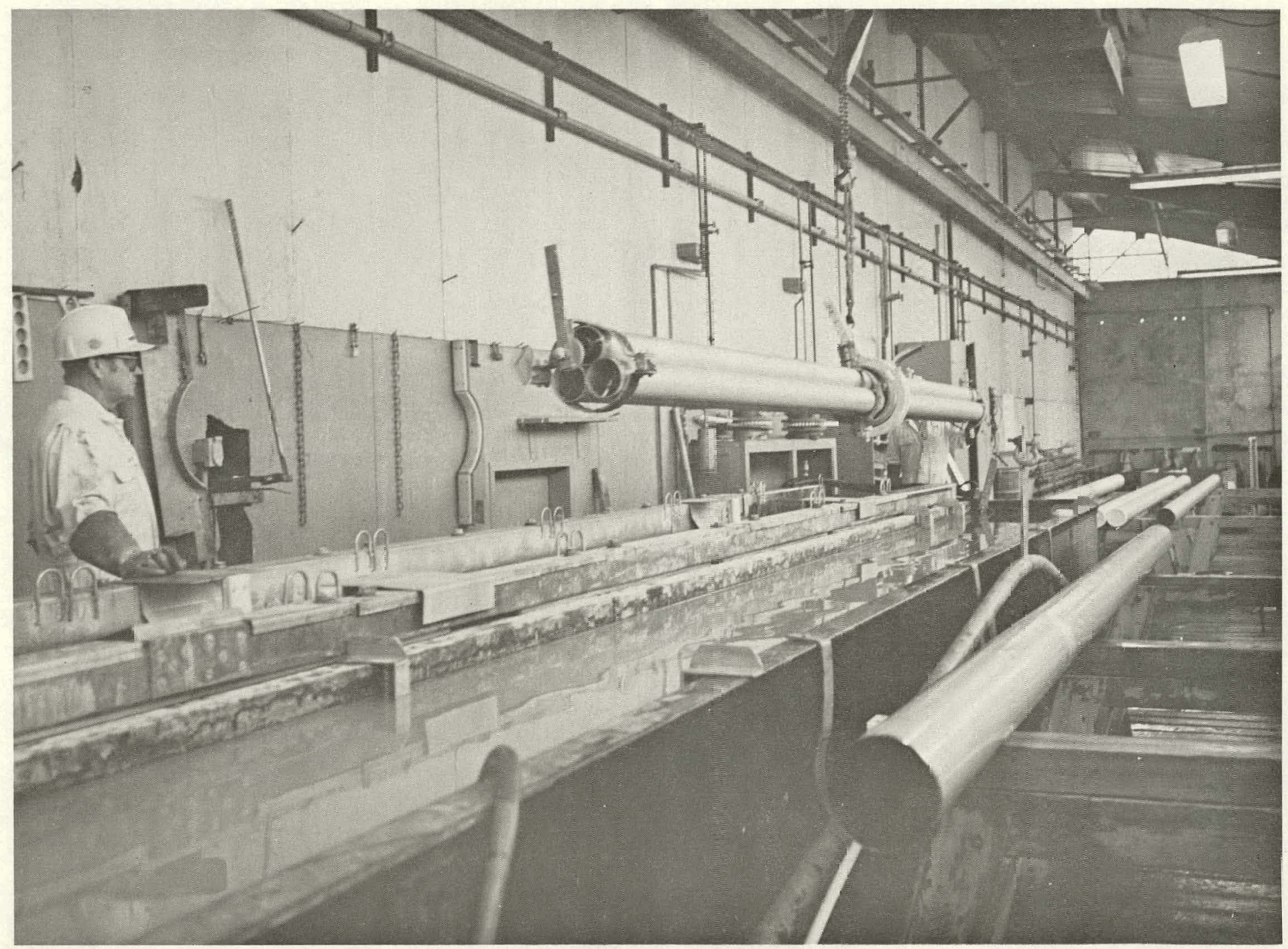

FIGURE 22. Electropolishing the Interior of Long Pipes (Three at a tine) 


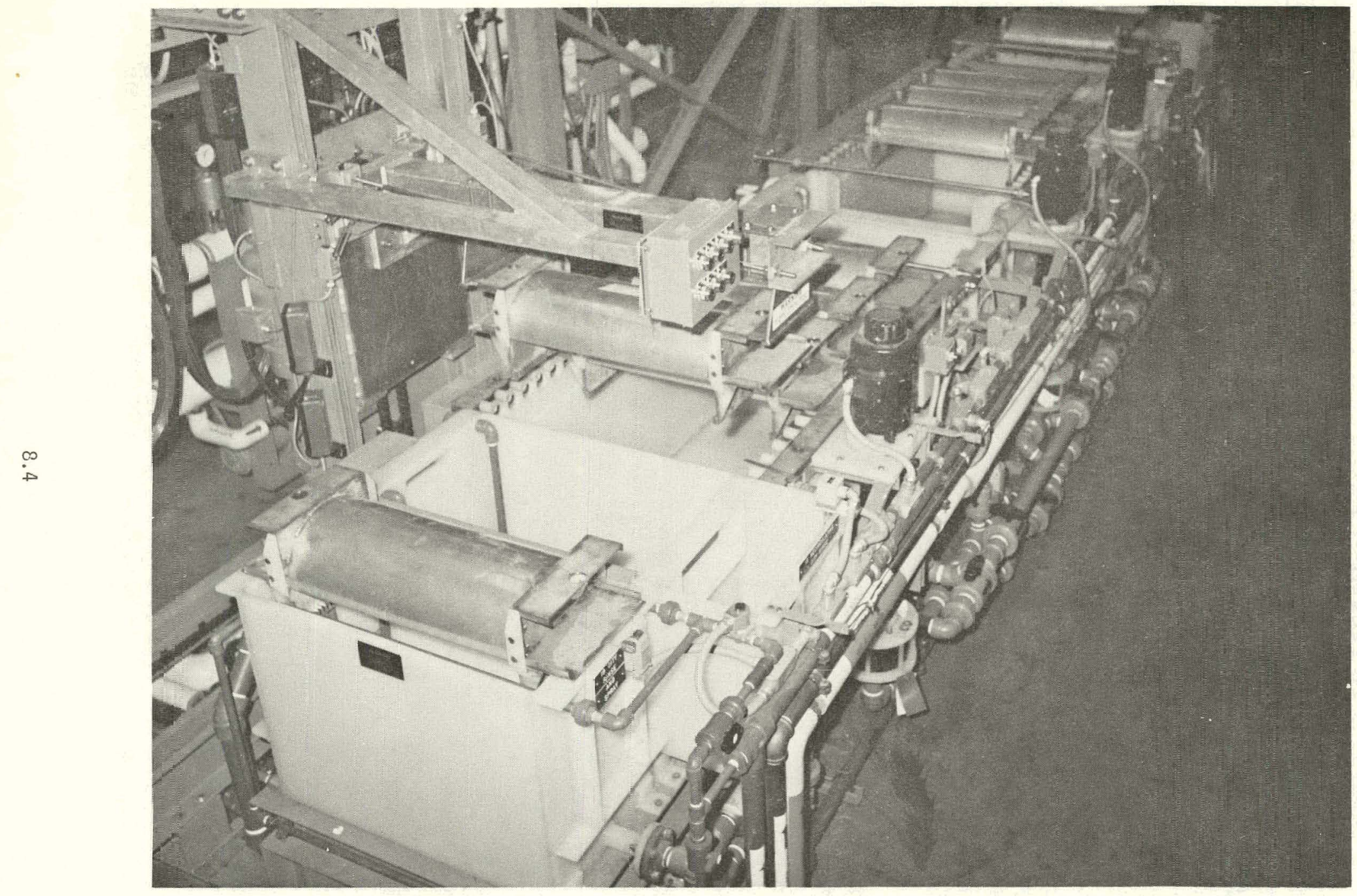

FIGURE 23. Industria: Automated Multitank Electropolishing System 


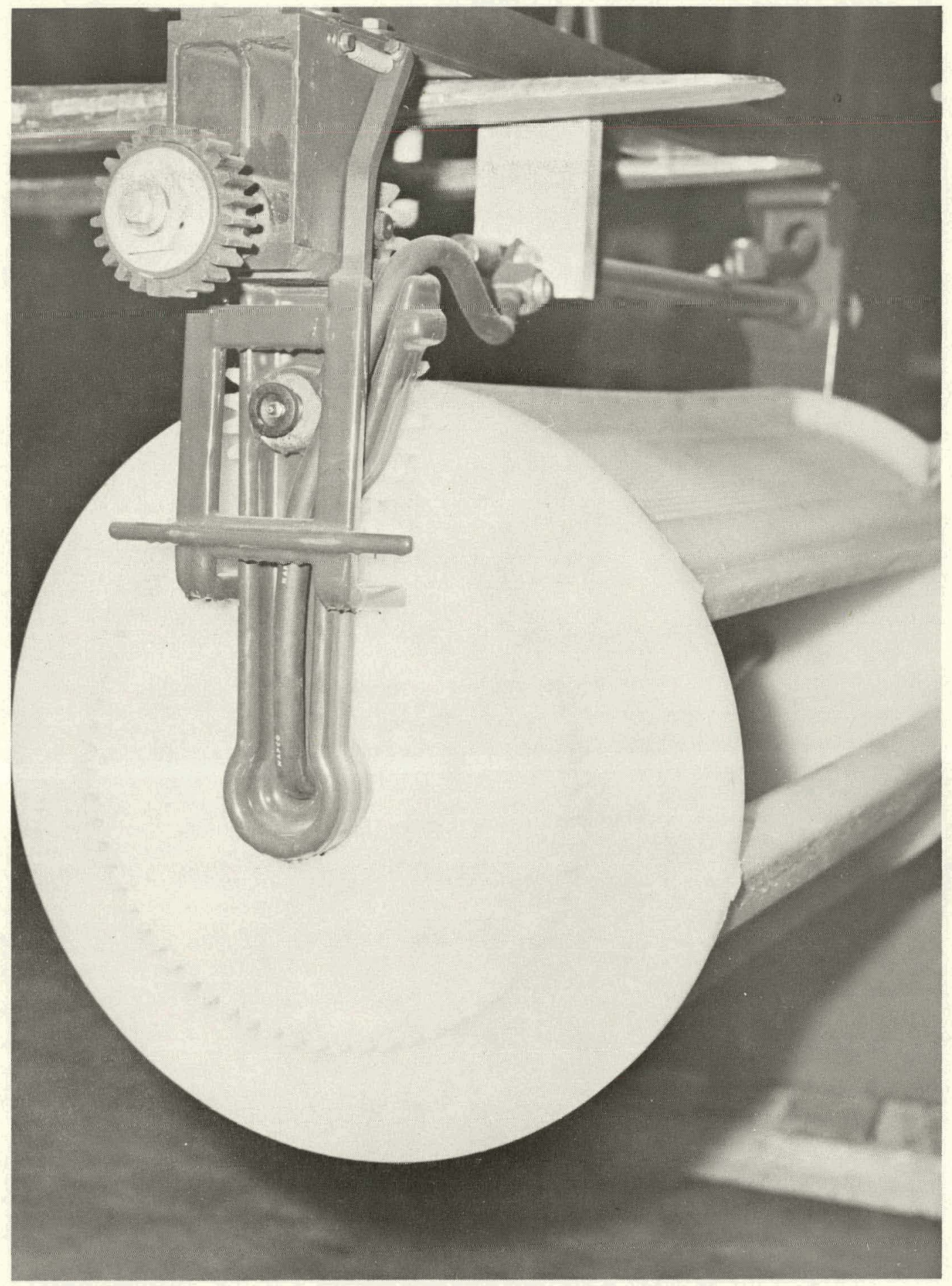

FIGURE 24. Barrel System for High-Volume Electropolishing of Sma11 Parts Without Rackinq 


\section{PREPOLISHING APPLICATIONS}

Significant interest has developed in using electropolishing to prepolish items that become contaminated in their normal service environment. Experience has shown that the smooth surfaces produced by electropolishing are much easier to clean using swab and other standard decontamination techniques than metal surfaces with a normal as-received finish. Figure 25, for example, shows typical stainless steel laboratory ware that was decontaminated by electropolishing. The highly polished surface produced by the electropolishing treatment substantially reduced the time and radiation exposure required for their subsequent decontamination using conventional techniques. Another advantage of electropolishing, as noted earlier, is that electropolished surfaces often have better corrosion resistance and other properties than normal as-received surfaces.

New items that are to be prepolished or decontaminated by electropolishing should be designed to minimize cracks and other inaccessible areas. For example, fifteen new 90-1b, interarea, sample shipping containers used by the Rockwell Hanford Operations Company were prepolished and also specifically designed with accessible stainless steel surfaces to facilitate periodic decontamination by electropolishing.

The stainless steel walls and all of the equipment for the walk-in hood for the pretreatment facility (Chapter 6) have been prepolished to facilitate the maintenance of a low-background contamination level. This included the prepolishing of two 19-ft-long bridge rails and the 10-ft-long, 400-1b traversing beam for the bridge crane. Innovative techniques were needed to electropolish components of this size. The rails were prepolished using an improvised electropolishing tank cut from 8-in.-diameter, acidresistant PVC pipe. The traversing beam for the bridge crane was prepolished in a 14- by 4- by 3-ft open pit (Figure 26) that was lined with sand, concrete curing blankets, plywood, and multiple layers of plastic and then filled with phosphoric acid electroiyte. The ability to successfully electropolish this large beam using this rudimentary electropolishing system illustrates the inherent versatility and adaptability of electropolishing as a surface prepolishing and decontamination technique.

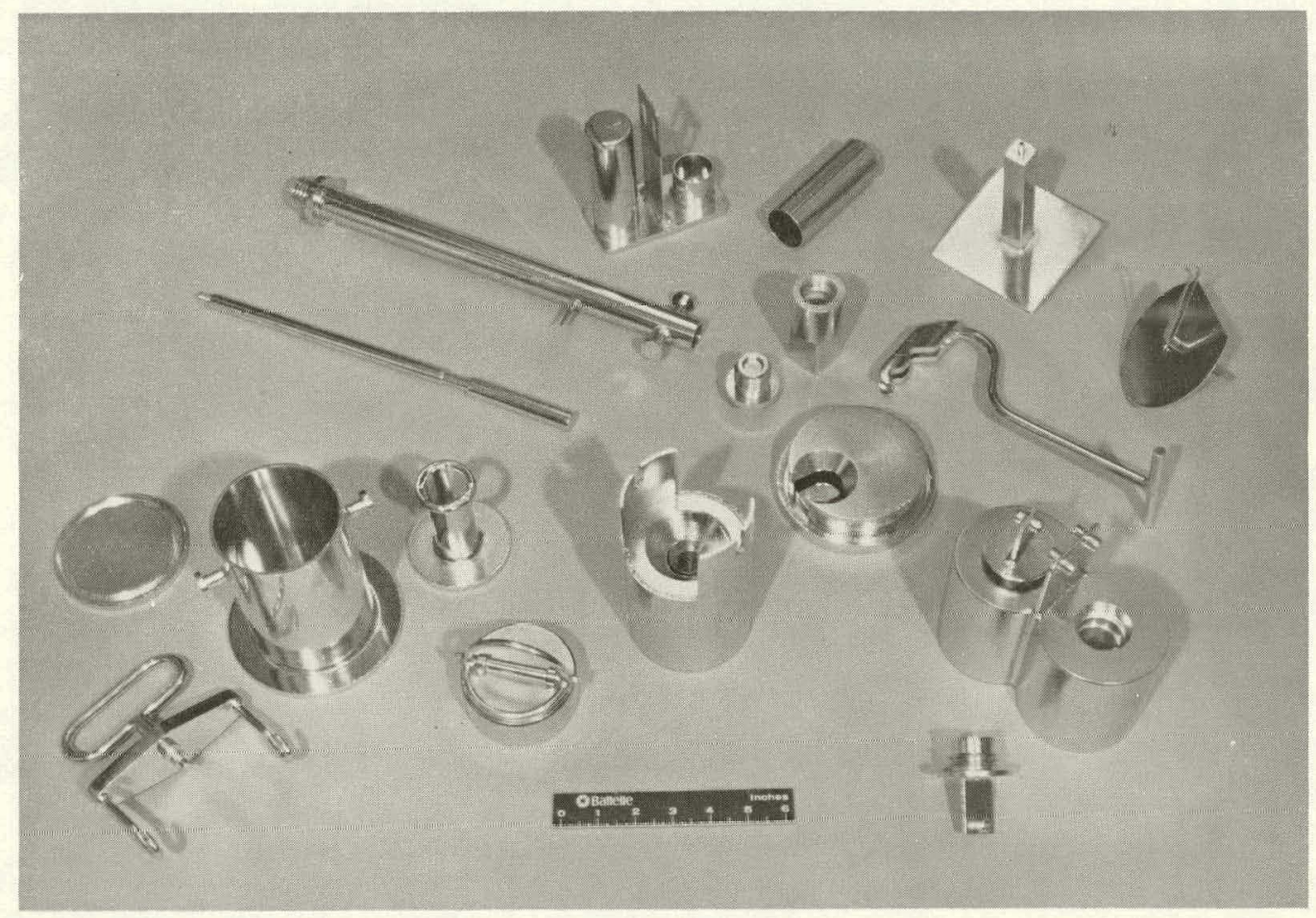

FIGURE 25. Stainless Steel Laboratory Ware Decontaminated by Electropolishing. The highly polished surface produced by electropolishing facilitated subsequent decontamination of these items using standard swab techniques. 


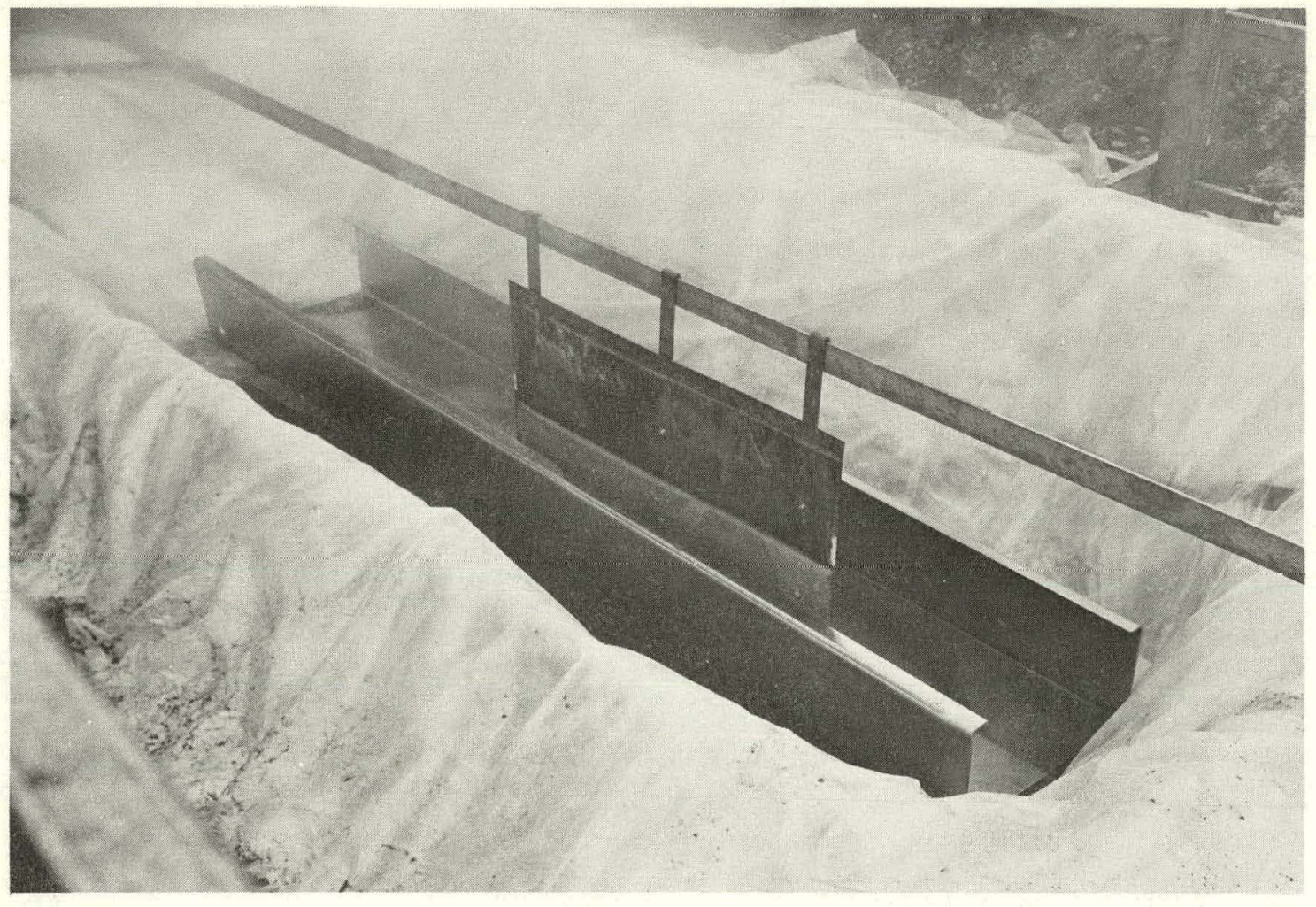

FIGURE 26. Open-Pit Electropolishing of Traversing Beam for Bridge Crane 


\section{RACKING TECHNOLOGY}

The material to be decontaminated using immersion electropolishing techniques must be supported in the electrolyte and also provided with the high electric current needed to effect electropolishing. This may be accomplished either through the use of a suitable anode fixture or "rack" or, in the case of small items, by using a rotating barrel or basket technique.

The material used for the electrically active parts of the rack, barrel, or basket must be capable of carrying high currents and also provide a good electrical contact to the items to be electropolished. In addition, it also must have a low erosion rate under electropolishing conditions to maximize both rack life and the current available for decontamination, while minimizing loading of the electrolyte with dissolved metal.

As a result of technology transfer activities, an investigation of titanium as a possible rack material for decontamination applications was initiated based on its use as a long-life rack material in the commercial electropolishing and electroplating industries. Titanium and similar passivating metals such as tantalum, niobium and tungsten form a thin, insulating surface oxide film that inhibits anodic dissolution. However, this film is easily disrupted by racking operations to provide electrical contact to the part to be electropolished.

A series of tests using phosphoric acid electrolytes have confirmed the low erosion rate of titanium under representative electropolishing decontamination conditions. The metal loss from titanium was less than one tenth that of copper or 304 stainless steel for equivalent voltages and cell geometries. More importantly, these tests demonstrated that. tit.anium can be decontaminated by electropolishing despite its low erosion rate. However, longer electropolishing times and higher voltages are required to decontaminate titanium as compared with rack materials that do not form a protective surface film. For example, the radiation reading for titanium contaminated with plutonium oxide was reduced from $30,000 \mathrm{dis} / \mathrm{min}+100 \mathrm{~cm}^{2}$ lu less than 100 $\mathrm{dis} / \mathrm{min} \cdot 100 \mathrm{~cm}^{2}$ by electropolishing for 30 min at $20 \mathrm{~V}(\mathrm{dc})$. Copper and stainless steel under comparable conditions, however, were decontaminated in less than 5 min at $12 \mathrm{~V}(\mathrm{dc})$. The ability to decontaminate rack surfaces and other system components by electropolishing is just as important as long life for decontamination applications. This permits cleaning of the facility and a reduction of contamination levels, whenever required, by reversing electrode polarity.
The suitability of titanium as a basket material was investigated using a small basket consisting of $1 \mathrm{ft}^{2}$ of expanded titanium sheet with diamond-shaped openings in an electrically insulated stainless steel support structure. Nine mild steel connector rings were placed in the basket and electropolished at $12 \mathrm{~V}(\mathrm{dc})$ for $3 \mathrm{~min}\left(3 \mathrm{~A} / \mathrm{in}^{2}\right.$ on the connector rings). The radiation level of the rings went from $2 \mathrm{mR} / \mathrm{hr}$ to background, except in heavily rusted areas (illustrating the need for effective pretreatment techniques). Even the bottoms of the rings next to the titanium sheet were decontaminated. More importantly, after several decontamination runs, the titanium basket itself remained uncontaminated.

However, there were indications of poor electrical contact between the parts to be decontaminated and the surface of the titanium sheet. The titanium was replaced with a tantalum sheet and similar tests were conducted with no evidence of arcing. These preliminary tests indicate that tantalum could be a better material than titanium for basket and barrel-type decontamination applications.

These observations are consistent with the earlier selection of tantalum as the contact material for the decontamination of fission product storage capsules (see Appendix).12 Although the rack itself was titanium, the use of tantalum for the spring contacts that transmitted the current to the capsules (Figure 27) satisfactorily reduced arcing problems.

The possible use of coating techniques to combine the low erosion rate characteristics of titanium and tantalum with the low-cost fabricability and conductivity of copper and stainless steel racks was briefly investigated.

A series of 0.25 - by 1.5 - by 6 -in. stainless steel and copper bars were plasma-spray coated with 5 to 10-mil thick layers of titanium or tantalum. These coatings were evaluated for erosion resistance and compatibility with the base material under accelerated electropolishing service conditions. The following results were obtained:

- Thermal cycling - The test bars were cycled 335 times from $10^{\circ}$ to $55^{\circ} \mathrm{C}$ to stimulate automated rack operation. There was no delamination or other detectible evidence of coating failure.

- Current Density - Electropolishing tests were conducted under conditions that gave a current demsity of $1 \mathrm{~A} / \mathrm{in}^{2}$ for 1 dentical uncoated bars. The equivalent current 
density for the titanium was $0.12 \mathrm{~A} / \mathrm{in} .^{2}$ This decreased to $0.04 \mathrm{~A} / \mathrm{in}^{2}{ }^{2}$ after momentarily raising the voltage to promote film formation. Similar behavior was noted for the tantalum with the initial current density of $0.10 \mathrm{~A} / \mathrm{in}^{2}$ decreasing to $0.01 \mathrm{~A} /$ in. $^{2}$

- Erosion Resistance - The test bars were maintained under electropolishing conditions for $56 \mathrm{hr}$. Both the 5 and $10 \mathrm{mil}$ titanium coatings failed to protect the stainless steel and copper bars due to crack initiation at the bar edges. The tantalum coatings gave complete protection to the base material over the entire test period.

These test results show that plasma-sprayed tantalum is a promising low-erosion-rate coating material for rack components. Studies are in progress to determine the decontamination characteristics of titanium and tantalum coatings and to further evaluate titanium and tantalum for rack, basket, and barreltype decontamination applications.

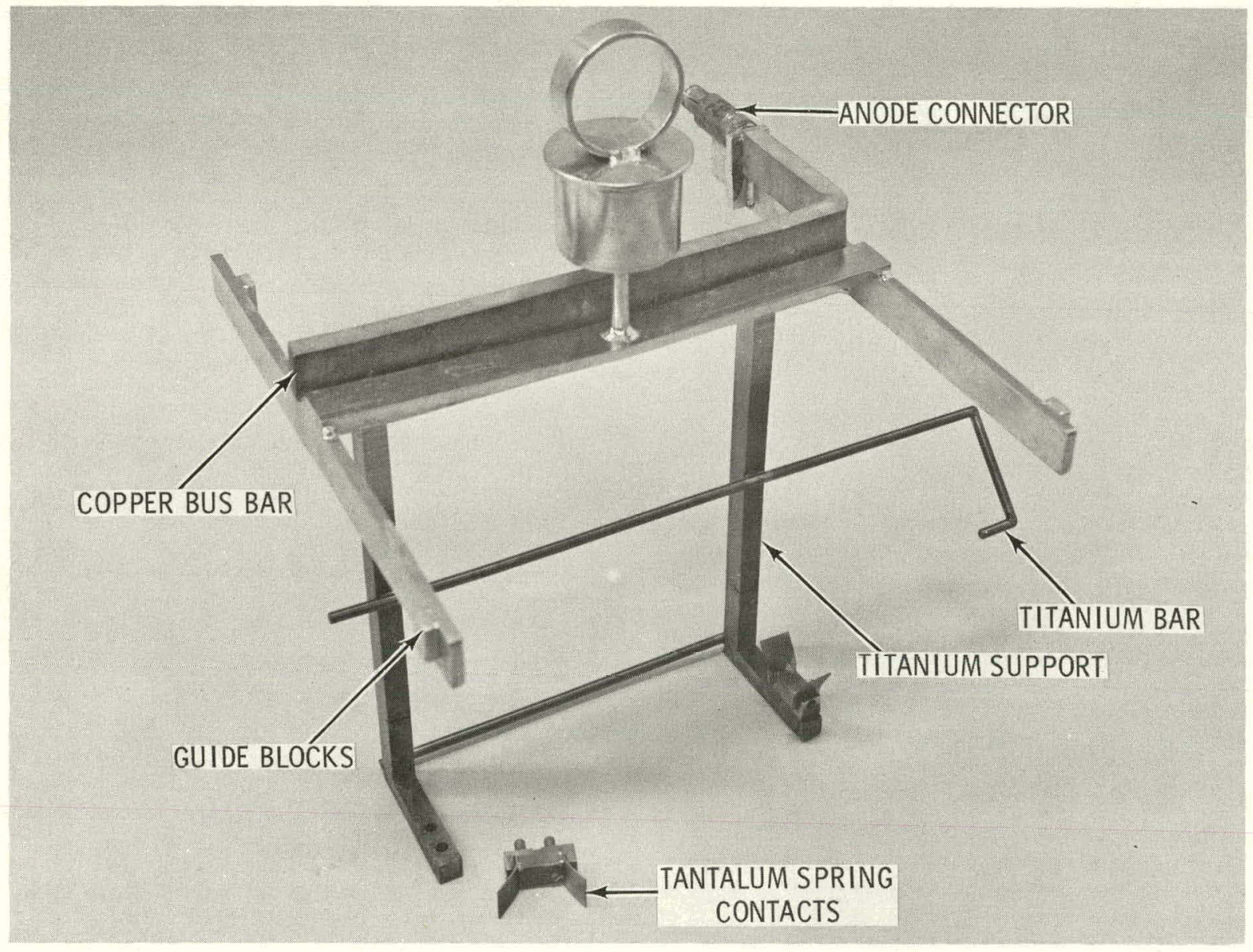

FIGURE 27. Titanium Rack Used in the Decontamination of Fission Product Storage lapsules. Taildalum was used for spring contacts to transmit current to the capsules. 


\section{ENTRAINED CONTAMINATION STUDIES}

Contaminated metallic waste must be sectioned into a size and geometry that is compatible with the size and type of electropolishing system used for decontamination. A 4- by 4- by 8-ft glove box, for example, could be cut into 4- by 4-ft plates for processing using a rack-type system, or into smaller pieces for decontamination using a barrel-type electropolishing system. Similarly, pipe and ducting would either be cut into short sections or else sectioned lengthwise to facilitate decontamination of the interior surfaces.

Mechanical sectioning techniques are effective for small quantities of waste, as discussed in Chapter 6 . However, fusion techniques, such as plasma arc torch or arc saw cutting, are required for high-volume waste processing applications and for remote operation to minimize personnel exposure. One disadvantage of fusion cutting techniques as compared with mechanical methods is the possibility of incorporating some of the surface contamination in the molten metal and thus in the recast layer which forms on the surface of the cut. This "entrained" contamination must be minimized or removed to achieve adequate decontamination of the sectioned component.

The amount of contamination in the recast layer can be reduced by precleaning components, as discussed in Chapter 6 , to remove gross contamination before sectioning. Other methods of minimizing or eliminating this entrained contamination are: 1) reducing the thickness of the recast layer by controlling and optimizing the cutting process, 2) using pretreatment techniques to remove some of the recast layer from the sectioned components, and 3) electropolishing the sectioned components using operating conditions that result in preferential removal of the recast layer. The studies that are in progress in each of these three areas are summarized in this chapter.

\subsection{RECAST LAYER STUDIES}

Optical metallography and scanning electron microscopy studies of plasma-arc-torch and arc-saw cut material were conducted to evaluate the thickness of the recast layer and the characteristics of the cut surfaces produced by thesc sectioning techniques. These studies also included, for comparison, an investigation of the surface produced by explosive cutting techniques of the type used for disassembly and for decontamination and decommissioning operations at retired nuclear facilities.
The arc-saw-cut material was 0.7-in.-thick 304 stainless steel plate sectioned at approximately $0.7 \mathrm{in./min}$. The thickness of the recast layer was $300 \mu \mathrm{m}$ for constant saw operation. The high cooling rates for this process resulted in a sharp, wel1-defined interface between the undisturbed base metal and the recast layer (Figure 28 ). The plasmaarc-torch-cut material was $0.25-i n$. stainless steel plate. The recast layer ranged in thickness from 10 to $60 \mu \mathrm{m}$ with a $175-\mu \mathrm{m}$ thick bead at the bottom of the cut. The interface was very irregular, however, with apparent intergranular penetration of the melt to a depth of at least another $50 \mathrm{um}$ (Figure 29).

The material cut using a shaped explosive charge was 0.3-in.-thick stainless steel pipe (cut from the inside) and 0.25-in.-thick mild steel pipe (cut from the outside). The cut surfaces did not have a recast layer, but. were severely deformed and exhibited extensive cracking (Figure 30 ). Many of these cracks had length-to-diameter ratios greater than 10 to 1 , making penetration by the electrolyte and decontamination of the interior surfaces improbable. Moreover, copper from the charge holder was plated onto the surface of the cut and even inside the cracks. Figure 31, for example, is a scanning electron micrograph (backscattered image) of a surface region of the mild steel specimen and a copper x-ray map of the same area. It illustrates the copper coating on the cut surface and shows that it does extend even inside a sealed crack.

These metallographic studies indicate that the dissolution of at least $1000 \mu \mathrm{m}$ of surface would be required to insure removal of all possible entrained contamination for the explosively cut material as compared with less than $300 \mu \mathrm{m}$ for most of the arc-saw and plasma-arc-torch-cut surfaces. For comparison, the removal of normal surface contamination by electropolishing usually requires the dissolution of less than $50 \mu \mathrm{m}$ of surface material.

\subsection{PLASMA-ARC-TORCH STUDIES}

Several discussions have been held with manufacturers of plasma-arc-torch cutting equipment to identify equipment, procedures, and operating conditions for safely and efficiently sectioning contaminated metal waste while minimizing the thickness of the recast layer on the cut edges. Two different sizes and types of plasma arc torches have been obtained for evaluation: a 400-A, water-injected torch and a 100-A, dry torch (Figure 32). The 400-A torch is capable of 


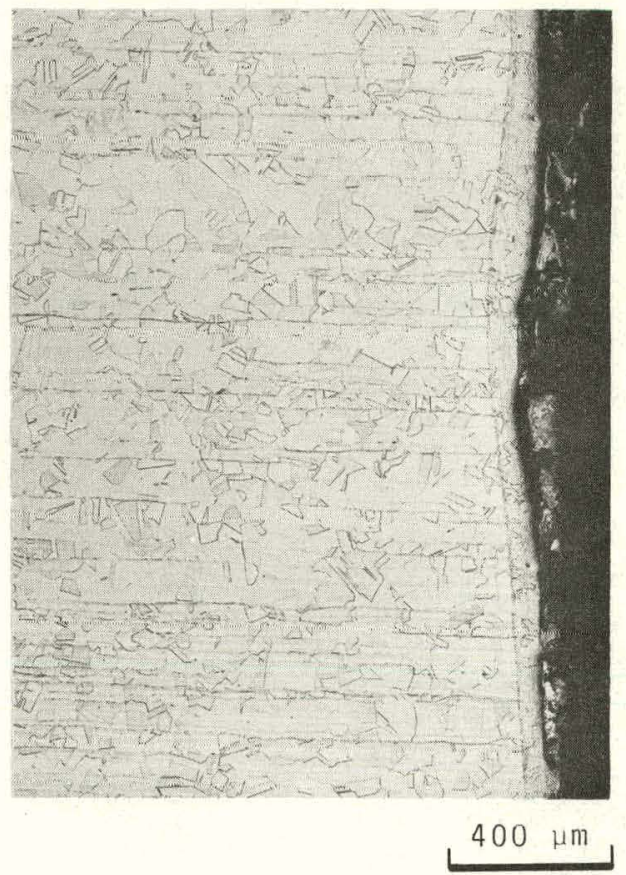

FIGURE 28. Optical Micrograph Showing the Recast Layer on a 0.7-ill.-thick Stainless Steel Plate Cut Using an Arc Saw at a Rate of

$0.7 \mathrm{in.} / \mathrm{min}$. The area $\mathrm{illustrated}$ is $0.5 \mathrm{in}$. from the start of the cut.

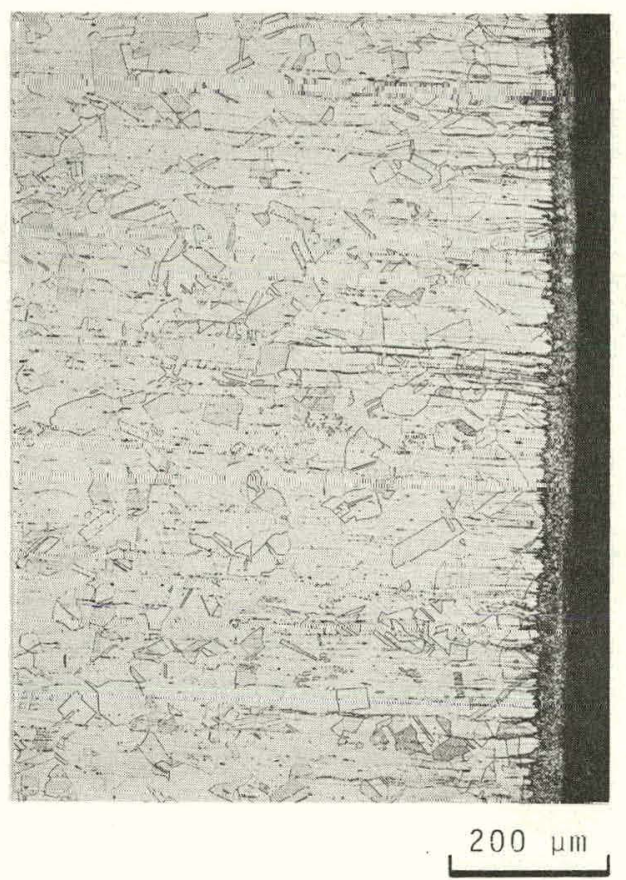

FIGURE 29. Optical Micrograph Showing the Recast Layer at the Center of 0.25-in.-thick Stainless Steel Plate Cut Using a Plasma Arc Torch 


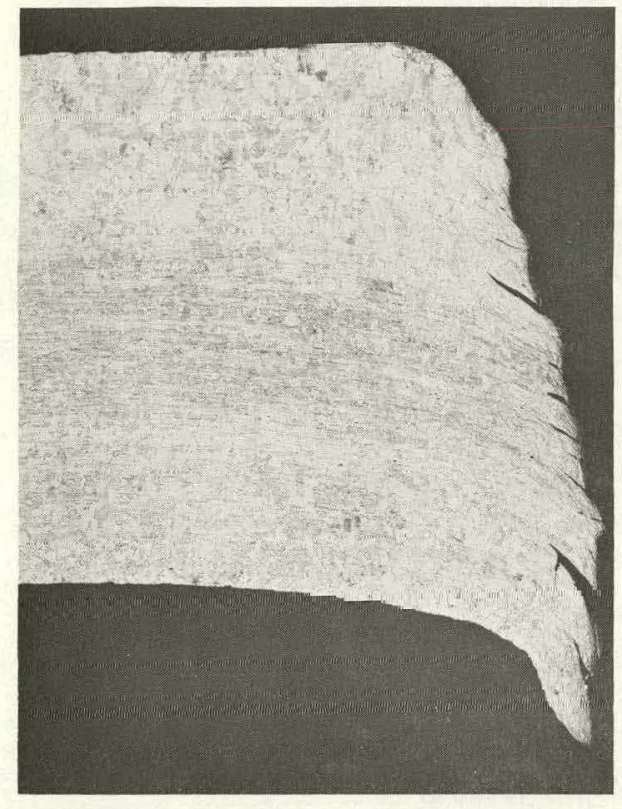

A

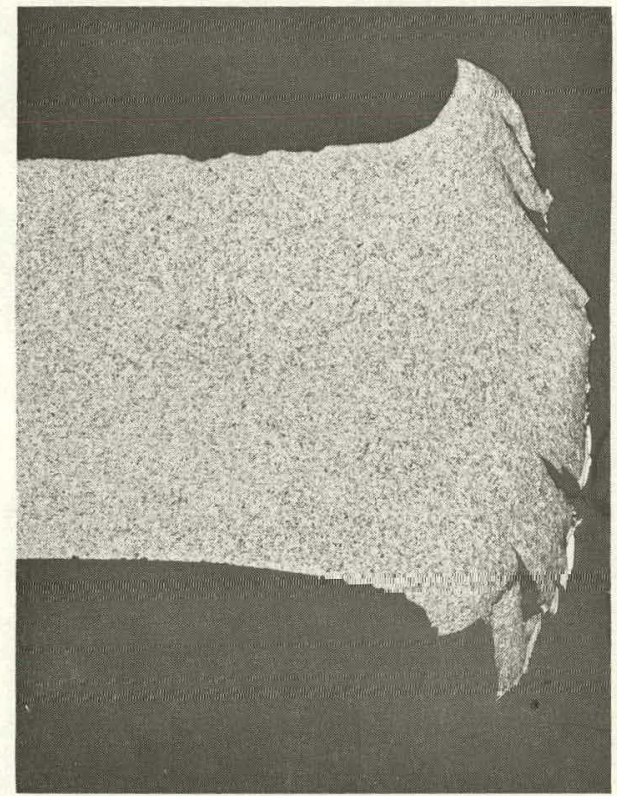

B

$2.5 \mathrm{~mm}$

FIGURE 30. Optical Micrographs Illustrating the Type of Surface Produced by Explosive Cutting: A) 0.3-in.-thick Stainless Steel Pipe Cut from the Inside, and B) 0.25-in.-thick Mild Steel Pipe Cut from the Outside

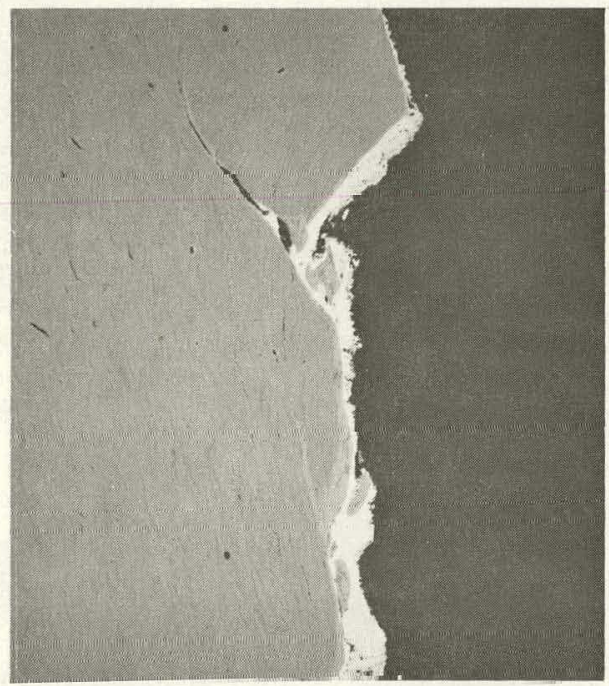

A

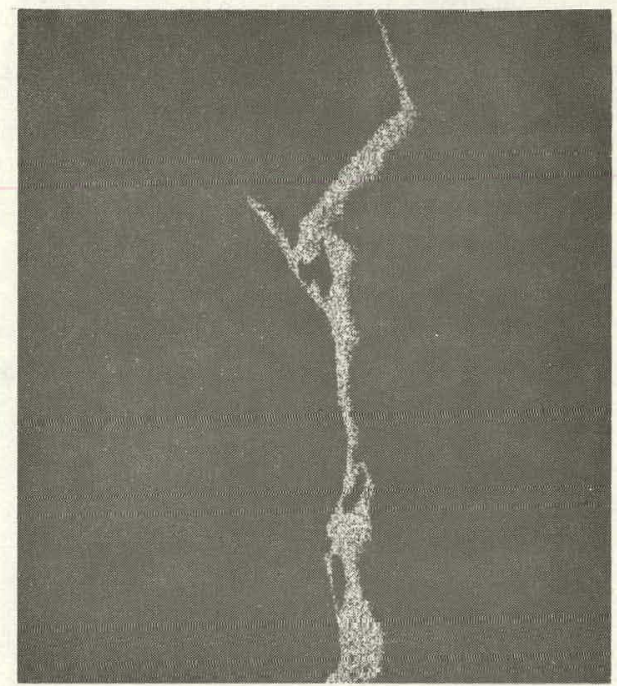

B

FIGURE 31. Scanning Electron Micrographs Illustrating the Surface Cracking and Copper Distribution for Explosively Cut Mild Steel Pipe: A) Back-Scattered Electron Image, and B) Copper X-Ray Map of the Same Region 


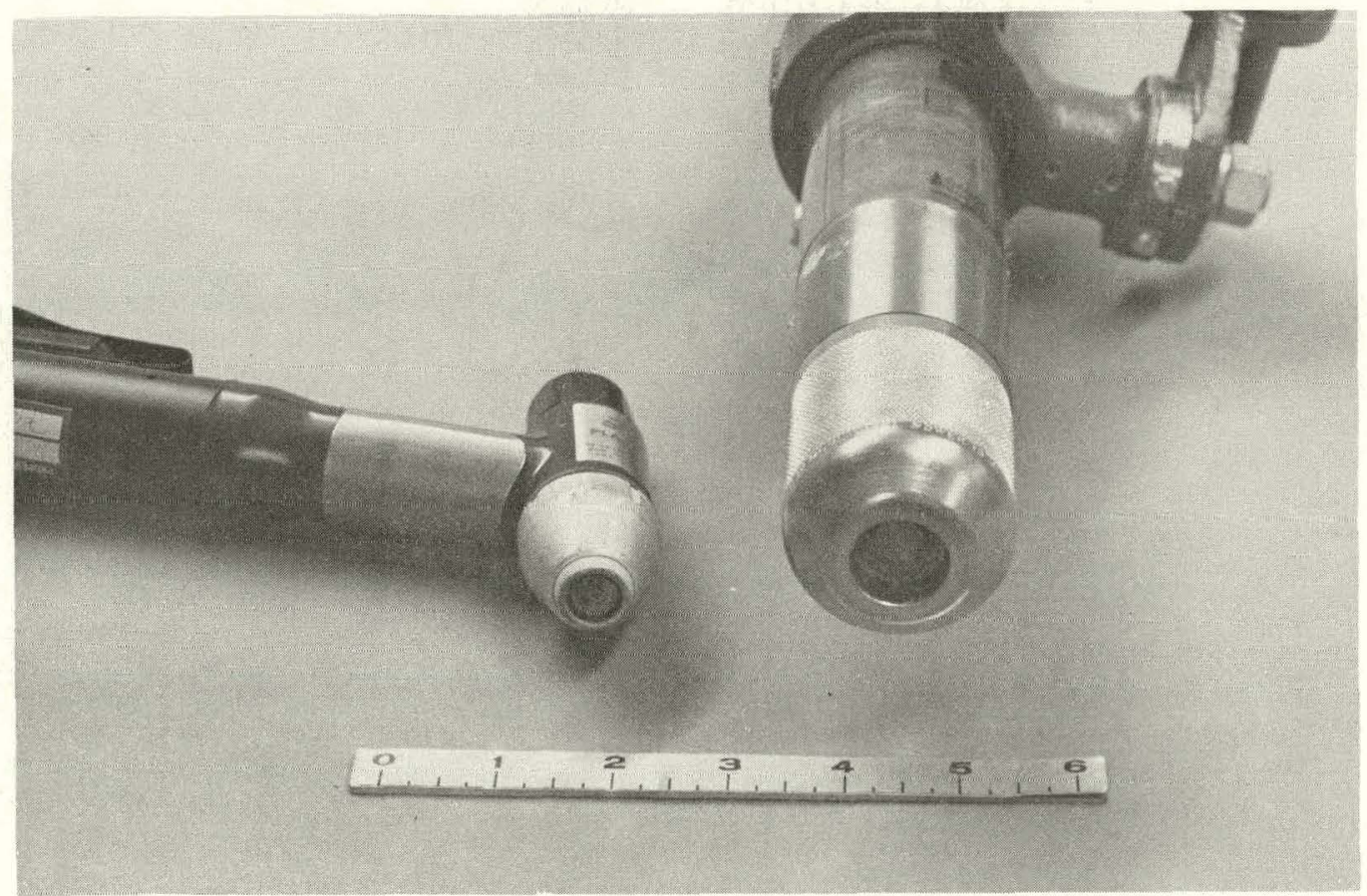

FIGURE 32. Plasma Arc Torches to be Used to Develop Effective Sectioning Techniques for Contaminated Metal While Minimizing the Thickness of the Recast Layer: 100-A, Dry Torch (Left) and 400-A, WaterInjected Torch (Right)

rutting stainless steel and other metals at speeds up to $200 \mathrm{in.} / \mathrm{min}$. Thls lur'ch will be used in conjunction with a water muffle and water table to evaluate containment of contamination during sectioning and the effect of the impinging water on the thickness of the recast layer. The 100-A, dry torch can cut $0.25-i n$. stainless steel at $40 \mathrm{in.} / \mathrm{min}$. This torch will be used to evaluate the effect of a small nozzle orifice, low-heat input, and operation at the maximum cutting speed on the thickness of the recast layer. In addition, efforts will be made to add a water muffle to the small torch to help contain dross and contamination and to reduce noise and ultraviolet radiation from the cutting operation. The low heat input and reduced cutting width of the small torch also will minimize metal loss (secondary waste) from the cutting operation. Calculations show that metal loss with this torch should be less than 2 wt\% for sectioned plates larger than 2 by $2 \mathrm{ft}$.

\subsection{PRETREATMENT STUDIES}

Tests were conducted using the vibratory finisher to determine if this pretreatment technique would remove at least part of the recast layer from cut edges. The initial studies using plastic media were not encouraging with resuccl lu elimination of the recast material because, as discussed in Chapter 6 , most of the metal removed by vibratory finishing is from sharp edges and corners. However, subsequent tests using a medium-wear-rate ceramic media demonstrated a reduction of more than one-half in the thickness of the recast layer (Figure 33). It should be noted that the recast layer produced by the smal1, dry torch (Figure 32 ) is discontinuous, suggesting the possibility of almost eliminating the recast layer through careful cunlrul of the torch operating parameters.

\subsection{ELECTROPOLISHING STUDIES}

A well-known characteristic of electropolishing is that the metal dissolution rate at edges is higher than the removal rate for planar surfaces. This phenomenon offers the possibility of preferentially removing the recast layer during the decontamination process through proper control of the electropolishing variahles. A series of edqe-effect tests was conducted using the 400-gal electropolishing facility to compare the metal removal rates at the edges and center of a 2 -ft by 1 -ft by $0.125-i n$. thick stainless 

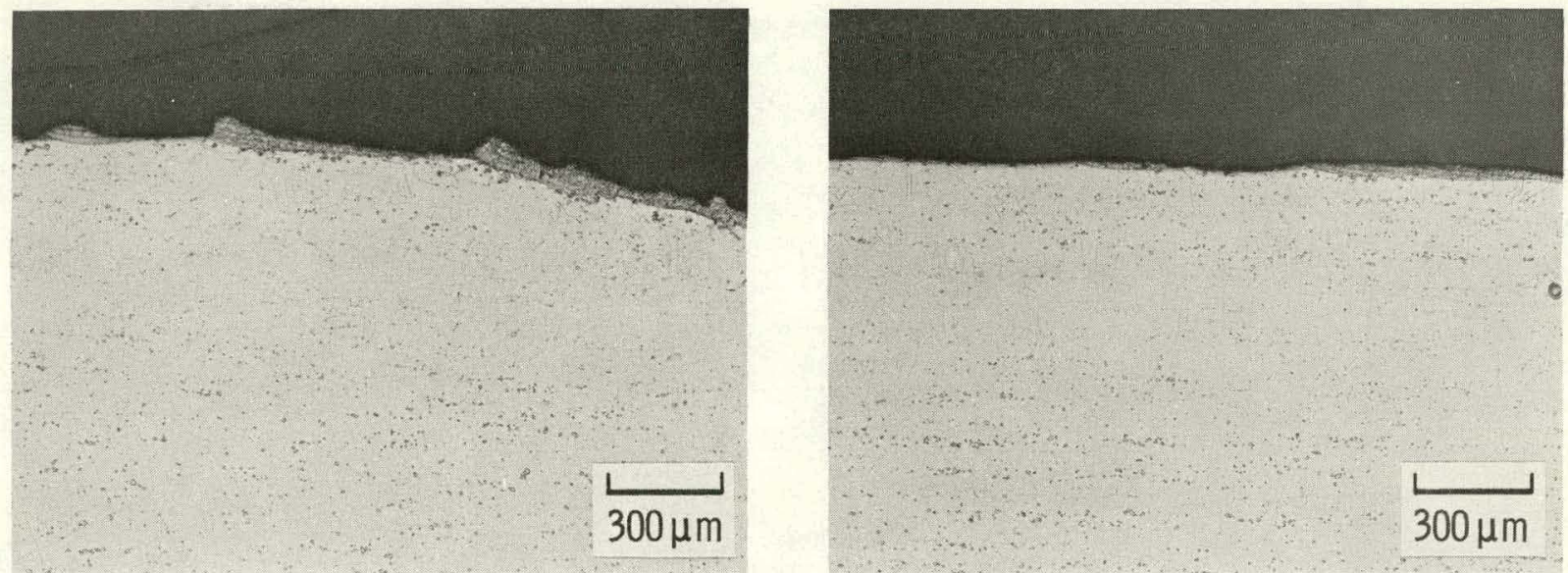

FIGURE 33. Use of Vibratory Finishing to Remove the Recast Layer Produced by Plasma-Arc-Torch Cutting: As Sectioned Using a 100-A, Dry Plasma Arc Torch (Left) and after Vibratory Finishing for $3 \mathrm{hr}$ (Right)

steel plate to determine if standard electropolishing treatments could remove the recast layer and to identify the variables affecting the relative removal rates.

The initial edge-effect tests were conducted in $75 \%$ phosphoric acid electrolyte at a current density of $100 \mathrm{~A} / \mathrm{ft}^{2}$. The metal plate was positioned vertically with one edge 2 in. from the tank wall (cathode). The other edges and the center of the plate were more than $1 \mathrm{ft}$ from the nearest cathode surface. The metal removal rate for the edgc nearest the cathode was 3.6 times the rate at the center of the plate, as compared with an edge-to-center metal removal rate ratio of 1.8 for the edge in the center of the tank.
The same tests were repeated with the current density increased from 100 to $300 \mathrm{~A} / \mathrm{ft}^{2}$. This increased the edge-tocenter metal removal rate ratio to 6.2 for the close cathode spacing and to 4.0 for normal cathode spacings. Operating at increased current densities thus produced a substantial enhancement in the relative edge erosion rate, demonstrating that it should be possible through proper control of electropolishing variables to preferentially remove the recast layer produced by arr.-saw and plasma-arc-torch cutting operations while only removing the 1 or 2 mils from planar surfaces needed for decontamination. 


\section{BASIC STUDIES AND PROCESS OPTIMIZATION}

Laboratory-scale studies are in progress to understand basic decontamination mechanisms and to optimize the decontamination process for various alloys and types of contamination with respect to electrolyte composition, electrode arrangement, electropolishing variables, and rinsing procedures.

\subsection{THROWING POWER STUDIES}

The ability of electropolishing to decontaminate surfaces that are shielded from the cathode (tube interiors, bolt holes, crevices, etc.) has been investigated. Results of preliminary studies show that the length of the polished region on the interior of 0.5 to 1.5-in.-diameter stainless steel tubes electropolished without using an internal cathode is about one-half the tube diameter for normal electropolishing conditions. This length-to-diameter ratio for internal surfaces increases to approximately three-fourths at high current densities. Increasing the degree of agitation of the electrolyte also increases the extent of the polished region and promotes polishing through narrow slots in the tube wa11 (Figure 34). Supporting decontamination studies indicate that the decontaminated region inside shielded areas may extend significantly farther than the highly polished region. For example, the interior of a plutonium-contaminated 8-in.-diameter by 35-in.-long stainless steel ventilation duct ( $90^{\circ}$ bend) was decontaminated from 115,000 $\mathrm{dis} / \mathrm{min} \cdot 100 \mathrm{~cm}^{2}$ to background in $15 \mathrm{~min}$ without using an internal cathode (Figure 35). This represents an internal decontamination distance of more than twice the pipe diameter.

\subsection{INTERNAL CATHODES}

Even though electropolishing has significant throwing power, as shown in the preceding section, internal cathodes are often required to facilitate the decontamination of difficultto-reach internal surfaces. The internal cathode arrangement illustrated in Figure 36, for example, was used to electropolish the inside of $0.29-$ in.-I.D. by $36-$ in.-long fuel cladding. Other applications of internal cathodes include:

- Use of an internal cathode to remove the remaining plutonium contamination from a

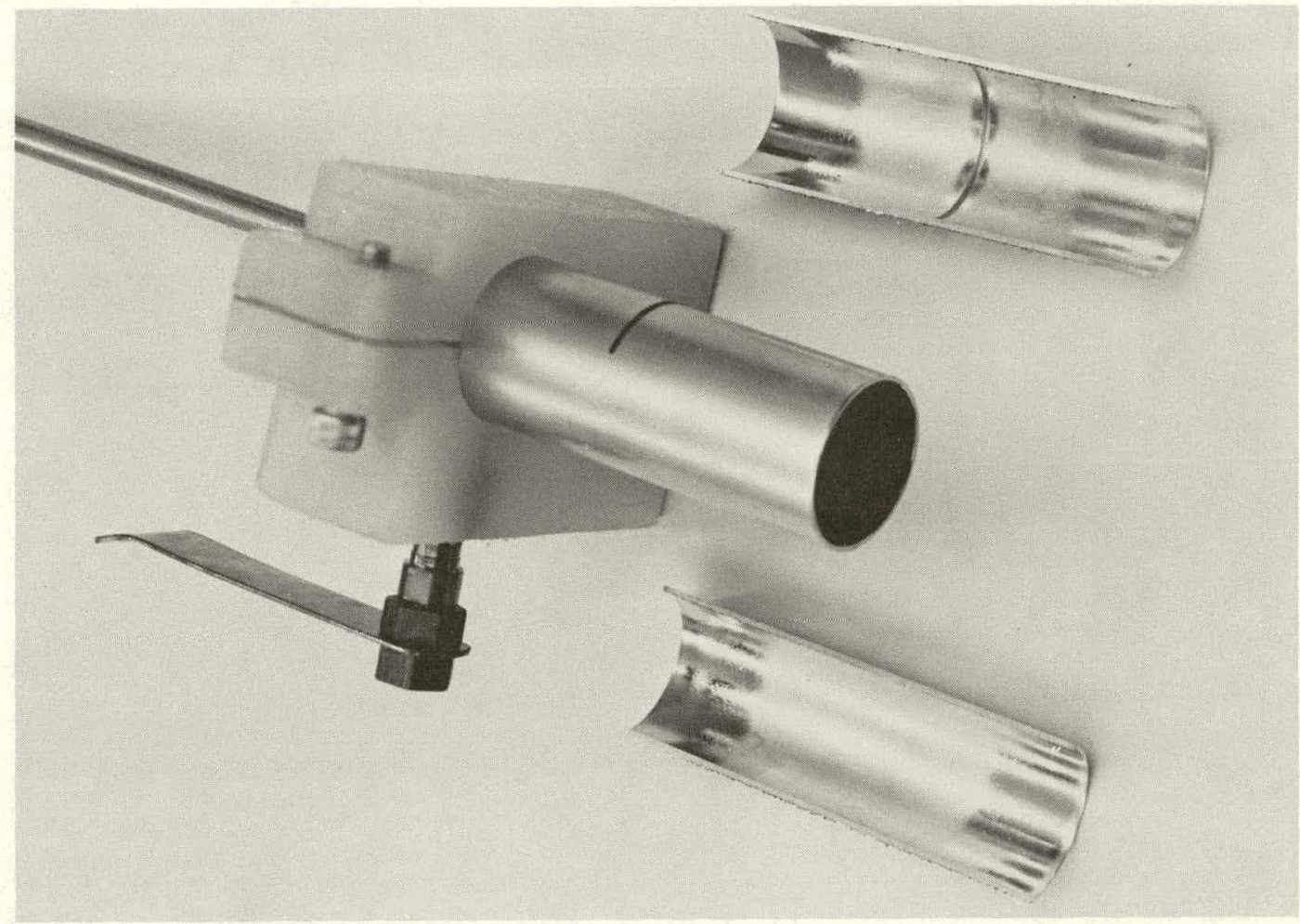

FIGURE 34. Test Fixture and Specimen Used to Investigate the Throwing Power of Electropolishing Solutions. Note the ability to electropolish interior surfaces and even through a $1-\mathrm{mm}$ slot without using an internal calliude. 


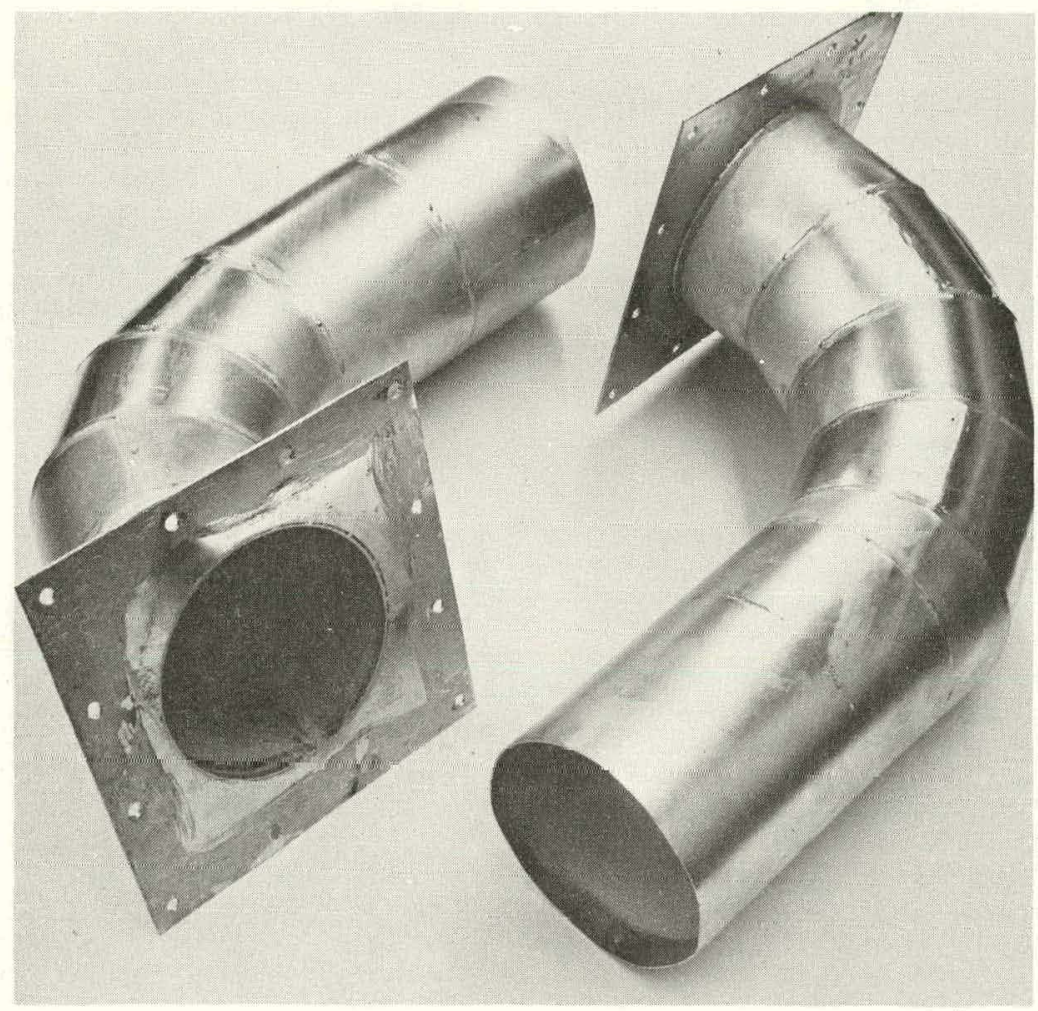

FIGURE 35. Stainless Steel Elbows (8-in. Diameter by 35-in. Long) Decontaminated Without an Internal Cathode

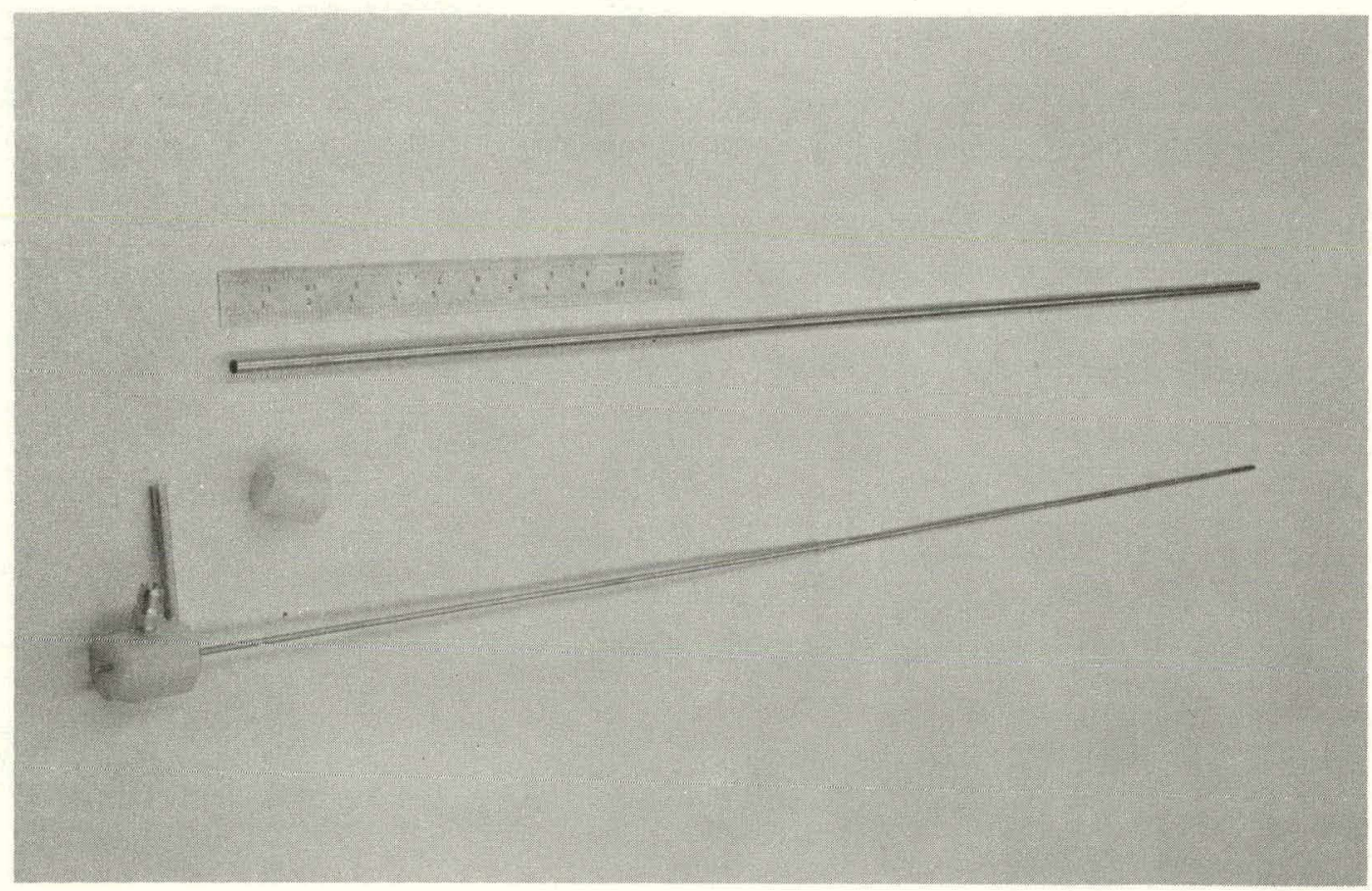

FIGURE 36. Internal Cathode (Bottom) Used to Electropolish the Inside of 0.29-in.-Diameter by 36-in.-Long Fuel Cladding (Top) 
16-in.-diameter by 22-in.-high stainless steel tank that had been used as the electropolishing tank for earlier decontamination studies. Electropolishing in the 400-gal system had first reduced the contamination from 20,000 to 2,500 dis/ $\min \cdot 100 \mathrm{~cm}^{2}$.

- Use of an internal cathode to decontaminate the inside of a 3.5-in.-diameter by 3-ftlong pipe that was contaminated and pitted by exposure to plutonium-containing acid solutions. The radiation level was reduced from $750,000 \mathrm{dis} / \mathrm{min} \cdot 100 \mathrm{~cm}^{2}$ to background in $10 \mathrm{~min}$.

- Use of an internal cathode consisting of a copper tube through which electrolyte was continuously pumped to electropolish the internal surfaces of a product receiving canister contaminated with plutonium nitrate solution to $>10^{6}$ dis/ $\min \cdot 100 \mathrm{~cm}^{2}$

\subsection{LABORATORY STUDIES}

Dissolved contamination ultimately may limit electrolyte life either by reaching a criticality safety or personnel exposure limit, or by reducing the effectiveness of the decontamination process. Laboratory studies using plutonium-contaminated electrolytes have shown, however, that metal surfaces can be decontaminated by electropolishing using even highly contaminated electrolytes.
Stainless steel specimens, for example, have been decontaminated to background radiation levels by electropolishing for only 5 min in electrolyte with a plutonium content as high as $7.2 \mathrm{~g} / \mathrm{l}$, or eight times the present criticality safety limit for the 400 -gal electropolishing facility. These studies have further shown that the decontamination of surfaces using contaminated electrolyte is facilitated by employing nitric acid rinsing procedures adapted from the commercial electropolishing industry.

Studies also were conducted for the 400 gal electropolishing system to estimate the amount of contaminated electrolyte and rinse solution (drag-out) that will be carried into the first and second rinse tanks during normal operation of the decontamination facility. The results show that the drag-out volumes should be less than $0.1 \mathrm{l} / \mathrm{m}^{2}$ for the electrolyte and less than $0.04 \mathrm{l} / \mathrm{m}^{2}$ for the rinse solutions. Based on these values and assuming uniform dilution of the contamination removed by electropolishing, a decontamination factor in excess of $1 \times 10^{6}$ was calculated for a worst-case decontamination treatment in a 400-gal electropolishing tank with a plutonium content of $150 \mathrm{mg} / \ell$ followed by simple rinsing in two 400-gal tanks. Substantially higher decontamination factors would be predicted through the use of counter-flow and spray rinsing techniques and by slow withdrawal of the electropolished items from the electrolyte to minimize drag-out. 


\section{CRITICALITY SAFETY STUDIES}

One of the major objectives of the decontamination program is to extend the life of the electrolyte to minimize the volume of secondary waste generated by the decontamination process. In the case of fissile contamination, solution life may be governed almost entirely by criticality safety considerations. For example, the criticality safety specification for operation of the 400-gal decontamination facility with plutonium and uranium-235 is $230 \mathrm{~g}$ of total fissile material in the decontamination facility. This corresponds to a maximum plutonium concentration in the electrolyte of $150 \mathrm{mg} / \mathrm{e}$ for the $400-\mathrm{gal}$ electropolishing tank.

Laboratory studies were conducted for plutonium and phosphoric acid electrolytes to estimate the amount of contamination introduced into the electropolishing bath per unit area of surface decontaminated and to determine the ultimate disposition of the contamination in the bath; i.e., in solution with the electrolyte, in combination with the electropolishing sludge, or plated onto the cathode. Initial results showed an average plutonium content of $0.7 \mathrm{~g} / \mathrm{ft}^{2}$ for just visible oxide on stiainless steel and $0.06 \mathrm{~g} / \mathrm{ft}^{2}$ for surfaces cleaned using conventional dry wiping techniques. Based on the $230-\mathrm{g} 1 \mathrm{imit}$, this would permit the decontamination of more than $3000 \mathrm{ft}^{2}$ of plutonium-contaminated surface area in the 400-gal system before disposa? of the electrolyte, even without precleaning and pretreatment to remove gross surface contamination or processing of the electrolyte to remove the dissolved contamination.. These studies also showed that the phosphoric acid electrolytes can contain more than $6 \mathrm{~g} / \ell$ of plutonium (or more than 40 times the criticality safety limit) without sludge formation or plating on the cathode.

The criticality safety controls for operation of the 400-gal decontamination facility include:

(1) All surfaces must be visible and wiped clean or the fissile material content must be determined by nondestructive analys is before the object is electropolished.

(2) No more than $20 \mathrm{~g}$ of fissile material can be added per decontamination cycle.

(3) X-ray fluorescence measurements of the plutonium content of the agitated electrolyte and tank bottom are required after the processing of each $100 \mathrm{ft}^{2}$.

(4) Independent chemical analyses of the electrolyte are required at the indicated 100- and 200-g levels.

(5) Disposal of the electrolyte is required at the $230 \mathrm{~g}$ limit.

Adherence to these procedures will ensure that less than $10 \mathrm{~g}$ of plutonium is added to the electropolishing system between measurements and that the system will be sub-critical by a large margin. 


\section{CONTAMINATION MEASUREMENT STUDIES}

Contamination measurement studies are in progress using a variety of measurement systems and techniques to quantitatively determine the pre- and post-treatment radiation levels of the surfaces decontaminated by electropolishing and to maintain an accurate inventory of the fissile material in the electropolishing, pretreatment and solution processing systems to ensure the criticality safety of the operation. The facilities, equipment, and approaches used for this work include:

- An x-ray fluorescence system for rapid quantitative analysis of the composition and fissile material content of the electrolyte and other process solutions. This unit is capable of measuring plutonium concentrations as $10 \mathrm{w}$ as $30 \mathrm{mg} / \ell$ in less than 20 min.

- A lead-shielded, low-background counting chamber for low level contamination measurements. This cave provides greater than $2 X$ attenuation of background radiation for the energy regions of interest for beta/gamma decontamination studies and about $20 \mathrm{X}$ attenuation for the lower energy regions used for measurement of plutonium contamination.
- A variety of sodium-iodide detector systems for fissile material inventory measurements of as-received items, and for monitoring the fissile material content of the electropolishing tanks, filters, and other components of the solution handling, storage and processing systems.

- Special detectors including surface barrier detectors for high-sensitivity measurement of surface alpha contamination, small detectors for contamination measurements inside holes and tubes, germanium detectors for high resolution identification of radionuclides, and special combination detectors for the low-background measurement of surface contamination.

- A computer-based signal analyzer for the quantative analysis of the data from the various detector systems.

- Facilities for melting decontaminated material and analyzing the resulting ingots to verify the removal or detection of contamination in cracks and other shielded areas. 


\section{POTENTIAL APPLICATIONS}

Rapid progress has been made in developing electropolishing into an effective decontamination technique that can remove transuranic and other surface contamination from a variety of metals and alloys. The technology is already sufficiently advanced to have many present applications as discussed and illustrated in this report. The continued development of electropolishing into a large-scale decontamination technique should lead to its widespread use in many areas of nuclear waste management, exposure reduction, prepolishing of components, and even for non-nuclear decontamination applications. The following list is just a sample of some of the possible areas of application of electropolishing as a decontamination technique:

- Decontaminate large volumes of transuranic and other surface-contaminated metallic waste to substantially reduce the amount of material requiring geologic disposal. This also would preserve irreplaceable metals and alloying elements for possible future use.

- Decontaminate failed equipment and also the tools and equipment used for maintenance operations to substantially reduce radiation exposure to maintenance personnel, while facilitating maintenance operations at operating nuclear industry facilities.

- Use in situ techniques to reduce radiation exposure and to facilitate dismantling operations at retired nuclear industry facilities.

- Use portable electropolishing systems for the on-site decontamination of metallic waste from decontamination and decommissioning operations to minimize the expense and possible environmental risk of transporting large volumes of rontaminated metal waste.

- Decontaminate canisters, equipment, shipping casks, and other components and surfaces contaminated by spent fuel handling, transportation, encapsulation and storage operations.

- Decontaminate canisters, equipment, shipping casks, and other components and surfaces contaminated by the preparation, transportation and disposal of high-level and other defense wastes.

- Use prepolishing techniques to facilitate subsequent decontamination using standard decontamination methods. This could be useful for large components and surfaces such as shipping casks and refueling pool walls, as well as for many types of smaller items.

- Design tanks, process equipment, piping, etc. with built-in cathodes to facilitate the periodic decontamination of operating nuclear industry facilities and the eventual decommissioning of retired facilities.

- Decontaminate expensive failed equipment and components to permit return to vendors or shipment to noncontrolled shops for repair.

- Decontaminate power reactor components (pumps, valves, spargers, refueling equipment and pool walls, fuel casks, metal filters, steam generator components, piping systems, waste disposal systems, etc.) to reduce radiation exposure and to facilitate refueling, inspection and maintenance operations.

- Use electropolishing to remove nonradioactive contaminants such as heavy metals or toxic chemicals from metal surfaces. Prepolishing techniques also could be used to minimize the deposition of contaminants and pollutants and to facilitate their removal using standard cleaning techniques. 
1. J. A. Ayres, Equipment Decontamination with Special Attention to Solid Waste Treatment - Survey Report, BNLW-B-90, Battelle, Pacific Northwest Laboratories, Richland, WA, 1971.

2. M. Parlapanski, "Corrosion Resistance of Electropolished Metals," Zashchita Metallov $6(2): 162,1970$.

3. J. R. Van Wazer, Phosphorus and Its Compounds, Vol. T, Interscience Publishers, New York, NY, 1958.

4. L. N. Filatova, T. N. Kurdyumova, and M. A. Shelyakina, "Sorption of Metal Ions by Sulfonic Cation Exchangers from Orthophosphoric Acid Solutions," Zh. Prikl. Khim. 47:2106, 1974 (Chemical Abstracts 81:176 $\overline{84} 7 \mathrm{t}$ ).

5. "Sorption Wins Phosphoric Acid from Finishing Wastes," Chemical Engineering, June 12, 1972.

6. L. E. Lancy, J. A. Steward, and J. H. Weet, Pilot Plant Optimization of Phosphoric Acid Recovery Process, EPA-670/2-75-015, Lancy Laboratories, Zelienople, PA.
7. Technical Information, Acid Purification Unit, BAPU 0IA, Eco-Tec Limited, Toronto, Canada, 1977.

8. M. J. Hatch and J. A. Dillon, "Acid Retardation," I and E.C. Process Design and Development 2(4):253, 1963.

9. K. Frankenfeld and K. Goetzmann, Purification of Technical Phosphoric Acid, Ger. Offen. 2,053,885, April 1972 (Chemical Abstracts $77: 37124 j, 1972$ ).

10. J. F. McCollough and L. L. Frederick, Purification of Wet-Process Phsophoric Acid with Methanol and Ammonia, U.S. Patent $3,975,178$, U.S. Patent Office, Washington, DC, August 1976.

11. J. F. McCollough and L. L. Frederick, "Purification of Phosphoric Acid with Methanol and Ammonia," J. Agri. Food Chem., 24(1):180-187, 1976.

12. H. W. Arrowsmith, et al., Electrochemical Decontamination of Strontium Fluoride Storage Capsules, BNWL-2725, Battelle, Pacific Northwest Laboratories, Richland, WA, February 1977. 
APPENDIX

DECONTAMINATION APPLICATIONS 


\section{DECONTAMINATION APPLICATIONS}

A number of projects are in progress to develop and use electropolishing for specific decontamination and exposure reduction applications at Hanford and other Department of Energy sites. Many of these applications are discussed in the body of this report. other examples that further illustrate the ability of electropolishing to decontaminate materials and components representing a variety of alloy compositions, a wide range of sizes and geometries, and different types of radioactive contamination include:

- Core drill bit. A mild steel core drill bit (Figure A-1) used by Rockwel1 Hanford Operations Company to sample solids in salt cake tanks. The drill bit including the case-hardened cutting edge and threads was decontaminated from $1 \mathrm{R} / \mathrm{hr}$ to nonsmearable. This permitted detailed examination of the drill and determination that the bit was not responsible for low core recoveries.

- Product receiving canister. A product receiving canister (Figure A-2) used by Rockwel1 Hanford Operations Company for the onsite transfer of plutonium nitrate solution. The radiation level of the 3-in.-diameter by 30-in.-deep 304L sample chamber was reduced from more than $1 \mathrm{mil}$ lion dis/min. $100 \mathrm{~cm}^{2}$ to background to permit use of the canister for a training class.
- Standards capsules. Stainless steel "standards" capsuTes ( 1 in. diameter by 1 in. long) containing plutonium oxide were electropolished after sealing by welding to remove the surface contamination in preparation for secondary encapsulation. Less than 4 min of electropolishing reduced surface contamination from 200,000 dis/ $\mathrm{min} \cdot 100 \mathrm{~cm}^{2}$ to background.

- Waste sampling tube. The interior of a 1.75-in.-diameter by 12-in.-long waste sampling tube from Rockwel1 Hanford Operations Company was decontaminated from $1 \mathrm{mR}$ to background in $20 \mathrm{~min}$.

- Water supply relief valve. Electropolishing was used on an emergency bas is to decontaminate a large water supply relief valve essential to the operation of Hanford $\mathrm{N}$-Reactor. Efforts to decontaminate the valve using conventional procedures were unsuccessful. Electropolishing reduced the radiation level of the valve and internals from $10 \mathrm{mR} / \mathrm{hr}$ to background, permitting release of the valve to a clean shop for the repairs needed to resume reactor operation.

- Aluminum compressor blades. Decontamination tests were conducted on several uranium-contaminated aluminum compressor blades (Figure $A-3$ ), representative of the type of scrap generated by the Cascade

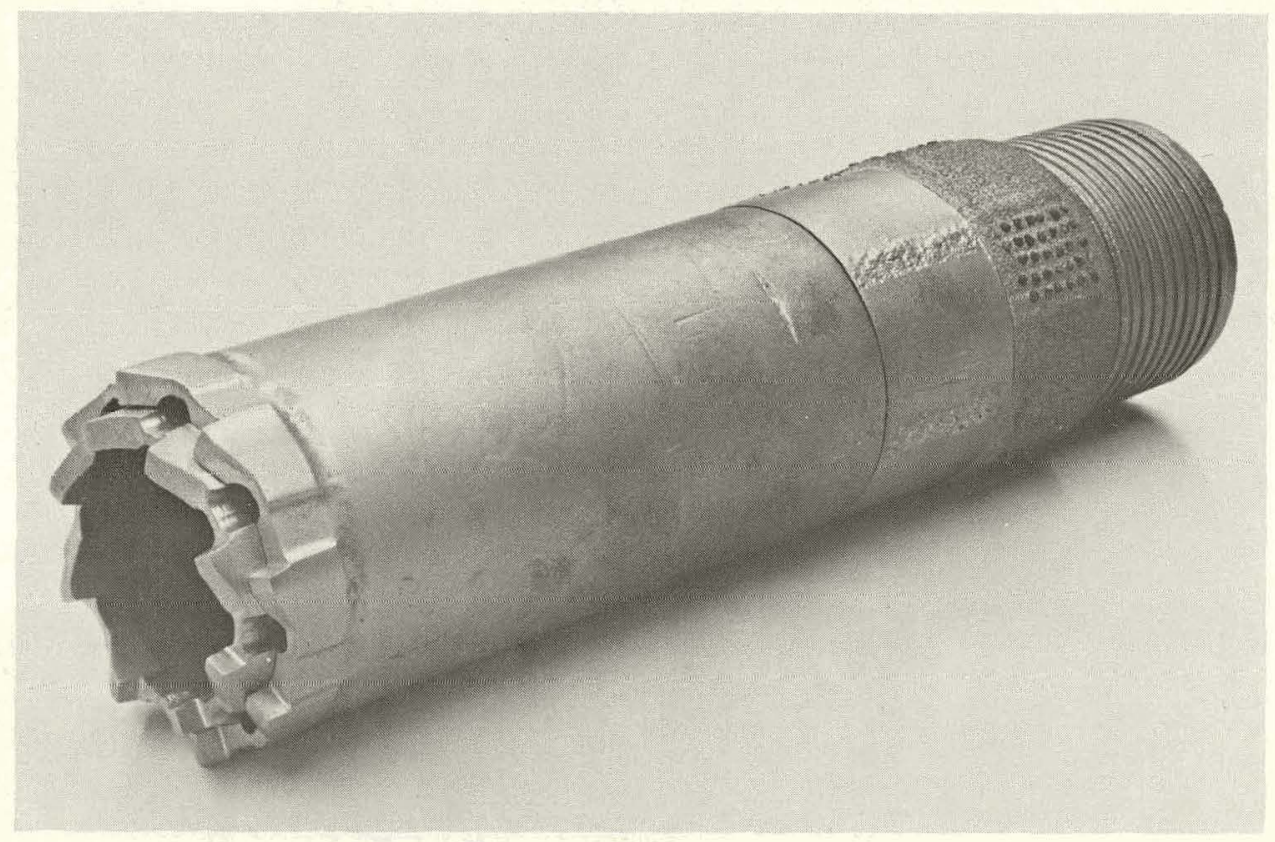

FIGURE A-1. Mild Steel Core Drill Bit Used to Sample Salt Cake in the Waste Tanks at Hanford. Electropolishing reduced the contamination level from i $\mathrm{R} / \mathrm{hr}$ to nonsmearable. 


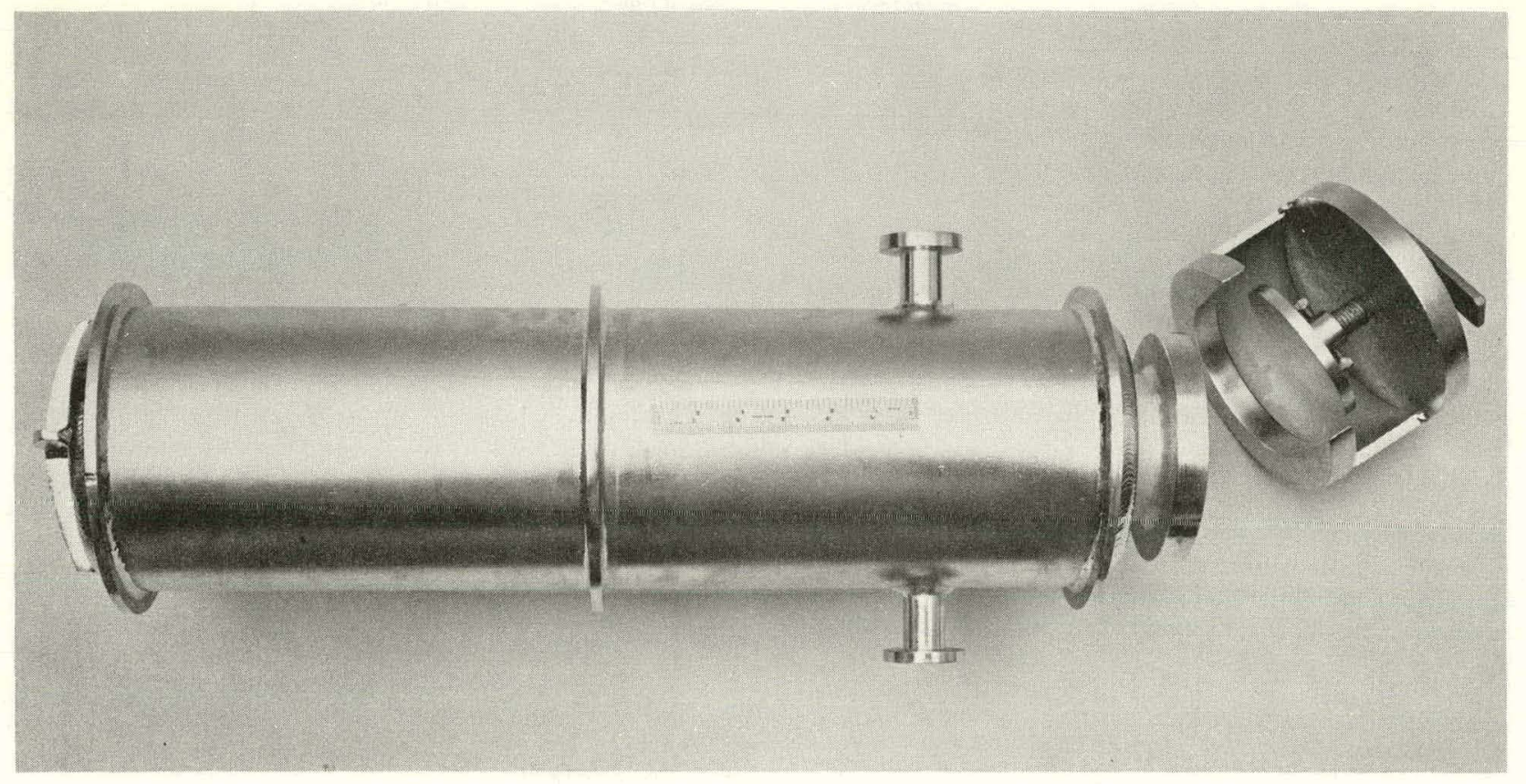

FIGURE A-2. Product Receiving Canister Used to Transport Plutonium Nitrate Solution. Electropolishing reduced the contamination level in the internal sample chamber from more than $1 \mathrm{M}$ dis/min.100 $\mathrm{cm}^{2}$ to background.

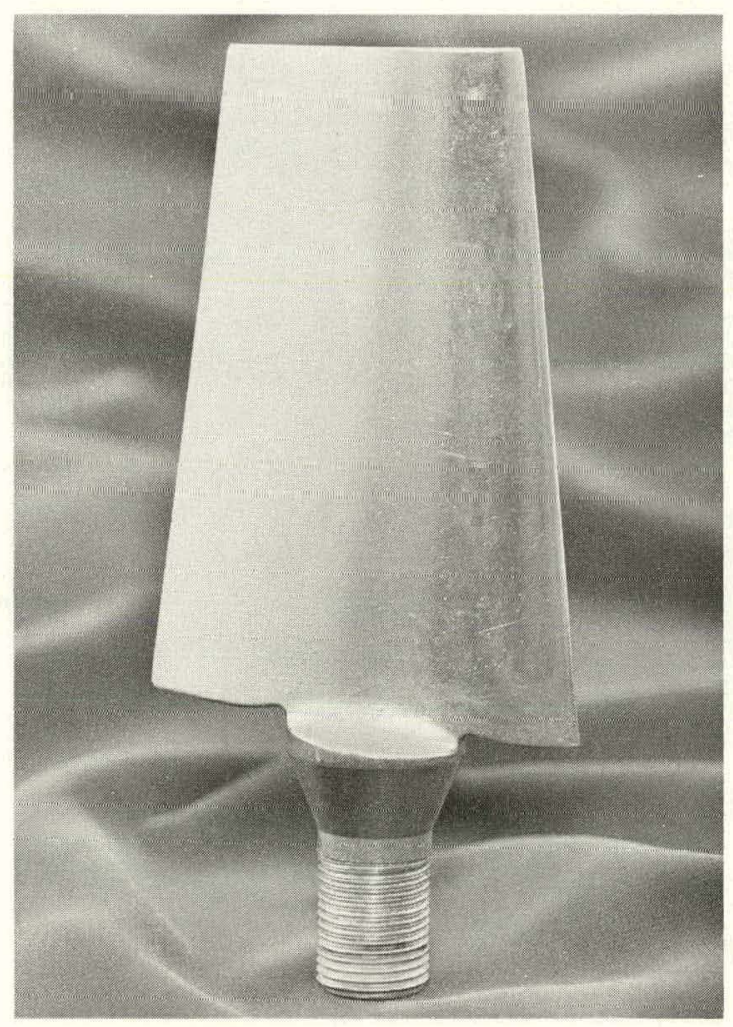

FIGURE A-3. Uranium-Contaminated Aluminum Compressor Blade Decontaminated by Electropolishing 
Improvement Program. The blades were about 3-in. wide and from 5- to 10-in. long. The as-received alpha surface contamination levels ranged from about 200 to $2000 \mathrm{dis} / \mathrm{min} \cdot 100 \mathrm{~cm}^{2}$ and the beta/gamma levels from about 1000 to 6000 counts/min. Electropolishing the blades for less than $10 \mathrm{~min}$ in a phosphoric acid electrolyte reduced the surface alpha and beta/gamma radiation levels of most of the blades to background. The metal removed to effect decontamination represented a weight change that ranged from on 1 y $0.5 \%$ to less than $3 \%$.

Comparison decontamination tests also were conducted using phosphoric-chromic and phosphoric-sulfuric electrolytes and a phosphoric-nitric chemical polishing technique. The phosphoric-chromic solution produced the best surface finish on the aluminum and also decontaminated the surfaces to background. The phosphoric-sulfuric electrolyte was not as effective as the phosphoric solution. The phosphoric-nitric chemical polish reduced the contamination levels on the blade surfaces, but was not as effective as electropolishing for the threaded areas.

- Vacuum system parts. A stainless steel diffusion pump adaptor (Figure A-4), which was once part of a 6-in. vacuum system attached to a plutonium glove box, was electropolished less than $10 \mathrm{~min}$. The contamination level of the adaptor, including the interior of the small tubing, was reduced to background. Elbows, flanges, and other system components were decontaminated also.

- Metallographic specimens. Electropolishing techniques are used routinely to decontaminate metallographic specimens. For example, electropolishing was used to remove plutonium contamination from FFTF fuel pin specimens to permit their examination using nonradioactive scanning electron microscopy and optical metallographic facilities.

- Manipulator tong assemblies. Figure A-5 shows a manipulator tong assembly used to handle highly radioactive material in fission-product hot-cell operations. The entire tong assembly was electropolished as a unit reducing beta-gamma radiation levels from $10 \mathrm{R} / \mathrm{hr}$ to background within $10 \mathrm{~min}$. This permitted the cold disassembly, repair, and reassembly of the unit for a substantial savings in time, expense, and personnel exposure. Two other types of manipulator tong assemblies were similarly decontaminated, repaired, and returned to service.
- Analytical instrument components. An atomic absorption spectrophotometer used for analysis of radioactive solutions has a stainless steel "chimney" that is exposed directly to the hot effluent gases. This results in the formation of a baked-on coating of intense alpha-beta-gamma contamination. A week of conventional cleaning in an ultrasonic bath only reduced the contamination level to $2 \mathrm{R} / \mathrm{hr}$. However, electropolishing dislodged this impervious coating and reduced the radiation level to background within $15 \mathrm{~min}$. A similar result was obtained for the removal of baked-on contamination for the filament holder of an emission mass spectrometer used to analyze fission products.

- Fission product storage capsules. The ability of electropolishing to rapidly remove strontium fluoride contamination from the surface of Hastelloy C-276 fission product storage capsules (Figure A-6) was demonstrated by a series of in-cell tests at the Hanford Waste Encapsulation and Storage Facility (WESF) using a special remote electropolishing system developed for the Rockwell Hanford Operations Company. Electropolishing for only 20 min reduced the smearable surface contamination levels from $5 \mathrm{R} / \mathrm{hr}$ to less than $5 \mathrm{mR} / \mathrm{hr}$. Previous efforts by WESF personnel using ultrasonic, chemical, wire brush scrubbing, and water spray decontamination techniques required several hours and sometimes several shifts to achieve the same degree of decontamination. This remote electropolishing system is now used routinely to remove cesium chloride contamination from stainless steel storage capsules, as well as strontium fluoride contamination from the Hastelloy-C storage capsules.

- Pneumatic cylinder and piston assembly. A 12-in.-diameter by 24-in.-high mild steel pneumatic cylinder and piston assembly (Figure A-7) used to actuate a steam valve at the Hanford N-Reactor was decontaminated on an emergency basis for United Nuclear Industries, Inc. This permitted the rebuilding of this critical component at a noncontrolled machine shop and avoided a delay in reactor startup.

- Demister. A heavily plutonium-contaminated demister was disassembled into three sections of $6-i n$. pipe plus two viewing port flanges and two small pieces that fit into the pipe sections. Ine pipe sections, which had a thick, tar-like residue built up internally, were pretreated with the high-pressure water spray system and then electropolished using an internal cathode to facilitate internal contamination. Next, the remaining inaccessible residue was removed by submerging the pipes in a hot water bath for 


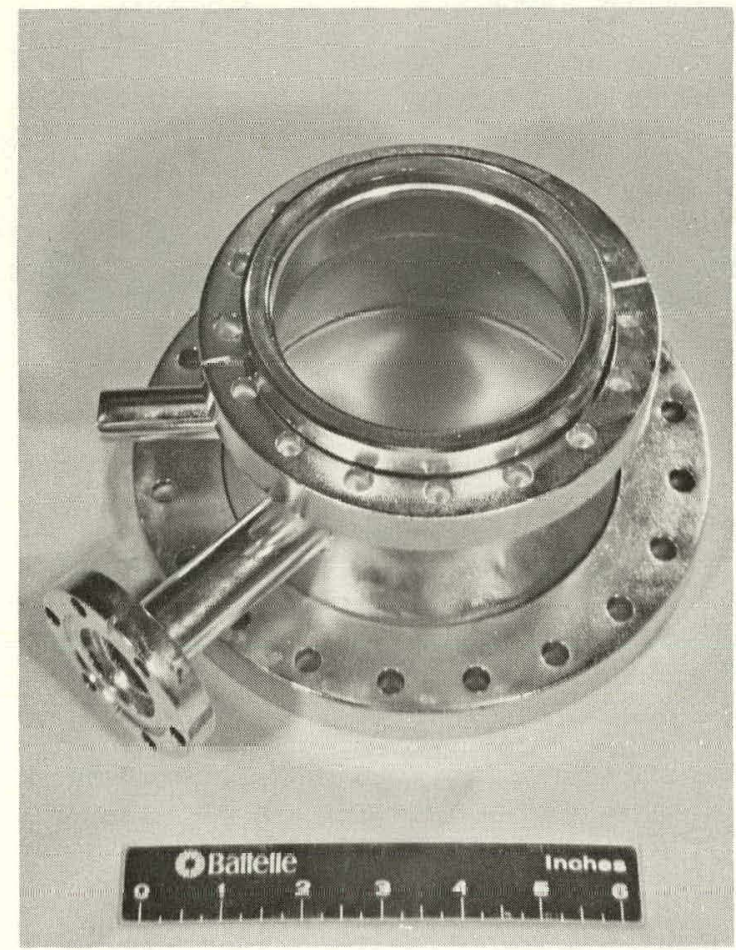

FIGURE A-4. Stainless Steel Diffusion Pump Adaptor from a Vacuum System Used on a Plutonium Glove Box. This component, including the tube interiors, was decontaminated by electropolishing in less than $10 \mathrm{~min}$.

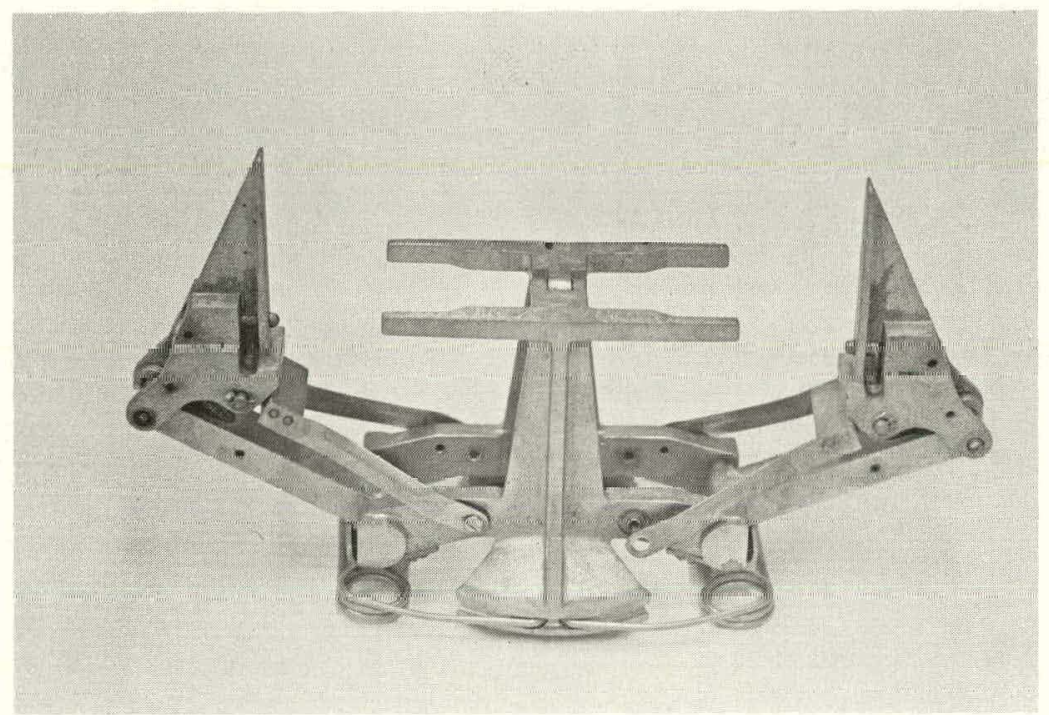

FIGURE A-5. Manipulator Tong Assemb1y Used in a Fission-Product Hot Cel1. The entire unit was electropolished without prior disassembly, reducing the beta/gamma radiation level from $10 \mathrm{R} / \mathrm{hr}$ to background within $10 \mathrm{~min}$. 


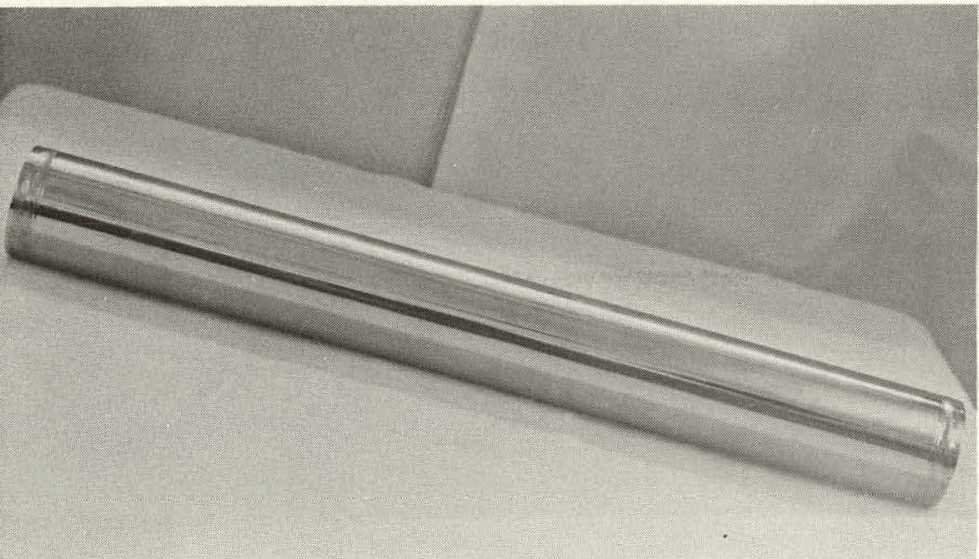

FIGURE A-6. Hastelloy C Fission Product Storage Capsule. Electropolishing for less than 30 min removed the external stontium fluoride contamination and produced a smooth, nonsmearable surface on the 2.25-in.-diameter by 19-in.-long capsule.

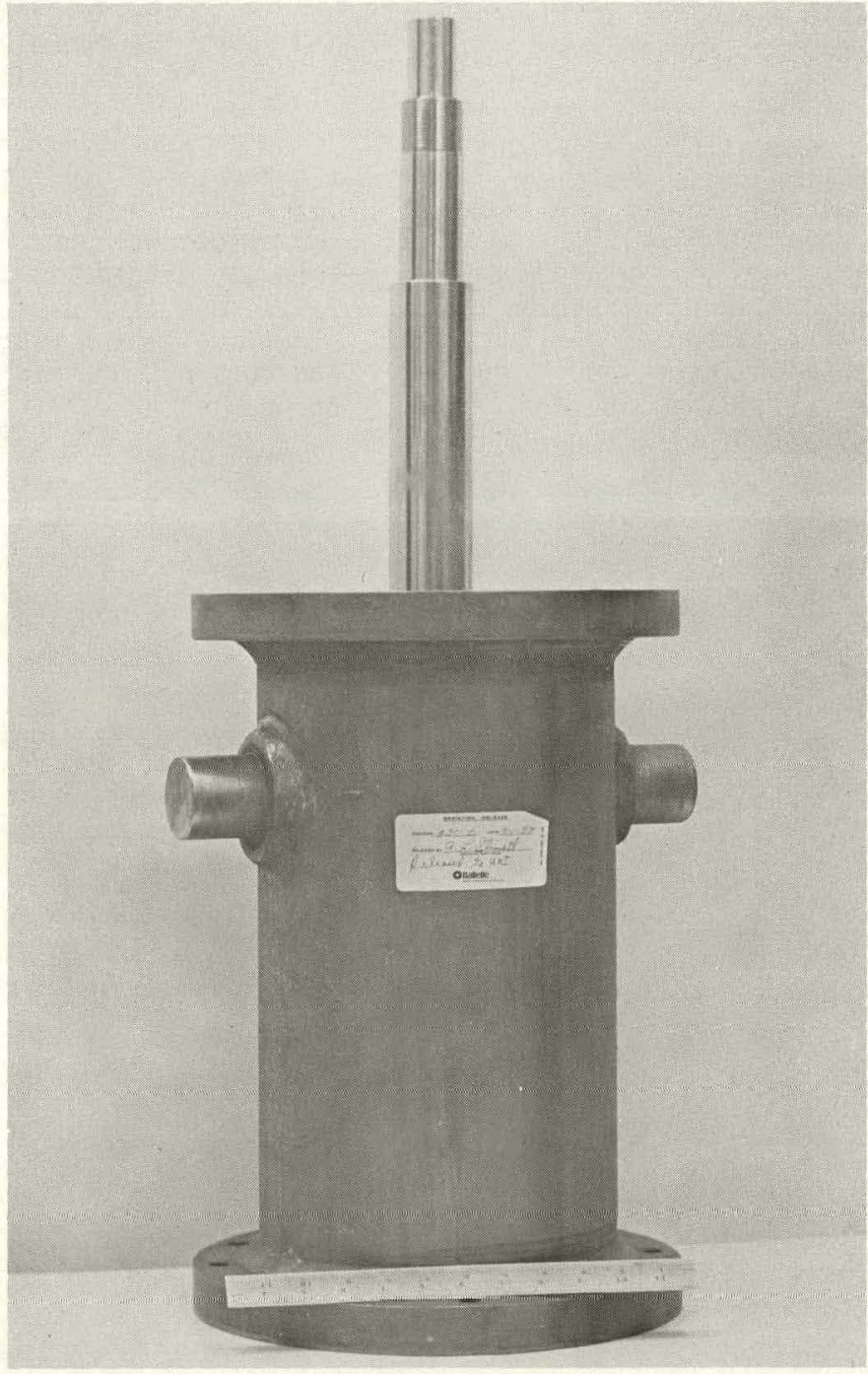

FIGURE A-7. Mild Steel Pneumatic Cylinder and Piston Assembly from Hanford $\mathrm{N}$-Reactor Decontaminated by Electropolishing. This permitted the rebuilding of this critical component at a noncontrolled machine shop and avoided a delay in reactor startup.

\section{A. 5}


$36 \mathrm{hr}$. Electropolishing was repeated and, finally, the in situ gun was used to decontaminate the remaining hot spots to background. The viewing port flanges were decontaminated from 42,000 dis/min. $100 \mathrm{~cm}^{2}$ to background by electropolishing at $200 \mathrm{~A}$ for $40 \mathrm{~min}$. The small pieces were successfully decontaminated using a titanium basket.

- Oxidized stainless steel canisters. Studies were conducted for the PNL-administered Commercial High-Level Waste Fixation Program to evaluate the potential of electropolishing as a decontamination technique for oxidized 304l. stainless steel canisters produced by the in-can melter waste solidification process. This work demonstrated that electropolishing using phosphoric acid electrolytes will remove oxide layers as thick as $200 \mu \mathrm{m}$ from representative canister surfaces. However, longer electropolishing times ( $1 \mathrm{hr}$ versus 10 to $20 \mathrm{~min}$ ) and more base metal removal (200 $\mu$ III versus 25 to $50 \mu \mathrm{m})$ are required than would be needed for the decontamination of unoxidized stainless steel.

A later study showed that the thinner oxide layer $(<16 \mu \mathrm{m})$ and associated internally oxidized region formed on Incone $1601{ }^{\circledR}$ by simulated in-can melter service is readily removed by the same type of electropolish-

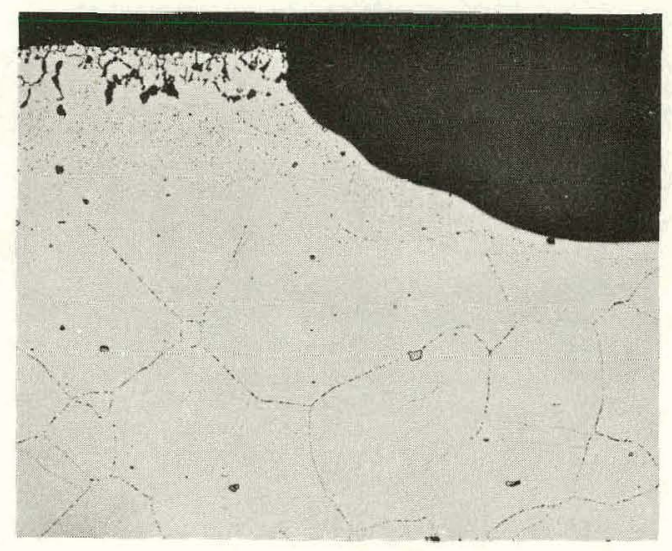

FIGURE A-8. Cross Section of 0xidized Inconel 601 Canister Material, Comparing the Original Oxidized Surface and the Descaled Surface Produced by Electropolishing

ing treatment used to decontaminate unoxidized metal surfaces. Figure A-8 compares the electropolished Inconel 601 surface with the oriqinal oxidized surface (masked to prevent its removal). It shows that electropolishing removes material uniformly and does not preferentially attack grain boundaries or other microstructural features even in the heavily oxidized areas.

(B) Registered trademark of Huntington Alloys. 